\title{
。
}

UNIVERSIDADE DE ÉVORA

DEPARTAMENTO DE GESTÃO DE EMPRESAS

Mestrado em Gestão de Empresas

Finanças Empresariais

\section{OS DETERMINANTES DA ESTRUTURA DE CAPITAIS: O CASO DAS EMPRESAS BRASILEIRAS NÃO-FINANCEIRAS DE CAPITAL ABERTO}

Dissertação de Mestrado sob orientação do Prof. Doutor Jacinto Vidigal da Silva (Esta dissertação não inclui as críticas e sugestões feitas pelo jưri)

\section{ANA CÉLIA DE OLIVEIRA PRADO}

Évora

2005 


\section{ANA CÉLIA DE OLIVEIRA PRADO}

\section{UNIVERSIDADE DE ÉVORA}

DEPARTAMENTO DE GESTÃO DE EMPRESAS

ORIENTADOR: Professor Dr. Jacinto Vidigal da Silva

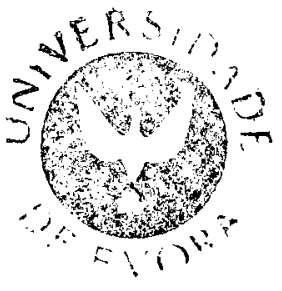

Data: Setembro/2005

155919

OS DETERMINANTES DA ESTRUTURA DE CAPITAIS: O CASO DAS EMPRESAS BRASILEIRAS NÃO-FINANCEIRAS DE CAPITAL ABERTO

Dissertação Elaborada no Âmbito do Protocolo UNIFAL/UE 
A Deus, pelo dom da vida e por sempre estar presente na minha caminhada.

A meus queridos pais, Domingos de Oliveira Prado e Ercília Agnolon de Oliveira Prado, e minha irmã, Ana Lúcia de Oliveira Arthur Jucá, pela família que me deram e, principalmente, por nunca terem deixado de acreditar em mim.

Ao meu amor, Marcio Aguiar Valença, pela paciência e carinho necessários a vencer os obstáculos do dia-a-dia.

Ao meu orientador, Prof. Dr. Jacinto Vidigal da Silva, pelo constante incentivo, sempre estando disposto a repassar os conhecimentos necessários à elaboração desta dissertação, e, por ter sempre indicado a direção a ser tomada nos momentos de maior dificuldade.

A todos os professores da Universidade Federal de Alagoas e da Faculdade de Alagoas, em especial, à Professora Alexandra Maria Rios Cabral Gouveia, pela troca de idéias e conhecimentos e incentivo à pesquisa.

A LOG Negócios \& Consultoria e seus consultores, que agradeço em nome do nosso líder, Luiz Otávio Gomes, por terem me proporcionado a vivência da experiência de atuação do profissional de economia no mercado de trabalho. 
"A vida é construida nos sonhos e concretizada no amor".

Francisco Xavier 


\section{ÍNDICE GERAL}

Índice de Tabelas

Índice de Gráficos

RESUMO

IV

ABSTRACT

1. INTRODUÇÃO

VIII

1.1. Breve Descrição da Área de Pesquisa

1.2. Fontes de Financiamento das Empresas no Brasil

1.3 Objetivos da Dissertação

1.4 Plano de Apresentação

\section{REVISÃO BIBLIOGRÁFICA}

2.1. Abordagem Baseada nos Efeitos Fiscais e nos Custos de Insolvência

2.1.1 Introdução

2.1.2 O Modelo Original de Modigliani e Miller

2.1.3 A Ótica da Tributação do Rendimento das Empresas e dos

Particulares

2.1.4 A Ótica dos Custos de Insolvência

2.2. Abordagem na Perspectiva da Teoria da Agência

2.2.1 Introdução

2.2.2 O Endividamento como Forma de Resolução dos Conflitos entre Administradores e Acionistas

2.2.3 O Endividamento como Forma de Resolução dos Conflitos entre Acionistas e Credores

2.3. Os Efeitos da Assimetria da Informação sobre Estrutura de Capitais

2.3.1 Introdução

2.3.2 A Sinalização Via Estrutura de Capitais

2.3.3 A Assimetria de Informação

2.3.4 A Hipótese de Pecking Order

2.4. Outras Linhas de Investigação Baseadas na Estratégia e no Controle

2.4.1 Introdução

2.4.2 Modelos Baseados na Estratégia

2.4.3 Modelos Baseados no Controle 
3.1. Hipótese e Definição das Variáveis 32

3.1.1 Abordagem Baseada nos Efeitos Fiscais e nos Custos de Insolvência 32

$\begin{array}{ll}\text { 3.1.1.1 Efeitos Fiscais } & 33\end{array}$

3.1.1.1.1 Taxa Média de Impostos $\quad 33$

3.1.1.1.2 Outros Benefícios Fiscais que Não o de Endividamento 34

3.1.1.2 Custos de Insolvência (Falência) 35

3.1.1.2.1 Risco do Negócio (Volatilidade) 35

3.1.1.2.2 Composição dos Ativos Fixos (Tangibilidade) 36

3.1.1.2.3 Oportunidades de Crescimento 37

3.1.1.2.4 Tamanho (Dimensão) 38

3.1.2 Abordagem na Perspectiva da Teoria da Agência 39

3.1.2.1 Composição dos Ativos Fixos (Tangibilidade) 39

$\begin{array}{ll}\text { 3.1.2.2 Oportunidades de Crescimento } & 40\end{array}$

3.1.3 Efeitos de Assimetria de Informações sobre a Estrutura de Capitais $\quad 40$

3.1.3.1 Rentabilidade $\quad 41$

3.1.3.2 Tamanho (Dimensão) $\quad 42$

3.1.3.3 Oportunidades de Crescimento $\quad 42$

3.1.3.4 Composição dos Ativos Fixos (Tangibilidade) 42

3.1.3.5 Flexibilidade Financeira 43

3.1.4 Outras Linhas de Investigação Baseadas na Estratégia e no Controle $\quad 44$

3.1.5 Resumo das Hipóteses $\quad 45$

3.2. Caracterização da Amostra $\quad 47$

$\begin{array}{ll}\text { 3.2.1 Banco de Dados } & 47\end{array}$

3.2.2 Escolha do Período de Análise da Amostra $\quad 50$

$\begin{array}{ll}\text { 3.2.3 A BOVESPA } & 52\end{array}$

3.3. Caracterização das Variáveis 55

3.3.1 Medidas do Endividamento $\quad 55$

3.3.2 Medidas dos Fatores Específicos das Empresas $\quad 57$

$\begin{array}{ll}\text { 3.3.3 Estatísticas Descritivas das Variáveis } & 58\end{array}$

3.4. Metodologia de Análise de Dados 59

$\begin{array}{ll}\text { 3.4.1 Análise de Correlação } & 59\end{array}$

3.4.2 Modelo de Regressão Linear Múltipla $\quad 60$

3.4.3 Estatísticas Utilizadas para Análise dos Modelos 63

3.4.3.1 Cálculo do Coeficiente de Determinação dos Modelos 63

3.4.3.2 Teste de Aderência Global do Modelo (Estatística F) 64

$\begin{array}{ll}\text { 3.4.3.3 Teste } t & 64\end{array}$

3.4.3.4 Independência das Variáveis Aleatórias Residuais 65

3.4.3.5 Multicolinearidade $\quad 65$ 
4. ANÁLISE DOS RESULTADOS DO TESTE EMPÍRICO 68

4.1.Análise dos Resultados da Estimação dos Modelos - Validação Estatística 68

4.1.1 Endividamento Total a Valor Contábil (EVC) 68

4.1.2 Endividamento Total a Valor de Mercado (EVM) 72

4.2.Análise dos Resultados da Estimação dos Modelos - Validação Teórica 75

5. CONSIDERAÇÕES FINAIS E DESENVOLVIMENTOS FUTUROS 81

REFERÊNCIAS BIBLIOGRÁFICAS $\quad 86$

$\begin{array}{ll}\text { ANEXOS } & \text { i }\end{array}$

Anexo A - Nível de Endividamento das Empresas Estudadas e Análise Individual ii

Anexo B - Classificação da Amostra por Empresa, segundo CNAE vii

Anexo C - Classificação da Amostra por Porte, segundo BNDES xiv

Anexo D - Valor de Mercado por Empresa da Amostra: 1999 a 2003 xix (em R\$ Mil)

Anexo E - Valor Contábil por Empresa da Amostra: 1999 a $2003 \quad$ xxiv (em R\$ Mil) 
Tabela 1 - Resumo Bibliográfico 31

Tabela 2 - Resumo das Hipóteses Testadas, Teoria da Estrutura de Capital 46 em que se Baseiam e Sinal Esperado do Coeficiente

Tabela 3 - Classificação da Amostra Segundo CNAE 48

Tabela 4 - Número de Empresas Registradas, Número de Empresas 53 Negociadas na BOVESPA, Valor de Fechamento do IBOVESPA e Valor de Mercado das Empresas Negociadas na BOVESPA

Tabela 5 - Evolução do Volume Total Negociado na BOVESPA de 1999 a 54 2003 por Tipo de Mercado (em R\$ bilhões)

Tabela 6 - Resumo das Variáveis Dependentes e Variáveis Explicativas $\quad 58$ dos Modelos

Tabela 7 - Estatísticas Descritivas das Variáveis Utilizadas nos Modelos $\quad 59$

Tabela 8 - Resultados da Análise de Regressão Linear Múltipla-Modelo 69 EVC

Tabela 9 - Análise de Variância (ANOVA) - Modelo EVC 69

Tabela 10 - Matriz de Correlação entre as Variáveis Explicativas - Modelo 71 EVC

Tabela 11 - Tolerância e VIF das Variáveis Explicativas - Modelo EVC 71

Tabela 12 - Proporção da Variância da Constante e das Variáveis 72 Explicativas - Modelo EVC

Tabela 13 - Resultados da Análise de Regressão Linear Múltipla-Modelo 73 EVM

Tabela 14 - Análise de Variância (ANOVA) - Modelo EVM 73

Tabela 15 - Tolerância e VIF das Variáveis Explicativas - Modelo EVM 75

Tabela 16 - Proporção da Variância da Constante e das Variáveis 75 Explicativas - Modelo EVM

Tabela 17 - As Variáveis dos Modelos e Seus Resultados Estatísticos $\quad 76$ 
Gráfico 1 - Estrutura de Capital das Empresas Brasileiras 1999 a $2003 \quad 5$

Gráfico 2 - Evolução das Fontes de Financiamento das Empresas 6 Brasileiras 1999 a 2003

Gráfico 3 - Efeitos Líquidos do Endividamento sobre o Valor da Empresa 18

Gráfico 4 - Participação dos Investidores no Volume Total da BOVESPA 55 2001 a 2003

Gráfico 5 - Comparativo do Valor das Empresas: Valor Contábil x Valor 56 de Mercado - 1999 a 2003 
Nas últimas décadas tem sido produzido um vasto número de trabalhos de investigação empírica sobre a problemática da estrutura de capitais; os quais têm procurado compreender a decisão de financiamento das empresas, e as razões porque se financiam de certa forma específica. Estas abordagens consideram que, diferentes fatores influenciam essa decisão, tais como: vantagens fiscais, custos de agência, custos de falência, assimetria de informação e custos de transação.

A presente dissertação tem como objetivo verificar se as variáveis específicas das empresas, indicadas pelas diferentes correntes teóricas referenciadas na literatura internacional para representar os fatores determinantes da estrutura de capitais, também são relevantes das decisões de financiamento das empresas não financeiras cotadas na Bolsa de Valores de São Paulo - BOVESPA no período entre 1999 e 2003.

Os resultados apurados, com base em modelos de regressão linear, sobre dados seccionais demonstram que as variáveis, (tangibilidade, oportunidades de crescimento, rentabilidade e flexibilidade financeira), são estatisticamente significativas e, por isso, constituem fortes determinantes das decisões de financiamento e da estrutura de capitais das empresas. Em relação às outras variáveis estudadas, (taxa média de impostos, outros benefícios fiscais que não o de endividamento, tamanho, volatilidade e classificação do setor de atividade), constatou-se que não têm suficiente significância estatística para explicarem as decisões de financiamento. 
Os resultados apurados permitem concluir que o comportamento das empresas não financeiras cotadas na BOVESPA, se enquadra nas teorias de Trade-Off(Efeitos fiscais e Custos de Insolvência), Teoria da Agência e Teoria do Pecking Order (Assimetria de Informações).

Palavras chaves: Estrutura de capitais, Endividamento, Seleção Hierárquica, Falência, Variáveis Financeiras. 
In the last decades, a vast number of empiric investigation studies about the capital structure problematic have been produced, these studies have been seeking to comprehend companies financing decision and reason why they finance in specific ways. These approaches uses different factors that influence these decisions, such as: fiscal advantages, agency costs, bankruptcy costs, information asymmetry and transaction costs.

The present study has the objective of verify if companies' specific variables, indicated by different theories referenced in international literature to represent the determinant factors of the capital structure, are also relevant to financing decisions of non-financial companies quoted on São Paulo Stock Exchange - BOVESPA.

The outcoming results based on linear regression about sectional data demonstrate that the variables: tangibility, growth opportunities, profitability and financial flexibility are statistically significant and because of this they constitute strong determinant factor of companies' capital structure. Regarding other studied variables, such as average tax, non-debts tax, size, volatility and activity setor classification, it was verified that they do not have enough statistical significance to explain the financing decisions.

The outcoming results also allow to conclude that non-financial companies behavior quoted on BOVESPA fits in Trade-Off theories (Fiscal Effects and Insolvency Costs), Agency Theory and Pecking Order Theory (Information Asymmetry).

Key Words: capital structure, debts, pecking order, bankruptcy, financial variables. 


\section{INTRODUÇÃo}

\subsection{Breve Descrição da Área de Pesquisa}

Existem várias controvérsias a respeito da estrutura de capitais das empresas. A principal questão em debate é a existência, ou não, de uma estrutura ótima de capitais. $O$ fato de ser um dos assuntos mais polêmicos e debatidos em finanças motivou a seleção deste tema para a realização desta dissertação de mestrado.

Nesta investigação serão abordadas as principais teorias desde a publicação do artigo sobre a irrelevância da estrutura de capitais em 1958 de Modigliani e Miller ${ }^{1}$, até os dias atuais, e que considera quatro correntes: Abordagem Baseada nos Efeitos Fiscais e nos Custos de Insolvência; Abordagem na Perspectiva da Teoria da Agência; Efeitos da Assimetria de Informação sobre Estrutura de Capitais; e Outras Linhas de Investigação Baseadas na Estratégia e no Controle.

A primeira corrente é baseada nos Efeitos Fiscais e nos Custos de Insolvência. A corrente citada foi iniciada com Modigliani e Miller (1958), os quais afirmaram que não existe uma estrutura ótima de capitais, e que o valor da empresa é determinado pelo mercado, conclusão que conduziu à hipótese de irrelevância da estrutura de capitais. Em 1963, complementando as suas primeiras proposições, Modigliani e Miller afirmaram que a estrutura de capitais não é irrelevante porque o valor da dívida tem influência no montante do imposto sobre a renda a pagar. Em 1977, Miller abordou os benefícios fiscais gerados pelas pessoas físicas. Se o endividamento traz benefícios fiscais porque

\footnotetext{
${ }^{1}$ Harris e Raviv (1991) consideraram o início da moderna teoria da estrutura de capitais a publicação do artigo de Modigliani e Miller em 1958.
} 
os encargos gerados por ele diminuem a base de cálculo do imposto sobre o lucro, surge um novo questionamento defendido por Kraus e Lintzenberger (1973) que argumentaram que os custos de falência podem ser elevados com o endividamento.

A segunda corrente, da Teoria da Agência, foi impulsionada por Jensen e Meckling (1976), que colocou a questão sobre a premissa de irrelevância da estrutura de capitais defendida inicialmente por Modigliani e Miller. Segundo esta teoria existem conflitos de interesses entre os interessados pela empresa (credores, acionistas, administradores), que geram custos de agência. Para ela é possível determinar um ponto ótimo de endividamento que minimize estes custos. $\mathrm{O}$ endividamento surge como forma de resolução de conflitos entre administradores e acionistas e entre acionistas e credores.

Os Efeitos da Assimetria de Informação sobre a Estrutura de Capitais representa a terceira corrente, a qual é fundamentada no efeito da informação assimétrica e na sinalização dos investidores, baseados na Teoria do Pecking $O r d e r^{2}$. A principal defesa desta corrente é que o processo de financiamento obedece a uma seleção hierárquica das fontes de financiamento e não a um nível de endividamento ótimo. Segundo Myers (1984), as empresas em geral, preferem os financiamentos internos aos externos, e o endividamento à emissão de novas ações.

Por fim, a última corrente é definida como Outras Linhas de Investigação Baseadas na Estratégia e no Controle. Segundo esta corrente, o posicionamento estratégico da empresa e as fontes de recursos utilizados para o crescimento determinam a estrutura de capitais. Destacam-se nestes estudos os trabalhos de Titman (1984) e Harris e Raviv

\footnotetext{
${ }^{2}$ Traduzido por hierarquização das fontes de financiamento.
} 
(1991). A perspectiva desta corrente é baseada no estudo das movimentações nos mercados de capitais relativas a operações de reestruturação e de ofertas de aquisição de empresas. Nesta área de investigação também se situam os trabalhos de Kim e Sorensen (1986) e Rajan e Zingales (1995).

A análise da vasta literatura empírica permite concluir, que há uma insuficiente clareza do ajustamento das várias teorias da estrutura de capitais às práticas de decisão de financiamento das empresas. Rajan e Zingales (1995) chegaram também a esta conclusão, e Graham (1996) questionou as razões por que a literatura empírica não consegue explicar melhor o endividamento das empresas.

A análise empírica da aplicabilidade das diferentes correntes teóricas, tem se baseado na análise dos fatores determinantes da escolha da estrutura de capitais das empresas, verificando na prática a significância das variáveis apresentadas nas diversas teorias abordadas, bem como, no ponto em que as mesmas divergem. Para tanto, a vasta produção de trabalhos empíricos permitiu o teste de muitas variáveis características das empresas, tais como: taxa média de impostos, outros benefícios fiscais que não o de endividamento, risco do negócio, tangibilidade, oportunidades de crescimento, tamanho, rentabilidade, flexibilidade financeira e setor econômico onde a empresa está inserida. 


\subsection{Fontes de Financiamento das Empresas no Brasil}

Desde a abertura da economia brasileira no início da década de 90 , as empresas nacionais passaram por grandes transformações, tendo os produtos e serviços de competir, em preço e qualidade, com os de outros países. Esta economia globalizada apresenta às empresas um conjunto de desafios, que exigem competitividade para se estabelecerem e crescerem neste mercado, levando-as a investirem em novas tecnologias para se tornarem mais eficientes. Para isso, procuram a redução dos custos e o aumento da produtividade, visando a maximização dos resultados.

Perante este contexto, as empresas necessitam de investimentos que promovam o crescimento e a modernização, para se adequarem aos padrões de competitividade que a nova ordem internacional exige. Surge assim, a primeira indagação: De onde são retirados os recursos financeiros necessários para dar suporte a esses novos investimentos?

As fontes de financiamento que podem ser utilizadas pelas empresas são: recursos próprios ou internos ou lucros retidos; recursos externos - via endividamento; e, recursos externos - via emissão de ações.

A questão a ser tratada neste trabalho de investigação é a identificação da existência, os tipos de padrões de financiamento das empresas brasileiras, e quais as fontes de financiamento prioritariamente utilizadas. Para tanto será analisado um grupo das 207 empresas, não financeiras de capital aberto, cotadas no mercado bolsista brasileiro no período entre 1999 a 2003. 
A análise da estrutura de capitais, com base nas demonstrações contábeis no período de 1999 a 2003, permite verificar que as empresas ${ }^{3}$ analisadas neste estudo, apresentam um nível de endividamento de $58 \%$.

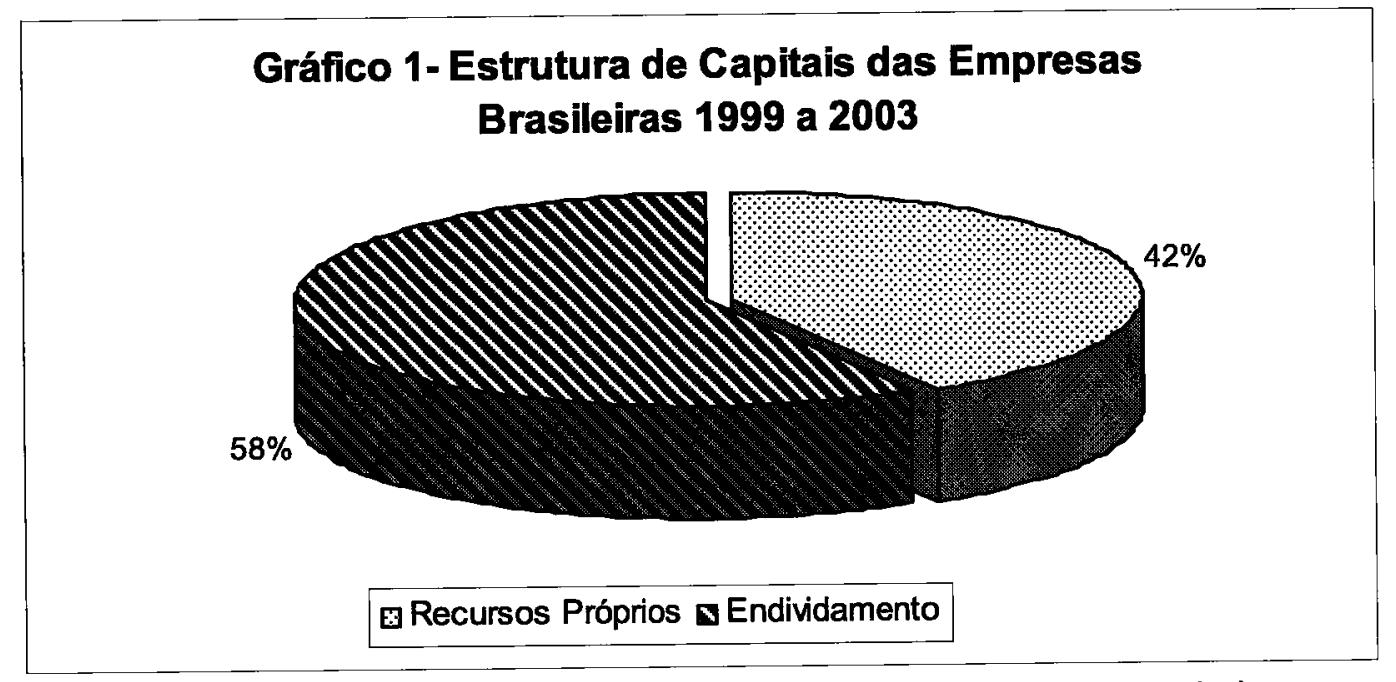

Fonte: Balanço Patrimonial do banco de dados SABE. Elaboração Própria.

O período de análise, de 1999 a 2003, foi delimitado devido ao processo inflacionário suportado pelo país, intensificado na década de 80 e início dos anos 90 , que poderia provocar distorções na análise dos dados. Só a partir do segundo semestre de 1994, com o lançamento do plano de estabilização econômica - Plano Real, a inflação presente na economia brasileira ficou dentro dos parâmetros definidos pelo FMI.

No período pós 1999, nota-se claramente que existiram avanços significativos na economia brasileira. A estabilidade econômica, juntamente com a reforma administrativa, previdenciária, abertura da economia e as privatizações, proporcionaram a criação de um ambiente macroeconômico favorável para a promoção e crescimento do

\footnotetext{
${ }^{3}$ Ver relação completa das empresas estudadas e análise individual no Anexo A. Os dados foram calculados com base no Balanço, através da seguinte fórmula: Endividamento Total/ (Endividamento Total + Patrimônio Líquido).
} 
Brasil; e, com a transição para o regime de câmbio flutuante, o ajuste das contas públicas e a flexibilização das taxas de juros, criaram cenário favorável para novos investimentos.

Quando se analisa a evolução da estrutura de capitais das empresas cotadas na Bolsa de Valores de São Paulo, nota-se que o endividamento cresceu no período, passando de $54,52 \%$ em 1999 para 61,84\% em 2003, conforme demonstrado no gráfico 2, a seguir. Este aumento de 7,32\%, na captação de recursos externos, é um forte indicador de que as empresas estão a promover o crescimento e a sobrevivência no mercado com o recurso à dívida.

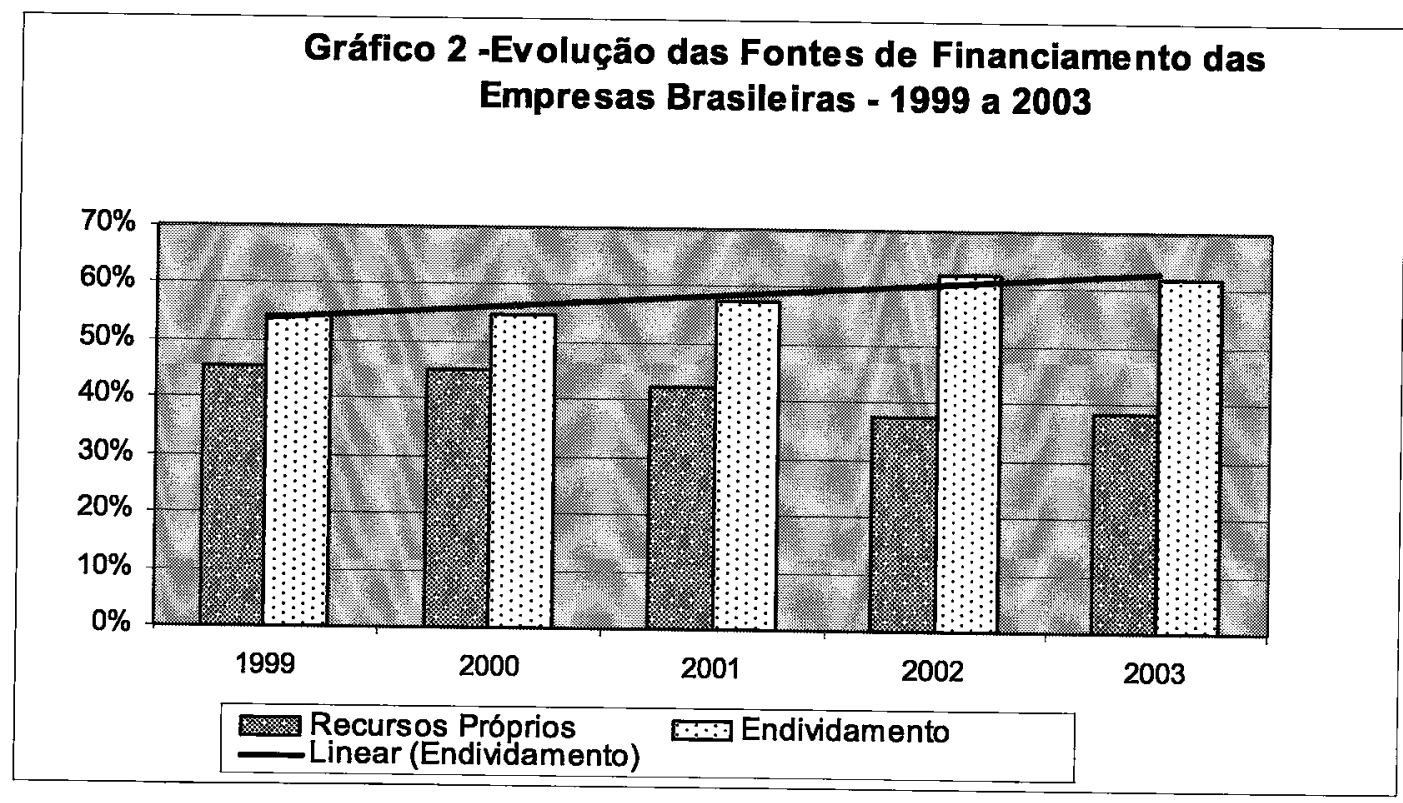

Fonte: Balanço Patrimonial do banco de dados SABE. Elaboração Própria.

Carvalho (2000) argumenta que no Brasil apenas um pequeno número de empresas utiliza o mercado de capitais para alavancagem financeira. Por exemplo, Barcellos (2002) verificou que no ano de 1996 a emissão de ações no Brasil correspondia a apenas 1\% da Formação Bruta de Capital Fixo. Este valor é muito baixo, mesmo quando comparado com outros países em desenvolvimento. Quanto ao acesso ao crédito 
bancário, o autor acima citado, também verificou que o indicador de desenvolvimento do sistema bancário, medido através da proporção do crédito bancário em relação ao PIB, registrou uma média de 46,7\% no período de 1994 a 1997, padrão comparável a países como Colômbia, Índia e México.

"Mercados de crédito e capitais eficientes são vitais para garantir competitividade às empresas brasileiras" (Barcellos, 2002, pg.7). Um mercado financeiro pouco desenvolvido traz vários custos às empresas, principalmente às menores que não têm acesso a fontes de capital, a custos mais competitivos. Esta situação pode levar a concentração de mercado e a desnacionalização.

Além do mercado de capitais ser pouco utilizado, outro fator para explicar a evolução das fontes de financiamento das empresas são as altas taxas de juros básicas, e os spreads que são extremamente elevados no país. No período da análise dos dados, entre 1999 e 2003, a média da taxa de juros básicas no país foi de 20,57\% a.a., sem contar com os spreads cobrados pelos bancos. Barcellos (2002) concluiu que, para a resolução deste problema, as empresas recorrem a linhas de crédito a longo prazo com taxas de juros mais competitivas, como por exemplo, o $\mathrm{BNDES}^{4}$. Os juros básicos cobrados pelo BNDES incluem o custo financeiro TJLP $^{5}$ que apresentou uma taxa média no período de análise de 10,97\% a.a., acrescido do spread básico (máximo 4\% a.a.) e do spread do agente repassador ${ }^{6}$, que varia de acordo com o tamanho da empresa e a negociação entre empresa e este agente.

\footnotetext{
${ }^{4}$ Bando Nacional de Desenvolvimento Social. Opera com linhas de crédito de longo prazo com valores inferiores aos cobrados pelos bancos comerciais.

${ }^{5}$ TJLP: Taxa de Juros de Longo Prazo.

${ }^{6}$ Bancos públicos e bancos privados.
} 


\subsection{Objetivos da Dissertação}

Esta investigação, tem por objetivo a identificação dos determinantes da estrutura de capitais das empresas não financeiras, cotadas na BOVESPA no período de 1999 a 2003, avaliando em que medida os pressupostos das teorias sobre a estrutura de capitais se aplicam empiricamente ao caso brasileiro. Dentro das teorias financeiras estudadas serão testadas as diversas variáveis explicativas para a realidade brasileira. Apesar de vários trabalhos semelhantes terem sido desenvolvidos em diversos países e no Brasil, todos concluem que a problemática continua, e que muitas questões ainda não foram respondidas de forma totalmente satisfatória, nomeadamente as seguintes: Qual a estrutura de capitais ótima para as empresas? Qual é a fonte de financiamento prioritariamente utilizada? Quais são as variáveis que influenciam a decisão e financiamento das empresas?

A importância deste estudo é a apresentação de um tema de grande relevância para o Brasil, relacionado com a identificação do padrão de financiamento das empresas brasileiras, e o que isto representa na economia do país.

No Brasil, vários foram os estudos nesta linha de pesquisa. Gomes e Leal (2000) realizaram um estudo seccional do endividamento médio das empresas brasileiras no período entre 1995 a 1997 para os fatores rentabilidade, risco, tamanho, tangibilidade, crescimento e subsetor industrial. Estes autores encontraram uma relação positiva entre o nível de endividamento e os fatores tangibilidade (confirmando a Teoria de Trade$O f f^{7}$ ) e risco, e relação inversa para os fatores rentabilidade (favorecendo a Teoria do

\footnotetext{
${ }^{7}$ Trade-off entre custos de falência e a vantagem fiscal da dívida.
} 
Pecking Order), crescimento e tamanho. Perobelli e Famá (2002) utilizaram a análise fatorial para examinar os fatores seguintes: estrutura dos ativos, expectativa de crescimento da empresa, singularidade, classificação da indústria, tamanho, volatilidade e lucratividade sobre a estrutura de capitais das empresas brasileiras no período de 1995 a 2000; Encontrando os seguintes resultados: Uma relação negativa entre o grau de endividamento de curto prazo e o crescimento dos ativos e tamanho das empresas, indicando que quanto menor for o porte, maior a propensão aos empréstimos de curto prazo e destas,as que possuem maior margem tendem a ser menos endividadas. Brito e Lima (2004) avançaram neste estudo, incluindo o impacto simultâneo do controle acionário (privado nacional, público nacional e controle estrangeiro) aos determinantes da estrutura de capitais, identificando que difere de acordo com o controlador da empresa.

Ferreira e Brasil (1997), Junior e Melo (1999), Moreira e Puga (2001) estudaram as fontes de financiamento utilizadas pelas empresas brasileiras para financiar o seu crescimento. Estes estudos confirmaram a hipótese de pecking order, onde as empresas preferem o autofinanciamento ao endividamento, e este a emissão de ações. Já Zonenschain (1998) encontrou uma relação inversa à teoria do pecking order, onde a principal fonte de financiamento identificada é a emissão de ações, seguida do endividamento e os lucros retidos.

A nível internacional, vários foram os estudos que abordaram esta linha de pesquisa, buscando identificar os fatores determinantes da estrutura de capitais como os trabalhos de Titman e Wessels (1988), Bradley et al. (1984) e Balakrishnan e Fox (1993) para 
empresas americanas; Rajan e Zingales (1995) para os paises do $\mathrm{G7}^{8}$; Antoniou et al. (2002) para as empresas francesas, alemãs e britânicas; Booth et al. (2001) para os países em desenvolvimento (Índia, Paquistão,Tailândia, Malásia, Turquia, México, Brasil, Coréia, Jordânia e Zimbábue); e Rita (2003), Simões (2002) e Ramos (2004) para as empresas portuguesas.

\subsection{Plano de Apresentação}

A presente dissertação está estruturada em cinco partes. No capítulo 1, "Introdução", foi apresentado o enquadramento do tema, observando-se a relevância teórico-empírica, e os objetivos que se pretendem atingir com o desenvolvimento deste trabalho. No capítulo 2, "Revisão Bibliográfica", será apresentada uma revisão da literatura sobre o tema, apresentando as diversas teorias sobre a estrutura de capitais das empresas, que resultam das diferentes correntes: As baseadas nos efeitos físcais e nos custos de insolvência, nas relações de agência, na assimetria de informação, nas questões de estratégia e de controle das empresas. No capítulo 3, "Descrição da Metodologia de Investigação", é descrita a metodologia de investigação, que inclui a apresentação das hipóteses em discussão e as variáveis associadas a cada uma, a caracterização da amostra e a discussão do método utilizado na análise dos dados: Regressão linear múltipla com dados seccionais. No capítulo 4, "Análise dos Resultados do Teste Empírico", apresenta os resultados dos testes empíricos realizados para verificar a validação estatística e teórica. No capítulo 5, "Considerações Finais e Desenvolvimentos Futuros", são enunciadas as conclusões obtidas com o estudo e propostas para a realização de trabalho de investigação no futuro.

\footnotetext{
${ }^{8}$ Composto pelos seguintes países: Estados Unidos, Japão, Alemanha, França, Itália, Reino Unido e
Canadá.
} 


\section{REVISÃO BIBLIOGRÁFICA}

Segundo Silva (1991), um dos problemas mais complexos da gestão financeira é o estudo da relação entre a estrutura de capitais e o valor da empresa, ou seja, do modo como o mix de financiamento afeta o seu valor.

O estudo teórico da estrutura de capitais das empresas começou a se desenvolver a partir da publicação em 1958 do artigo: "The cost of Capital, Corporate Finance, and Theory of Investiment", de Modigliani e Miller, considerado, por muitos autores, como o marco inicial no estudo das modernas finanças empresariais. Com base no pressuposto do mercado de capitais perfeito ${ }^{9}$, estes autores concluíram que a estrutura de capitais escolhida não afetava o valor da empresa. Com base nestas proposições surgiram várias outras correntes sobre o estudo dos determinantes da estrutura de capitais e do valor da empresa.

A revisão teórica, a ser apresentada neste capítulo, e que servirá de base para o desenvolvimento desta investigação, reúne as principais teorias produzidas ao longo do tempo sobre as estruturas de capitais, desde Modigliani e Miller (1958) até os dias atuais, e será divida em quatro seções: Abordagem Baseada nos Efeitos Fiscais e nos Custos de Insolvência; Abordagem na Perspectiva da Teoria da Agência; Efeitos da Assimetria de Informação sobre Estrutura de Capitais; e, Outras Linhas de Investigação Baseadas na Estratégia e no Controle.

\footnotetext{
${ }^{9}$ As hipóteses de mercado perfeito incluem (1) ausência de impostos; (2) inexistência de custos de corretagem ou custos de colocação de títulos; (3) informações simétricas: administradores e investidores têm a mesma informação sobre as perspectivas de investimento da empresa; e (4) os investidores podem tomar empréstimos com as mesmas taxas que as empresas (Gitman, 2002).
} 


\subsection{Abordagem Baseada nos Efeitos Fiscais e nos Custos de Insolvência}

\subsubsection{Introdução}

Esta abordagem está baseada em um conjunto de teorias sobre a estrutura de capitais, cuja fundamentação teórica defende a existência de um ponto ótimo de endividamento, ou de equilíbrio, entre capitais próprios e de terceiros, associada à relação de custo e benefício de cada fonte a ser utilizada. Os principais estudos relacionados com esta corrente são os realizados pelos seguintes autores: Modigliani e Miller (1958), Modigliani e Miller (1963), Miller (1977), Kraus e Litzenberger (1973), Soctt (1976), Warner (1977) e Kim (1978).

O modelo original, de Modigliani e Miller (1958), aborda a teoria da irrelevância da estrutura de capitais, concluindo que o endividamento da empresa não altera o seu valor. Essa teoria foi fortemente criticada porque se baseava em mercados perfeitos, e em prática eram observadas imperfeições nos mercados.

A evolução da teoria das estruturas de capitais foi determinada pela análise das conseqüências derivadas das imperfeições do mercado, entre as quais se destacam as seguintes: Modigliani e Miller (1963) que aperfeiçoaram seu trabalho anterior de 1958, introduzindo na teoria o efeito fiscal dos impostos (tributação) sobre os rendimentos empresariais, e, Miller (1977) que abordou o efeito de tributação das-pessoas singulares.

Contrapondo as idéias de Modigliani e Miller (1963) e Miller (1977), que não consideraram os efeitos dos custos de falência nos seus estudos, surgiram Kraus e 
Litzenberger (1973), Scott (1976), Warner (1977) e Kim (1978) que introduziram os efeitos dos custos de insolvência, concluindo que, o endividamento afeta o valor da empresa no sentido em que aumenta o seu risco, e, conseqüentemente, implica em custos de falência.

\subsubsection{O Modelo Original de Modigliani e Miller}

A análise de Modigliani e Miller (1958), sobre a estrutura de capitais, assume que o custo dos capitais de terceiros permanece constante para quaisquer níveis de endividamento, considerando-se um ambiente sem imposto e sendo o valor da empresa independente do seu nível de endividamento. Nestas condições, surgiu a Teoria da Irrelevância, para a qual o padrão de financiamento das empresas não afeta o nível de investimento, uma vez que o valor da empresa não se altera independentemente do tipo de fonte que a mesma utiliza para crescer. Nestas condições, o valor da empresa depende exclusivamente do fluxo de caixa por ela gerado, e não da maneira como este é distribuído entre recursos de terceiros e recursos próprios.

Para fundamentar esta hipótese de irrelevância da estrutura de capitais, estes autores basearam-se nas seguintes premissas (Perobelli e Famá, 2002): Ausência de custos de falência; Todas as empresas se situam na mesma classe de risco; Ausência de impostos; Ausência de crescimento nos fluxos de caixa das empresas; Ausência de assimetria de informações e de custos de agência.

Modigliani e Miller (1958) fundamentaram a sua teoria de irrelevância da estrutura de capitais nas empresas através de duas proposições: De acordo com a Proposição I, na 
ausência de imperfeições do mercado, como não existem impostos, o valor de mercado de uma empresa é independente da sua estrutura de capitais, sendo dado, unicamente, pela expectativa dos seus resultados operacionais futuros, descontado ao custo do capital próprio.

A Proposição II argumentou que o custo do capital próprio é uma função linear do endividamento, enquanto o custo do capital de terceiros é constante. Os acionistas exigem uma maior rentabilidade com a maior utilização do endividamento, devido ao aumento do risco financeiro. Essa maior taxa de rendimento, associada ao risco na composição do custo médio do capital, é compensada pelo peso do capital próprio que diminui quando é utilizado maior endividamento.

\subsubsection{A Ótica da Tributação do Rendimento das Empresas e dos Particulares}

A publicação em 1963, de Modigliani e Miller, introduziu os efeitos dos impostos sobre os lucros das empresas. Estes autores reconheceram que as proposições do primeiro artigo (1958) eram válidas em uma economia sem impostos, onde os custos do capital eram indiferentes do nível de endividamento. Porém, numa economia real, os juros pagos pelas empresas contribuem para a diminuição da base de cálculo do imposto de renda, constituindo um benefício fiscal. Concluíram ainda que, se o custo da dívida diminui devido ao efeito do imposto sobre os lucros da empresa, então o endividamento contribui para aumentar o valor da empresa ${ }^{10}$. Mantidas as demais premissas adotadas no seu estudo anterior, e incluída a vantagem físcal da utilização da dívida, se o valor da

\footnotetext{
${ }^{10}$ Os juros são dedutiveis, o que torna a dívida mais barata que o capital próprio, ou seja, para os investidores quanto mais dívida a empresa utiliza, maior será seu valor e o preço das ações (Barcelos, 2002).
} 
empresa depende do nível de endividamento, isso levaria a uma estrutura ótima de capitais totalmente constituída por capital de terceiros.

A dedução dos impostos significa que o custo do empréstimo Ki é subsidiado pelo governo. Se Kd é o custo do empréstimo antes do imposto e $\mathrm{T}$ é a taxa de imposto de renda, tem-se que: $\mathrm{Ki}=\mathrm{Kd} *(1-\mathrm{T})$.

Nesses pressupostos não são considerados os custos de insolvência financeira. Pela teoria proposta por Modigliani e Miller (1963), tem-se que, quanto maior for o grau de endividamento, maior será o valor da empresa. Na prática, dificilmente uma empresa utiliza a totalidade de recursos de terceiros para se financiar, uma vez que isso levaria ao aumento do seu risco, e conseqüentemente aos custos de falência.

Esta discussão dos efeitos fiscais da dívida constituiu um ponto central para o desenvolvimento de estudos posteriores, como o de Miller (1977) que introduziu, na discussão, a questão dos impostos sobre o rendimento das pessoas particulares.

Miller (1977) analisou as conseqüências da diferença na tributação do capital próprio e do capital de terceiros ao nível dos particulares, e a possibilidade dos investidores estarem sujeitos a diferentes taxas de impostos. O mesmo autor concluiu que, quando todas as oportunidades estão disponíveis para as empresas, os investidores estão sob condições de mercado perfeito, sendo a estrutura de capitais irrelevante.

$\mathrm{Na}$ prática, as empresas combinam recursos de terceiros com recursos próprios em sua estrutura de capitais, surgindo a teoria do trade-off entre os benefícios fiscais do 
endividamento e os custos de falência, onde o nível ótimo de endividamento é o resultado da ponderação entre os custos e os benefícios. Para Miller (1977), os custos de falência são muito pequenos quando comparados às vantagens fiscais da utilização da dívida, e devem, por isso, não ser considerados.

\subsubsection{A Ótica dos Custos de Insolvência}

Uma situação de falência é definida como “[...] um mecanismo legal que permite aos credores assumirem o controle da empresa, quando a descida do valor das ações provoca o não cumprimento da dívida" (Brealey e Myers, 1998, p. 487).

Os custos de falência se tornaram um fator determinante na decisão de financiamento e, por isso, podem influenciar a estrutura ótima de capitais. Quanto mais capitais alheios as empresas inserirem na sua estrutura de capitais, mais elevadas serão as probabilidades de sofrerem pressões relacionadas à falência, devido ao aumento do risco.

A introdução da discussão dos custos de falência surgiu com Kraus e Lintzenberger (1973), destacando-se também os trabalhos de Scott (1976), Warner (1977) e Kim (1978). Perante a introdução dos custos de falência, na discussão sobre a estrutura de capitais das empresas, o argumento dos benefícios fiscais oriundos da contratação das dỉvidas perdeu consistência.

Kraus e Lintzenberger (1973) argumentaram que os custos de falência podem ser bastante elevados para as empresas. Estes custos podem ser diretos, que representam os 
custos relacionados com alienação dos ativos de uma empresa por valores inferiores, os custos administrativos e de advocacia com o próprio processo de falência; e os indiretos, que se referem à percepção dos agentes econômicos das difículdades da empresa. Destes, destacam-se os relacionados com os fornecedores relativos à diminuição ou corte do crédito, com os clientes, ligados à redução das vendas devido ao aumento da procura de produtos similares junto aos concorrentes, dos recursos humanos internos que procuram alocação em outras firmas, e, dos ofertantes de capital que não desejam correr riscos em novos investimentos nestas condições.

Scott (1976) demonstrou que, uma empresa se encontra em uma situação de falência, quando o resultado, antes dos juros e impostos, for inferior ao valor dos encargos financeiros, e a empresa não conseguir captar recursos para suprir essa insuficiência de caixa.

Warner (1977) em seu estudo, sobre o processo de falência das empresas nos Estados Unidos do setor de transporte ferroviário, identificou que os custos indiretos do processo de falência representavam, em média, 5,3\% do valor dos ativos. $O$ mesmo autor verificou que as empresas deveriam ter uma estrutura de endividamento baseada no trade-off entre custos de falência, e, a vantagem fiscal da dívida, não importando o valor destes custos.

Kim (1978) definiu a capacidade de endividamento da empresa como, "o montante máximo de dívida que uma empresa com certo nível de endividamento pode contrair num mercado perfeito de capitais", demonstrando a existência de um nível ótimo de endividamento na presença de custos lineares de falência. 
O gráfico 3, a seguir, apresenta os efeitos líquidos do endividamento na determinação do valor da empresa, onde percebe-se claramente o trade-off gerado entre os benefícios fiscais e os custos de insolvência, gerados pela utilização do endividamento e como influência a determinação do valor da empresa.

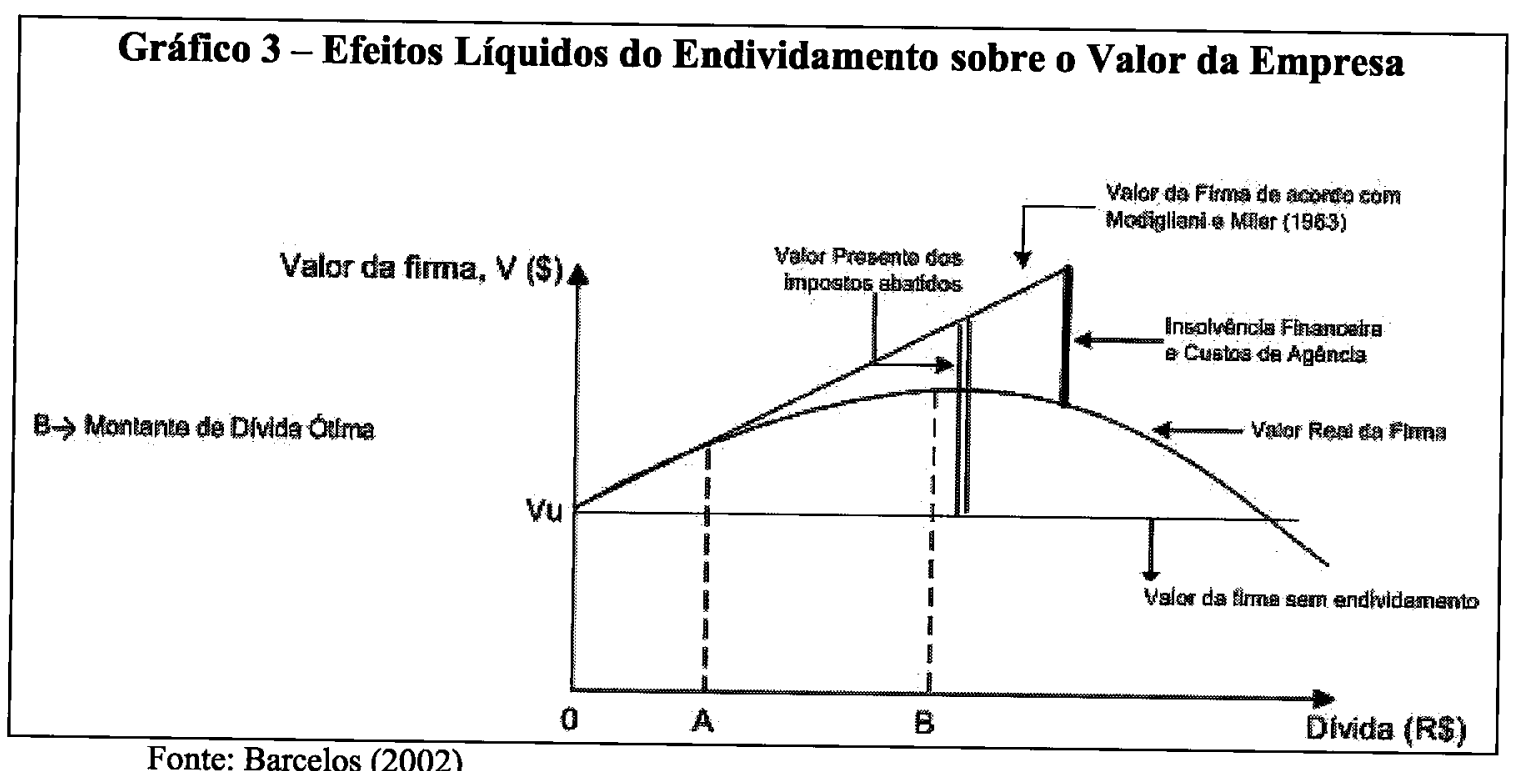

\subsection{Abordagem na Perspectiva da Teoria da Agência}

\subsubsection{Introdução}

A insuficiência explicativa da abordagem anterior, em torno da questão dos impostos e dos custos de falência, conduziu o debate para outras direções, surgindo então a Teoria da Agência, que teve como precursores os trabalhos de Jensen e Meckling (1976), Myers (1977), Jensen (1986), Stulz (1988), Stulz (1990) e Harris e Raviv (1990).

Os modelos baseados nos custos de agência definem que a estrutura de capitais é determinada pelo conflito de objetivos entre acionistas versus administradores, e 
acionistas versus credores. De um lado ficam os acionistas, que querem sempre o lucro máximo de um projeto, apostando em maiores riscos. Do outro lado, os gestores mais conservadores, que apostando em projetos menos rentáveis, porém de menores riscos e que comprometam menos o seu desempenho. Quanto aos credores, estes preferem que os acionistas invistam em projetos mais seguros e menos arriscados, para garantirem o pagamento do endividamento contraído.

Para Jensen e Meckling (1976), a empresa apresenta-se como um palco de conflitos de interesses entre proprietários dos títulos e os dirigentes que decidem sobre os ativos, tendo estes conflitos influência sobre as decisões financeiras. Estas relações podem ser de dois tipos: Diretivas - entre dirigentes que atuam como agentes e os proprietários que atuam como principais ${ }^{11}$; e de Endividamento - entre os acionistas (agentes) e os credores (principais). Estes custos de agência seriam conseqüências do possível prejuízo, que possa sofrer o principal, devido, às possíveis atuações do agente. Estes custos se repercutem no valor dos títulos, provocando diminuição de seu valor. Assim, conclui-se que, mesmo na ausência de impostos e de custos de falência, a procura da minimização dos custos de agência justifica a existência de uma estrutura ótima de capitais.

\footnotetext{
${ }^{11}$ Os que são afetados pelas decisões financeiras.
} 


\subsubsection{O Endividamento como Forma de Resolução dos Conflitos entre Administradores e Acionistas}

Na gestão da empresa, os proprietários contratam os gerentes para defenderem os seus interesses através da atribuição de autoridade, que representa um custo para o controle das decisões entre acionistas e administradores.

Stulz (1988) e Harris e Raviv (1990) verificaram que, os gestores têm sempre preferência na manutenção da atividade da empresa, mesmo que, em situação extrema, os investidores prefiram a sua liquidação; ao contrário dos acionistas. Deste modo, a tendência dos gestores é de preferir a realização de investimentos em alternativa ao pagamento dos dividendos.

Existem duas formas de minimizar os conflitos entre administradores e acionistas em decorrência dos custos de agência; A primeira seria a participação do gestor no capital social da empresa, fazendo com que os conflitos antagônicos sejam minimizados. A segunda seria o endividamento, onde, através da contratação de dívida, se consegue a redução dos fluxos de caixa disponíveis e a diminuição da aquisição por parte dos gestores de benefícios não pecuniários ${ }^{12}$ (Jensen,1986).

Quando a empresa tem fluxos de caixa disponíveis, os gestores preferem reinvestir em projetos com VAL (Valor Atual líquido) positivo a distribuírem dividendos, agravando ainda mais o conflito entre acionistas e administradores (Jensen 1986).

\footnotetext{
12 Estes beneficios não pecuniários se constituiriam em regalias como aquisição de sofisticados equipamentos e mobílias de escritório, entre outros beneficios aos gestores.
} 
Os custos de agência, associados aos fluxos de caixa disponíveis, foram classificados, segundo Stulz (1990), em custos de sobre-investimentos, quando o gestor aufere benefícios, não pecuniários, relacionados com o nível de investimento realizado, levando ao investimento em projetos com VAL negativos; e custos de subinvestimentos, que surgem, quando o gestor rejeita boas oportunidades de investimento, quando a empresa tem insuficiência nos fluxos de caixa.

A política de endividamento, como forma de resolução dos conflitos entre acionistas e administradores, foi defendida por Jensen (1986) e Stulz (1990). Quando da contratação de dívida, as regras de amortização e pagamento de encargos financeiros são impostas à empresa, o que reduz os fluxos de caixa disponíveis, tendo o gestor menos recursos para aplicação em projetos não rentáveis. Por outro lado, impõe disciplina no pagamento, sob pena da empresa entrar em não cumprimento das suas obrigações. Neste aspecto, o endividamento faz com que seja reduzido, ou eliminado, o custo de agência, constituindo-se num elemento de controle das práticas dos gestores.

O endividamento traz benefícios aos conflitos entre acionistas e gestores, uma vez que, contribui para que o administrador se empenhe em maximizar o valor da empresa, através do aumento dos benefícios do custo do capital, e conseqüentemente, do aumento dos lucros e da redução do fluxo de caixa disponíveis, que poderia ser destinado a investimentos não ligados à produção e a projetos não rentáveis. Sendo assim, o endividamento comporta os benefícios de agência ao reduzir o arbítrio dos gestores. 


\subsubsection{O Endividamento como Forma de Resolução dos Conflitos entre Acionistas e}

\section{Credores}

O problema de agency, criado pelo relacionamento entre acionistas e credores, surge do fato dos credores fornecerem fundos à empresa de acordo com sua expectativa de risco. Visando diminuir o risco, os credores impõem certas técnicas de monitoramento e controle dos devedores, que resultam em custos de agenciamento (Gitman, 2002).

Myers (1977) considerou que os acionistas de uma empresa que apresenta elevado nível de endividamento e esteja em risco de falência, não têm razões para investirem em projetos rentáveis, porque os payoffs positivos, daí resultantes, beneficiariam os titulares da dívida. Daí, a estrutura de capitais influencia a rejeição de investimentos com VAL positivo que aumente o valor da empresa. Quanto maior o investimento da empresa em ativos, que dão a opção de realizar oportunidades de crescimento no futuro, menor deverá ser o financiamento com dívida, indicando uma relação negativa entre o endividamento e as oportunidades de crescimento.

Tendo os acionistas uma responsabilidade limitada sobre os recursos de terceiros aplicados na empresa, isso leva, a mesma, a investir em projetos mais arriscados e com baixa rentabilidade ou até em projetos com VAL negativo, que sejam financiados através de dívidas, com a transferência de valor dos credores para os acionistas, que é designada de "efeito de substituição de ativos". Emery e Finnerty (1997) defenderam que, no caso do projeto ter sucesso, os ganhos extras seriam dos acionistas, e no caso contrário, os resultados negativos seriam suportados pelos credores. 
Segundo Silva (1991), a transferência de valor pode ser realizada através da política de distribuição de dividendos, uma vez que o preço das ações diminuir com o pagamento dos dividendos, porque a perda de valor é partilhada com os credores.

Neste aspecto, pode-se concluir que, o endividamento resulta numa forma de diminuir os conflitos entre credores e acionistas, uma vez que, os investimentos em projetos que apresentem VAL positivo garantem aos credores o recebimento dos valores acertados.

Diamond (1989) destaca que, para se defenderem, os credores impõem cláusulas específicas nos contratos de empréstimo impedindo más decisões operacionais e despesas de investimento sem o acordo das partes, proibição de venda de ativos e limitações nas distribuições dos dividendos, o que proporciona a minimização dos custos de agência.

A teoria baseada nos custos de agência não dá um suporte empírico necessário a tomada de decisões quanto a estrutura de capitais a ser adotada pelas empresas, surgindo outras correntes baseadas na influência da informação sobre as decisões financeiras.

\subsection{Os Efeitos da Assimetria da Informação sobre a Estrutura de Capitais}

\subsubsection{Introdução}

Esta abordagem, baseia-se no efeito da informação assimétrica e da sinalização sobre a estrutura de capitais, tendo como corrente principal, a defesa de que o processo de financiamento obedece a uma seleção hierárquica das fontes de financiamento; e, 
portanto, não assenta na determinação de um ponto ótimo entre capitais próprios e de terceiros.

A Teoria da Seleção Hierárquica, também conhecida como pecking order, defende que as empresas não possuem um mix de endividamento ótimo, mas sim, uma preferência na utilização de capitais próprios, ou alheios, para financiar seu crescimento. Nesta corrente destacam-se os estudos de Donaldson (1961), Ross (1977), Leland e Pyle (1977), Myers (1984) e, Myers e Majluf (1984).

\subsubsection{A Sinalização Via Estruturas de Capitais}

As decisões financeiras tomadas pelas empresas têm valor de informação. Sendo assim, a valorização dos títulos das empresas, depende da forma como o mercado interpreta os sinais dados pelas decisões financeiras dos gestores, na medida em que estes sinais se constituem como indícios sobre os fluxos de rendimentos futuros.

A Teoria da Sinalização tem em Ross (1977) e Leland e Pyle (1977) a publicação dos seus primeiros trabalhos, cuja argumentação se fundamenta na observação que os gestores sabem mais acerca das perspectivas, riscos e valores das respectivas empresas, do que os investidores externos. Aqueles têm informações privilegiadas acerca dos fluxos de rendimento e das oportunidades de investimento. Nesta perspectiva, conhecem as qualidades da empresa e podem ocultar as suas debilidades, sendo difícil, e por vezes impossível, para o observador externo averiguar estes aspectos. 


\subsubsection{A Assimetria de Informações}

A assimetria de informações pode conduzir a sub-valorização da empresa pelo mercado, uma vez que, os investidores não dispõem de todas as informações necessárias para balizar uma correta estimação do valor do investimento. Esta situação prejudica não apenas os proprietários dos títulos, mas também, se repercute de forma negativa sobre os dirigentes, incentivando os mesmos a procurarem a forma mais credível de transmitir a informação favorável para o mercado.

A assimetria de informações acontece também entre acionistas e gestores, por estes não estarem certos da atuação dos administradores em defenderem os seus interesses. Daí, os acionistas incentivarem o endividamento como uma forma de limitar os fluxos de caixa disponíveis na empresa para melhor controlarem a atuação dos gestores, bem como para os acionistas valorizarem a situação e as perspectivas da empresa, interpretando as decisões financeiras como sinais sobre informações privilegiadas que os gestores detêm.

\subsubsection{A Hipótese de Pecking Order}

Donaldson (1961) estudou as práticas de financiamento numa amostra de grandes empresas, concluindo que os gestores tinham preferência pelos fundos gerados internamente ao financiamento externo. Myers e Majluf (1984) fundamentaram a conclusão de que há hierarquia de preferências pelos gestores que reflete os custos relativos de várias fontes de financiamento. A decisão sobre cada fonte de

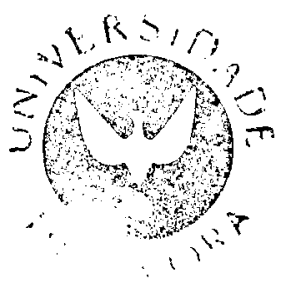


financiamento, capital próprio ou de terceiros, é baseada na presença de problemas de informação entre os agentes internos e os externos à empresa.

Myers (1984) estabeleceu interações entre os investidores e a estrutura de capitais, concluindo que, a estrutura de capitais é determinada de forma a minimizar as decisões de investimento ineficientes causadas pela informação assimétrica. A informação pode afetar o valor da empresa, se os investidores a sub-avaliarem ao estarem menos informados do que os gestores acerca dos valores dos ativos.

A aplicação da teoria de pecking order é pouco observada em empresas de pequenas dimensões. Segundo Barcelos (2002), entre vários fatores, destaca-se a estrutura que apresenta volatilidade nos seus rendimentos, baixos valores dos seus ativos, pouca transparência da informação financeira que prestam ao mercado, e o não cumprimento das exigências legais, em principal do colateral ${ }^{13}$ exigido pelas instituições financeiras. Essas variáveis levam este tipo de empresas a terem pouco acesso ao crédito.

\subsection{Outras Linhas de Investigação Baseadas na Estratégia e no Controle}

\subsubsection{Introdução}

Uma teoria que vem sendo apresentada em trabalhos recentes, sobre a temática da estrutura de capitais, é a do relacionamento com a estratégia da empresa, isto é, da relação entre a estrutura de capitais e a estratégia adotada pelas empresas. Esta corrente, que está fundamentada no posicionamento estratégico da empresa e na escolha dos

\footnotetext{
${ }^{13}$ Garantias reais exigidas pelos bancos quando as empresas recorrem ao financiamento.
} 
recursos a utilizar, foi desenvolvida nos estudos de Titman (1984), Harris e Raviv (1991), Balakrishan e Fox (1993), e, Arias et al. (2000).

$\mathrm{Na}$ abordagem orientada para o controle da empresa se destacam os estudos de Kim e Sorensen (1986), Stulz (1988), Harris e Raviv (1988), Rajan e Zingales (1995), e La Porta et al. (1999). Esta abordagem surgiu nos anos 80, caracterizada por movimentações nos mercados de capitais relativas a operações de reestruturação e de ofertas de aquisição de empresas. Neste âmbito, relaciona-se a estrutura de capitais com a disputa pelo domínio da empresa. A estrutura de capitais pode ser utilizada como estratégia de anti-takeover ${ }^{14}$, afetando o valor da empresa e a probabilidade da mesma ser objeto de compra e na determinação do preço de aquisição.

\subsubsection{Modelos Baseados na Estratégia}

Titman (1984) investigou as interações entre a estratégia e o nível da dívida, tendo apurado endividamentos mais baixos nas empresas que vendem produtos duráveis ou que dão assistência técnica e nas empresas que vendem produtos dificilmente copiáveis, devido aos maiores custos que essas empresas impõem aos clientes, fornecedores e trabalhadores, em situação de falência.

Harris e Raviv (1991) introduziram modelos baseados nas características e princípios da organização industrial. Os autores dividiram estes modelos em duas categorias: Uma classe de abordagens onde exploram a relação entre a estrutura de capitais da empresa

${ }^{14}$ Mudança na estrutura de capital implementada como resposta a ameaças na propriedade da empresa (Simões, 2002). 
com a estratégia de mercado adotada; e a outra, onde se exploram as relações entre a estrutura de capitais com as características dos inputs ou outputs da empresa.

Balakrishan e Fox (1993) realçaram a existência de uma forte relação entre a estratégia e a estrutura financeira da empresa. Onde a estratégia empresarial influencia a estrutura financeira, volume de recursos captados no mercado, tipo de financiamento, custo do capital, entre outros.

Arias et al. (2000) defenderam que algumas formas de determinadas estratégias influenciam a estrutura de capitais das empresas. Estes autores verificaram que os financiadores possuem uma maior motivação, para financiarem empresas que adotam estratégias de diversificação e de diferenciação de produtos, porque estas apresentam menor risco e uma menor probabilidade de insolvência.

\subsubsection{Modelos Baseados no Controle}

"Este ramo de abordagem amplia os seus argumentos para as relações entre todos os grupos: acionistas, gestores, credores, empregados, fazendo referência a um conjunto de acordos institucionais através dos quais as empresas são dirigidas e controladas" (Simões, 2002, pág. 43).

Kim e Sorensen (1986) encontraram uma relação positiva do endividamento como por exemplo, o aumento do preço das ações detidas pela gestão. Isto se deve ao fato de os 
titulares da dívida não terem direito a voto, o que torna a gestão mais sensível à performance ${ }^{15}$ da empresa.

Stulz (1988) e Harris e Raviv (1988) focaram o papel dos gestores na manipulação do sucesso da operação para assumir a posse da empresa. A distribuição de votos reflete-se na probabilidade de sucesso de uma oferta de aquisição e em seu preço.

Rajan e Zingales (1995) verificaram que, atuando na defesa de seu interesse particular, os diretores preferem, por vezes, sobre-endividar a empresa, e, outras vezes, subendividar. Para evitar conflitos entre acionistas e dirigentes, a participação diretiva no capital contribui para a convergência de interesses. As modificações no controle societário disciplinam a conduta dos gestores, e explicam o interesse destes em alinhar as suas opções com os objetivos dos acionistas. Sendo assim, a estrutura de propriedade influencia as decisões e o controle sobre os recursos da empresa, afetando a estrutura de capitais.

La Porta et al. (1999) concluíram no seu estudo que, ao contrário dos Estados Unidos, onde existe uma grande dispersão do capital, levando a que não exista um pequeno grupo que controla a empresa, em outros países a gestão de topo é constituída por elementos da família que controlam a empresa ou mesmo o Estado.

\footnotetext{
$\overline{{ }^{15} \text { Rendimentos auferidos pela empresa. }}$
} 


\subsection{Resumo}

As várias correntes teóricas, descritas neste capítulo, sugerem um conjunto de fatores específicos das empresas como determinantes das decisões de financiamento e das estruturas de capitais. Estes fatores foram estudados, em numerosos trabalhos empíricos, para testar os pressupostos das diferentes correntes teóricas por um elevado número de autores.

Dada a grande variedade de trabalhos, de autores e de proxies utilizadas, para representar os fatores específicos determinantes da estrutura de capitais, elaborou-se a tabela 1 de síntese da revisão bibliográfica, realizada neste capítulo. 


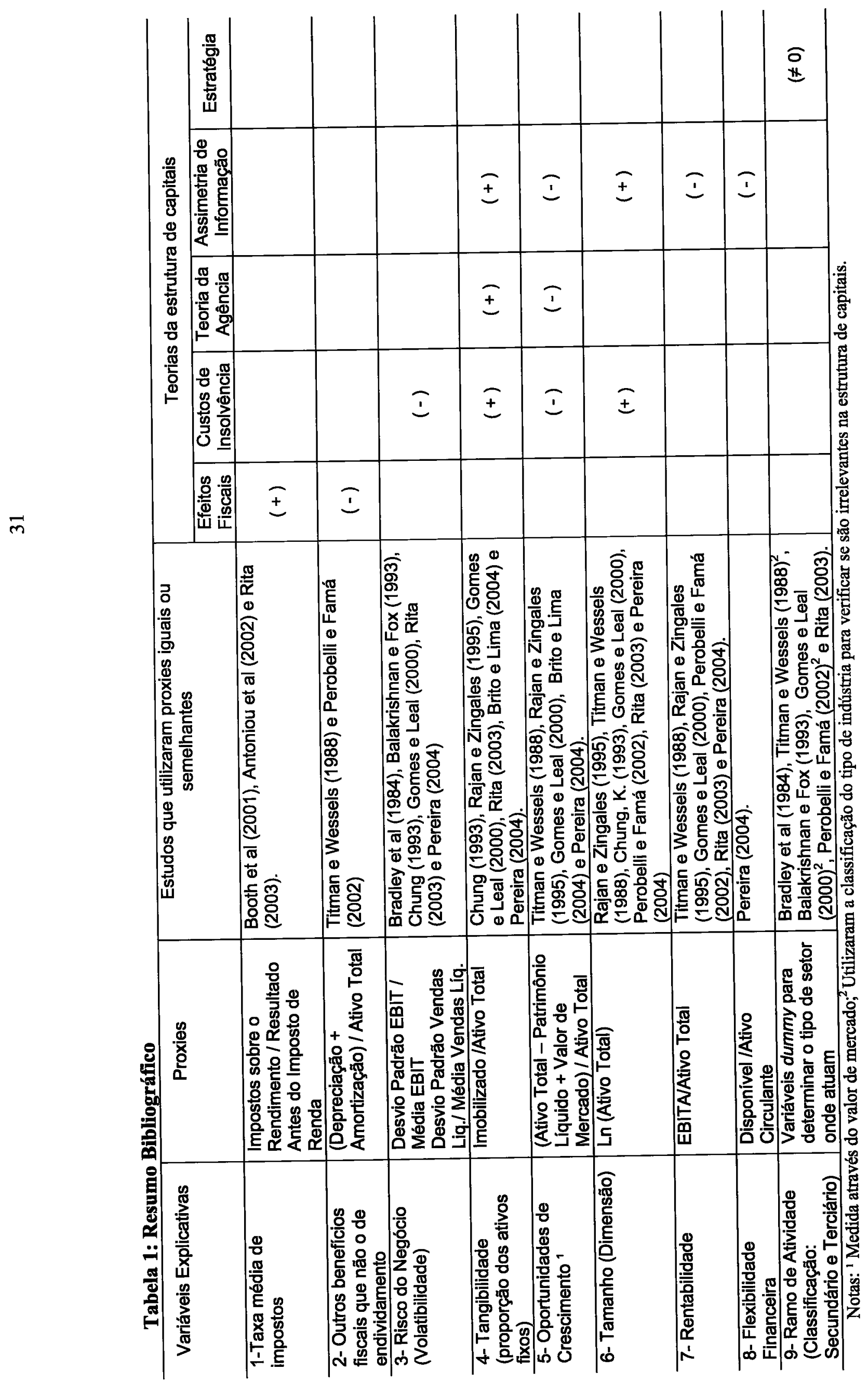




\section{DESCRIÇÃO DA METODOLOGIA DE INVESTIGAÇÃo}

\subsection{Hipótese e Definição das Variáveis}

Com base na literatura revista no capítulo anterior, e atendendo aos objetivos da dissertação, foram formuladas as hipóteses em discussão, as quais têm por objetivo a identificação dos determinantes da estrutura de capitais das empresas.

Do conjunto das principais variáveis explicativas específicas das empresas apontadas na literatura internacional, como determinantes da estrutura de capitais, foram selecionadas as seguintes: A taxa média de impostos, outros benefícios fiscais que não o de endividamento, o risco do negócio (volatilidade), a proporção dos ativos fixos (tangibilidade), as oportunidades de crescimento, o tamanho da empresa (dimensão), a rentabilidade, a flexibilidade financeira e o setor de atividade em que a empresa está inserida.

O comportamento que as teorias sugerem, para cada um dos determinantes da estrutura de capitais, está descrito nas seções seguintes.

\subsubsection{Abordagem Baseada nos Efeitos Fiscais e nos Custos de Insolvência}

A estrutura de capitais das empresas é composta por capitais próprios e capitais alheios. O mix de utilização de recursos internos e externos para financiamento da empresa fez surgir a Teoria do Trade-Off entre os benefícios fiscais resultantes do financiamento e 
os custos de falência a serem gerados por esta utilização. A seguir serão apresentadas as variáveis inseridas nesta corrente de estudo.

\subsubsection{Efeitos Fiscais}

Desde o artigo de Modigliani e Miller (1963), que inseriu os efeitos fiscais sobre as estruturas de capitais, o impacto dos impostos sobre o rendimento das empresas é um ponto bastante enfatizado pela teoria financeira. Os encargos financeiros, gerados pela utilização de dívidas, são dedutíveis dos lucros obtidos pelas empresas, constituindo-se assim, o endividamento, num benefício fiscal. Para verificar o efeito deste determinante sobre a estrutura de capitais das empresas serão analisadas duas variáveis: A taxa média de impostos suportada pelas empresas, e outros benefícios fiscais que não o de endividamento.

\subsection{Taxa Média de Impostos}

Segundo a teoria, existe uma relação positiva entre a taxa de imposto sobre o rendimento das empresas e o endividamento. Se os encargos financeiros são dedutíveis fiscalmente para o cálculo dos lucros das empresas, então, há implicitamente um ganho fiscal com o endividamento, aspecto que leva as empresas com altas taxas fiscais, a obterem um incentivo para o uso de mais dívida. Booth et al. (2001), Antoniou et al. (2002) e Rita (2003) utilizaram esta variável como determinante da estrutura de capitais das empresas. 
Graham et al. (1998) e Graham e Harvey (2001), entre outros autores, encontraram uma relação positiva entre a taxa média de impostos e o endividamento.

A hipótese 1, a ser testada, é que existe uma relação positiva entre a taxa média de imposto sobre a renda e o endividamento.

Nesta dissertação é utilizado o rácio: Impostos sobre o rendimento / Resultado Antes do Imposto de Renda, para cálculo da Taxa Média do Imposto de Renda.

\subsection{Outros Benefícios Fiscais que Não o de Endividamento}

Outro ponto levantado, por Titman e Wessels (1988), é a existência de outros benefícios fiscais que não os gerados pelo endividamento; Segundo estes autores, as empresas que contam com benefícios fiscais resultantes da depreciação e subsídios, deveriam ter menos incentivo à utilização de recursos de terceiros na sua estrutura de capitais, pois têm menos benefícios fiscais gerados pelo pagamento dos encargos financeiros. É de esperar uma relação negativa entre esta variável e o endividamento.

Bradley et al. (1984) encontraram uma relação negativa entre outros benefícios fiscais que não o de endividamento e o endividamento. Manos et al. (2001) estudaram a relação desta variável com a Teoria do Trade Off, afirmando que os benefícios fiscais que não o de endividamento levam à diminuição deste (Rita 2003).

A hipótese 2 a ser testada é que, a existência de outros benefícios fiscais que não o de endividamento apresentam uma relação negativa com o endividamento. 
Para cálculo da variável Outros Benefícios Fiscais que Não o de Endividamento foi utilizada a seguinte proxie: (Depreciação + Amortização)/ Ativo Total.

\subsubsection{Custos de Insolvência (Falência)}

Se, por um lado, o uso do endividamento traz para a empresa benefícios fiscais, por outro lado, aumenta os custos de falência esperados, uma vez que, a utilização de capital de terceiros na estrutura de capitais, acarreta custos para a empresa. A introdução dos custos de falência, iniciados com os estudos de Kraus e Lintzenberger (1973), tornou este fator determinante da decisão de financiamento das empresas.

Para avaliar o efeito deste determinante sobre a estrutura de capitais das empresas serão testadas quatro variáveis: Risco do negócio (volatilidade), composição dos ativos (tangibilidade), oportunidades de crescimento e tamanho (dimensão).

\subsection{Risco do Negócio (Volatilidade)}

Segundo a Teoria dos Custos de Insolvência, empresas que apresentam maior risco têm uma maior probabilidade de não honrarem os seus compromissos, e de irem à falência. Esta situação leva as empresas que apresentam maior risco a terem menos dívida, enquanto, as de menores riscos apresentam um nível de endividamento mais elevado.

Bradley et al. (1984), Chung (1993), Balakrishnan e Fox (1993) encontraram uma relação negativa entre a volatilidade e o endividamento. Gomes e Leal (2000) 
encontraram uma relação positiva da variável risco com o endividamento nas empresas brasileiras.

Para comprovação do tipo de relação em discussão será testada a hipótese 3, que o risco do negócio apresenta uma relação negativa com o endividamento.

No teste da hipótese 3 , serão utilizadas duas proxies para determinação da variável risco do negócio; A primeira é definida pelo Desvio-Padrão EBIT/ Média EBIT, e a segunda, pelo Desvio-Padrão das Vendas líquidas/Média das Vendas Líquidas, sendo EBIT $^{16}$ o resultado da empresa sem as depreciações e amortizações.

\subsection{Composição dos Ativos Fixos (Tangibilidade)}

Empresas que mantêm ativos fixos (tangíveis) e que podem facilmente ser vendidos no mercado, podem endividar-se mais do que aquelas que mantêm ativos intangíveis e/ou especializados, que perdem mais rapidamente o seu valor em caso de dificuldades financeiras. A composição dos ativos fixos das empresas interfere na captação de recursos, uma vez que estes ativos são utilizados como garantia real para os credores.

Quanto maior for o valor dos ativos tangíveis, que representa o colateral a ser dado aos credores, maior será a capacidade de endividamento da empresa. Pela mesma razão, quanto menor for o valor dos ativos tangíveis, menor deverá ser a propensão ao endividamento.

\footnotetext{
${ }^{16}$ EBIT (Earning Before Interests and Taxes) ou LAJI (Lucro Antes dos Juros e Impostos) representa o resultado da atividade da empresa. Fórmula: Lucro Operacional - Resultado Financeiro.
} 
Titman e Wessels (1988), Chung, K. (1993), Rajan e Zingales (1995), Gomes e Leal (2000) e Brito e Lima (2004), em seus estudos empíricos, encontraram relação positiva entre endividamento e o fator tangibilidade e o endividamento, confirmando assim a teoria.

A hipotese 4, a ser testada, é que a tangibilidade apresenta uma relação positiva com o endividamento.

Esta variável será calculada através do rácio: Imobilizado/Ativo Total.

\subsection{Oportunidades de Crescimento}

Empresas com crescimento rápido tendem a ter menos dívidas, devido a investirem constantemente em novos projetos; o endividamento alto poder gerar maiores custos de agenciamento e de falência, além de dificuldades na captação de novos recursos, quando necessários (Gomes e Leal,2000). Assim, o endividamento apresenta uma relação negativa com as oportunidades de crescimento da empresa.

Bradley et al.(1984), Chung (1993), Rajan e Zingales (1995) e Kayo e Famá (1997) encontraram relação negativa entre o endividamento e as oportunidades de crescimento da empresa confirmando a teoria. Já Brito e Lima (2004), contrariando a teoria, encontraram sinal positivo entre o fator endividamento $e$ as oportunidades de crescimento. 
A hipótese 5, a ser testada, é que as oportunidades de crescimento apresentam uma relação negativa com o endividamento.

Também Jensen e Mecking (1976) e Myers (1977) defendiam que as oportunidades de crescimento das empresas possuem uma relação inversa com o endividamento. Este argumento é sustentado no pressuposto que as empresas, possuidoras de oportunidades de crescimento tendem a captar menos recursos financeiros no mercado como estratégia de redução dos custos de agência. A variável Oportunidades de Crescimento será definida pelo rácio: (Ativo Total - Patrimônio Líquido + Valor de Mercado) / Ativo Total.

\subsection{Tamanho (Dimensão)}

A influência da dimensão como determinante da estrutura de capitais é de que, segundo a Teoria dos Custos de Insolvência, empresas de grande porte têm menor probabilidade de falência do que as pequenas. As grandes empresas têm mais acesso ao crédito junto dos bancos, pagando juros menores; o que constitui maiores benefícios na contratação de empréstimos. Esta situação conduz a esperar uma relação positiva entre tamanho e o endividamento.

Rajan e Zingales (1995) encontraram uma relação positiva entre endividamento e o tamanho, confirmando a teoria. Jả Titman e Wessels (1988), Chung, K. (1993) e Gomes e Leal (2000) encontraram uma relação inversa entre o valor da dívida e o tamanho das empresas, contrariando o previsto pela teoria. 
A confirmação do sentido da relação será realizada, baseando-se na hipótese 6; Que o tamanho apresenta uma relação positiva com o endividamento.

A Variável Tamanho da empresa será medida pelo logarítmo do Ativo Total.

\subsubsection{Abordagem na Perspectiva da Teoria da Agência}

Jensen e Meckling (1976), precursores da Teoria da Agência, argumentaram que a estrutura de capitais é determinada pelos custos de agência dos conflitos entre acionistas e administradores, e acionistas e credores; daí, surgindo o endividamento como forma de resolução destes conflitos.

Para verificar o efeito deste determinante sobre a estrutura de capitais das empresas serão analisadas duas variáveis: A Tangibilidade e As Oportunidades de Crescimento da Empresa.

\subsubsection{Composição dos Ativos Fixos (Tangibilidade)}

$\mathrm{Na}$ composição dos ativos da empresa, espera-se que, quanto mais ativos fixos (tangíveis) uma empresa possuir, maiores as possibilidades de obter um mais baixo custo do endividamento quando da contratação de empréstimos junto aos credores, devido a estes ativos, servirem de colateral na contratação do endividamento. E, em caso de liquidação do empréstimo gera proteção para os credores, diminuindo assim os custos de agenciamento. Da mesma forma, quanto mais ativos intangíveis as empresas possuem, menor será o acesso ao endividamento, devido aos problemas da exigência do 
colateral pelo agente financiador, que em caso de falência, não terá garantias reais para liquidação da dívida. Assim, a Tangibilidade, testada na hipótese 4 anterior, é que esta variável possui em relação positiva com o endividamento.

\subsubsection{Oportunidades de Crescimento}

O endividamento gera para as empresas maiores custos de agenciamento. Sendo assim, empresas com oportunidades de crescimento acelerado e que investem muito em seu crescimento, tendem a realizar uma menor utilização destes recursos, o que leva a uma relação negativa entre endividamento e as oportunidades de crescimento da empresa, a ser testada na hipótese 5 , já mencionada.

\subsubsection{Efeitos da Assimetria de Informação sobre a Estrutura de Capitais}

A Teoria da Assimetria de Informação baseia-se no efeito da informação assimétrica sobre a estrutura de capitais. Agentes externos e gerentes não dispõem das mesmas informações, e as que dispõem não têm o mesmo nível de detalhamento, surgindo assim um custo relacionado com esta assimetria de informações. Myers (1984) concluiu que, a estrutura de capitais das empresas é determinada como uma forma de minimizar estes custos. O processo de financiamento obedece a uma seleção hierárquica das fontes de financiamento, no qual são preferidos recursos internos aos de terceiros e estes à captação através de ações. 
As variáveis a serem analisadas para determinação do efeito da assimetria da informação sobre a estrutura de capitais são a rentabilidade, o tamanho, oportunidades de crescimento, a tangibilidade e a flexibilização financeira.

\subsubsection{Rentabilidade}

Segundo a Teoria do Pecking Order, proposta por Myers (1984), as empresas preferem o financiamento através de recursos internos aos externos. Empresas lucrativas tendem a ter menos endividamento na sua estrutura de capitais, por utilizarem os fluxos de caixa positivos para autofinanciamento, o que diminui os custos de assimetria de informações. Desta forma, espera-se que a rentabilidade possua uma relação negativa com o endividamento.

Titman e Wessels (1988), Rajan e Zingales (1995), Ferreira e Brasil (1997), Junior e Melo (1999), Gomes e Leal (2000), Moreira e Puga (2001), Brito e Lima (2004) e Procianoy e Schorrenberger (2004) confirmaram a Teoria de Pecking Order, e encontraram uma relação negativa entre o endividamento e a rentabilidade. Eid (1996) e Zonenschain (1998), nos seus estudos, apontaram para uma relação inversa à seleção hierárquica proposta pela Teoria do Pecking Order; onde o primeiro autor, identificou que as empresas preferem o endividamento, depois as ações ordinárias,e, por último os lucros retidos; e a segunda autora, que as empresas preferem a emissão de ações ao endividamento e este aos lucros retidos.

A hipótese 7, a ser testada, é que a rentabilidade apresenta uma relação negativa com o endividamento. 
A rentabilidade, enquanto fator determinante da estrutura de capitais das empresas, será representada pelo rácio EBITA/Ativo Total. Onde o EBITA $^{17}$ representa o rendimento da empresa acrescido das amortizações e depreciações.

\subsubsection{Tamanho (Dimensão)}

Devido às empresas, de grande porte, terem uma melhor classificação de crédito, obtém com isso menores taxas de juros e maior acesso a empréstimos. Esta situação leva a uma diminuição dos custos de assimetria de informação, e uma relação positiva entre tamanho e o endividamento, a ser testada na hipótese 6 anterior.

\subsubsection{Oportunidades de Crescimento}

Empresas, com oportunidades de crescimento acelerado, tendem a realizar uma menor utilização do financiamento externo, o que leva a uma relação negativa entre endividamento e as oportunidades de crescimento da empresa, a ser testada na hipótese 5, já mencionada.

\subsubsection{Composição dos Ativos Fixos (Tangibilidade)}

Segundo a teoria de assimetria de informação, quando as empresas emitem dívida, elas incorrem num custo superior por deterem informações mais detalhadas do que as disponíveis para os credores. Quanto mais ativos tangíveis a empresa possuir no total de seus ativos, maior a garantia dos credores no recebimento, em caso de liquidação da

\footnotetext{
${ }^{17}$ EBITA (Earning Before Interests Taxes, Depreciation and Amortization) ou LAJIDA (Lucro Antes dos Juros Impostos, Depreciações e Amortizações) Representa a geração de caixa da companhia. Fórmula: EBIT + Depreciação, Amortização, Exaustão - Equivalência Patrimonial.
} 
empresa, pois estes ativos servem de garantia aos empréstimos concedidos (Gomes e Leal, 2000). Assim sendo, a Variável Tangibilidade possui uma relação positiva com o endividamento, e será testada na hipótese 4 anterior.

\subsubsection{Flexibilidade Financeira}

Segundo a teoria da seleção hierárquica, empresas que possuem liquidez nos seus ativos não recorrem ao endividamento, porque os gestores preferem o autofinanciamento, ou seja, o poder da empresa em levantar fundos para expandir a atividade, faz com que, recorram menos ao mercado externo para captação. Antoniou et al. (2002) argumentaram que empresas possuidoras de liquidez, tendem a apresentar baixo nível de endividamento. Já Manos et al. (2001) defenderam que, quando a empresa possui capacidade de liquidez dos seus compromissos, isto faz com que aumente a sua capacidade de endividamento, o que leva a que esta variável possua uma relação positiva com o nível da dívida.

A hipótese 8, a ser testada, é que a flexibilidade financeira apresenta uma relação negativa com o endividamento.

Empresas que possuem maior liquidez em seus ativos recorrem menos ao endividamento. Esta afirmação é sustentada pela Teoria do Pecking Order que defende a preferência do autofinanciamento das empresas. Esta Variável é definida pelo rácio: Disponível/Ativo Circulante. O Disponível representa os ativos de maior liquidez na empresa. 


\subsubsection{Outras Linhas de Investigação Baseadas na Estratégia e no Controle}

A estratégia adotada pela empresa influencia a sua estrutura de capitais. Estratégias de empresas que investem em diversificação e diferenciação têm menos probabilidade de incorrerem em falência, utilizando assim maior endividamento (Arias et al., 2000); Titman (1984) defendeu que as empresas atuantes no segmento de bens duráveis, e que dão assistência técnica, tendem a ter um nível de endividamento mais baixo, devido aos maiores custos impostos numa situação de falência. Assim, verifica-se que as estratégias adotadas pelas empresas dependem do setor em que atuam.

Vários estudos empíricos estudaram o tipo da classificação de indústria, e outros o ramo de atividade, onde a empresa atua para verificar a importância desta variável na definição da estrutura de capitais. Nesse estudo serão utilizados os setores de atividade, onde as empresas estão inseridas: Primário, Secundário e Terciário para testar a variável estratégia.

Bradley et al. (1984), Titman e Wessels (1988), Chung (1993) e Baslakrishan e Fox (1993) encontraram significância entre o setor onde as empresas atuam e a estrutura de capitais, demonstrando que o nível de endividamento é influenciado por esta variável.

As empresas da amostra foram classificadas nos três grandes setores da economia onde atuam: Primário, Secundário e Terciário. O setor secundário, com $81,17 \%$ da proporção da amostra, sendo representados pela indústria extrativista, indústria transformadora, produção e distribuição de eletricidade, gás e água e construção civil. E o terciário, com 
$18,83 \%$, representado pelo setor comércio e de serviço. Não houve incidência de empresas classificadas pelo setor primário.

O cálculo da influência desta variável nos modelos foi verificado através de variável dummy para o setor econômico, onde a empresa está inserida, (se secundário=0 e se terciário=1).

Assim será testada a seguinte hipótese:

A hipótese 9, a ser testada, é que o setor de atividade, onde a empresa está inserida, é um determinante do seu nível de endividamento.

\subsubsection{Resumo das Hipóteses}

A tabela 2, a seguir, apresenta um resumo das hipóteses a serem testadas neste estudo, relacionando a teoria em que se sustentam e o sinal esperado para os coeficientes relativos a cada hipótese. 
Tabela 2 - Resumo das Hipóteses Testadas, Teoria da Estrutura de Capital em que Baseiam e Sinal Esperado do Coeficiente.

\begin{tabular}{l|l|c|c}
\hline $\mathbf{N}^{\circ}$ & \multicolumn{1}{|c|}{ Hipóteses } & $\begin{array}{c}\text { Teoria da Estrutura de } \\
\text { Capital }\end{array}$ & $\begin{array}{c}\text { Coeficiente } \\
\text { do Modelo }\end{array}$ \\
\hline 1 & $\begin{array}{l}\text { Existe uma relação positiva entre a taxa } \\
\text { média de impostos e o endividamento. }\end{array}$ & Efeitos Fiscais & $\beta>0$ \\
\hline 2 & $\begin{array}{l}\text { A existência de outros benefícios que não } \\
\text { do endividamento apresenta uma relação } \\
\text { negativa com o endividamento. }\end{array}$ & Efeitos Fiscais & $\beta<0$ \\
\hline 3 & $\begin{array}{l}\text { O risco do negócio apresenta uma } \\
\text { relação negativa com o endividamento. }\end{array}$ & Custos de Insolvência & $\beta<0$ \\
\hline 4 & $\begin{array}{l}\text { A tangibilidade apresenta uma relação } \\
\text { positiva com o endividamento. }\end{array}$ & $\begin{array}{c}\text { Custos de Insolvência } \\
\text { Teoria da Agência } \\
\text { Assimetria de Informações }\end{array}$ & $\beta>0$ \\
\hline 5 & $\begin{array}{l}\text { As oportunidades de crescimento } \\
\text { apresentam uma relação negativa com o } \\
\text { endividamento. }\end{array}$ & $\begin{array}{c}\text { Custos de Insolvência } \\
\text { Teoria da Agência } \\
\text { Assimetria de Informações }\end{array}$ & $\beta<0$ \\
\hline 6 & $\begin{array}{l}\text { O tamanho apresenta uma relação } \\
\text { positiva com o endividamento. }\end{array}$ & $\begin{array}{c}\text { Custos de Insolvência } \\
\text { Assimetria de Informações }\end{array}$ & $\beta>0$ \\
\hline 7 & $\begin{array}{l}\text { A rentabilidade apresenta uma relação } \\
\text { negativa com o endividamento. }\end{array}$ & Assimetria de Informações & $\beta<0$ \\
\hline 8 & $\begin{array}{l}\text { A flexibilidade financeira apresenta uma } \\
\text { relação negativa com o endividamento. }\end{array}$ & Assimetria de Informação & $\beta<0$ \\
\hline 9 & $\begin{array}{l}\text { O setor de atividade onde a empresa está } \\
\text { inserida é um determinante do seu nível } \\
\text { de endividamento }\end{array}$ & Estratégia & $\beta \neq 0$ \\
\hline
\end{tabular}

Fonte: Modelo de apresentação de Gomes e Leal (2000) adaptado pela autora.

Neste estudo serão utilizadas duas diferentes definições para as variáveis dependentes, ou seja, as medidas do endividamento, que representam à estrutura de capitais e que visam verificar os determinantes propostos pela teoria financeira. A primeira é definida pela razão entre o Endividamento Total (representado pelas dívidas de curto e longo prazo) em relação ao Patrimônio Líquido da empresa; e a segunda utiliza o valor de mercado das empresas, com base na cotação de suas ações no mercado, definida por Endividamento Total, (representado pelas dívidas de curto e longo prazo), em relação ao valor de mercado da empresa.

Diversos estudos empíricos utilizaram variáveis semelhantes, tais como: Rajan e Zingales (1995), Titman e Wessels (1988), Gomes e Leal (2000), Manos et al. (2001), Booth et al (2001), Brito e Lima (2004), Rita (2003), entre outros. 


\subsection{CARACTERIZAÇÃO DA AMOSTRA}

\subsubsection{Banco de Dados}

A amostra utilizada na estimação dos modelos foi extraída do SABE - Sistema de Análise de Balanços Empresariais, desenvolvido em parceria com o IBMEC - Instituto Brasileiro de Mercado e Capitais. Foram estudadas as Demonstrações Financeiras (Balanço Patrimonial, Demonstrativos de Resultados e Demonstrações das Origens e Aplicações de Recursos - DOAR) de 437 empresas no período de 1999 a 2003. Este banco de dados reúne as mais importantes empresas e bancos de capital aberto do Brasil, com grande nível de abrangência setorial, além dos dados de mercado coletados junto à BOVESPA.

Desta amostra, foram excluídas as empresas que fazem parte do setor financeiro, e as empresas que atualmente não estão cotadas na BOVESPA, (que representavam 110 casos), as empresas que se encontravam canceladas, concordatárias e suspensas (com 26 casos), ficando a amostra reduzida a 301 empresas operacionais.

Dado que, algumas empresas não apresentavam todas as informações necessárias foram excluídas as que apresentavam: receitas nulas no período de análise, (10 casos); não tinham dados necessários em todo período de análise, (27 casos); apresentavam patrimônio líquido negativo em todo o período de análise, (25 casos); não tiveram movimentação no mercado de derivativos, ou seja, as suas ações não foram negociadas em algum ano do período analisado, (32 casos). Após a eliminação das empresas enquadradas em cada uma das situações descritas, a amostra final ficou constituída por 207 empresas. 
A amostra das empresas ${ }^{18}$ foi agrupada por categorias individuais, segundo a Classificação das Atividades Econômicas - CNAE do Instituto Brasileiro de Geografia e Estatística - IBGE, conforme tabela 3 abaixo:

Tabela 3 - Classificação da Amostra Segundo CNAE ${ }^{19}$

\begin{tabular}{c|l|c|c}
\hline Seção & \multicolumn{1}{|c|}{ Descrição CNAE } & $\begin{array}{c}\text { Quantidade de } \\
\text { Empresas }\end{array}$ & $\%$ \\
\hline C & Indústrias extrativas & 2 & 0,97 \\
\hline D & Indústria de transformação & 125 & 60,39 \\
\hline E & Produção e distribuição de eletricidade, gás e água & 31 & 14,98 \\
\hline F & Construção & 10 & 4,83 \\
\hline G & $\begin{array}{l}\text { Comércio; reparação de veículos automotores, objetos } \\
\text { pessoais e domésticos }\end{array}$ & 12 & 5,80 \\
\hline H & Alojamento e alimentação & 3 & 1,45 \\
\hline I & Transporte, armazenagem e comunicação & 24 & 11,58 \\
\hline \multicolumn{1}{|c|}{ Total } & 207 & 100,00 \\
\hline Fonte: CNAE. Versão 1.0. IBGE. Rio de Janeiro, 2003. Elaboração Própria
\end{tabular}

O agrupamento das empresas, pelo setor econômico onde atuam, permitiu verificar que $81,17 \%$ pertencem ao setor secundário, representado pela indústria: Indústria extrativista, indústria transformadora, produção e distribuição de eletricidade, gás e água e construção civil. Assim, verifica-se que a indústria transformadora representa $60,39 \%$ do total da amostra. Os restantes, 18,83\%, representam o setor terciário: comércio e serviço. Deste último, destacam-se com $9,66 \%$ as empresas do setor de telecomunicações. Observa-se um peso significativo do setor secundário na amostra, assumindo uma predominância neste estudo.

\footnotetext{
${ }^{18}$ Ver classificação individual por empresa no Anexo B.

${ }^{19}$ Considerado apenas as Seções.
} 
A amostra de empresas ${ }^{20}$ também foi agrupada segundo o seu porte, de acordo com classificação, (micro, pequena, média e grande empresa), do $\mathrm{BNDES}^{21}$, levando-se em consideração a receita operacional bruta auferida no ano de 2003. Obteve-se como resultado que, das 207 empresas analisadas, 90,3\% são grande empresas e 9,7\% são médias.

Calculou-se a média das variáveis utilizadas no período de análise 1999 a 2003, com exceção das variáveis: Risco do negócio que, (foi calculado através do desvio padrão do EBIT), e das vendas no período e o ramo de atividade secundário e terciário, (calculado através de variável dummy).

A utilização das médias visa minimizar distorções decorrentes da grande variabilidade dos indicadores retirados do balanço patrimonial nas contas do ativo e passivo, refletem a posição de final de período, enquanto os indicadores como o EBIT e o EBITDA, as receitas e os resultados, refletirem o ocorrido ao longo do ano de análise. Este procedimento, também contribui para diminuir distorções nos resultados dos testes, causados por efeitos dinâmicos, como: Mudanças na tributação, variação nas taxas de juros, entre outros, sendo este mesmo procedimento utilizado em vários estudos empíricos analisados.

\footnotetext{
${ }^{20}$ Ver classificação por empresa no Anexo C.

21 BNDES - Banco Nacional de Desenvolvimento Social. Na classificação do porte da empresa é analisado a receita operacional bruta sendo: Microempresa: até R\$ 1.200 mil; Pequena Empresa: superior a R\$ 1.200 mil e inferior ou igual a R\$ 10.500 mil; Média Empresa: superior a R\$10.500 mil e inferior ou igual a R\$ 60.000 mil e Grande Empresa superior a R\$ 60.000 mil.
} 


\subsubsection{Escolha do Período de Análise da Amostra}

A década de 80 e início dos anos 90 foram marcados pela estagnação da economia brasileira, por altas taxas de inflação e pequeno crescimento do PIB real. Além disso, foi uma época de conturbada mudança no campo político, visto que a ditadura cede lugar à democracia, a partir da eleição indireta em 1985, e consolidada em 1990 com eleições diretas para a Presidência da República. Segundo Lacerda (2001), nos anos 80, a economia brasileira vivenciou uma década perdida, vários planos de estabilização que visavam conter a inflação e as suas causas foram implementados, porém sem sucesso.

Para Giambiagi et al. (2005), a década de 90 foi considerada como a "década das transformações". Estas transformações podem ser divididas em três etapas: 1991-1994; $1995-1998$ e 1999-2002.

A primeira etapa, de 1991 a 1994, foi marcada pela abertura econômica e as privatizações. No início, a abertura foi realizada de forma abrupta, levando a um choque nas empresas nacionais relativo à adaptação à concorrência externa. A economia brasileira adaptou-se à globalização dos mercados, e começou a adotar propostas "liberais"22 com a redução do tamanho do estado, promovendo a privatização das empresas públicas e reformas administrativas. A estabilização permanecia, no entanto, um desafio resistente às várias tentativas de eliminação da inflação.

A segunda etapa, de 1995-1998, foi marcada por grandes transformações: Estabilização da moeda, reformas e desequilíbrios macroeconômicos. Com o lançamento, na segunda

\footnotetext{
${ }^{22}$ Baseadas no liberalismo econômico "que se apóia no funcionamento da economia de mercado e no livre-comércio entre as nações como fonte de progresso". (Loureiro,1995).
} 
metade de 1994, com o plano de estabilização da economia - Plano Real, as repercussões na economia foram imediatas, observando-se uma queda abrupta das taxas inflacionárias e o controle da inflação. O Plano obteve tanto sucesso que elegeu, o então ministro da fazenda, Fernando Henrique Cardoso, como Presidente da República do Brasil para um mandato de 4 (quatro) anos, sendo posteriormente reeleito por mais 4 (quatro) anos. Porém, o entrave às decisões de investimento, e retomada do crescimento do país, era a existência de dois grandes desequilíbrios - o externo e o fiscal. Segundo Giambiagi et al.(2005) até 1998, sempre que a economia brasileira vivenciava uma crise estavam presentes três elementos: Altas taxas de inflação, crise externa e descontrole fiscal.

No período de 1999-2002, registrou-se uma tríplice mudança dos regimes cambial, monetário e fiscal. Estas mudanças provocaram avanços significativos na economia brasileira. Segundo Motta (2001), a estabilidade econômica, juntamente com as reformas administrativa e previdenciária, a mudança na política cambial através do câmbio flutuante, abertura da economia e continuidade ao processo de privatizações iniciadas em 1998, proporcionaram a criação de um ambiente macroeconômico favorável à promoção do crescimento sustentável. A privatização transferiu para o controle privado empresas públicas deficitárias, ou superavitárias, com níveis de investimentos inadequados para o crescimento, pondo fim, ao monopólio dos setores do petróleo e telecomunicações. A alteração no tratamento do capital estrangeiro permitiu que dois grandes setores da economia, exploração mineral e energia elétrica, pudessem ser controlados por empresas estrangeiras. Em conseqüência deste conjunto de mudanças, a economia brasileira ficou muito mais moderna e competitiva (Giambiagi et al.,2005). 
Estas mudanças na economia brasileira intensificaram o desenvolvimento das operações de fusões e aquisições de empresas nacionais por empresas estrangeiras bem como por outras empresas nacionais. Segundo Guarita (2002) foram os seguintes fatores que impulsionaram este processo de fusões e aquisições: "Necessidades de ganhos de escalas de produção; atuação em outras regiões geográficas; surgimento de novos produtos; e busca de sinergias financeiras e tecnológicas".

Em 2003 foi eleito Luiz Inácio da Silva, com uma nova perspectiva de crescimento econômico e estabilização da inflação, dando continuidade a política que vinha sendo adotada por seu antecessor.

A delimitação do período de análise, nesta dissertação, foi o definido para o período de 1999 a 2003 por corresponder a um melhor ambiente macroeconômico da economia brasileira. Devido à amostra, ter por base as empresas não-financeiras de capital aberto cotadas na BOVESPA, realiza-se na seção seguinte uma breve caracterização deste mercado.

\subsubsection{A BOVESPA}

A BOVESPA é atualmente o maior centro de negociação com ações da América Latina, e, integra todas as bolsas brasileiras em torno de um único mercado de valores.

O mercado acionário brasileiro encerrou, em Dezembro de 2004 com o Índice Bovespa (Ibovespa), em 26.196 pontos, apresentando desempenho positivo quando comparado ao ano anterior. No ano de 2004, existiam 390 empresas registradas com um volume 
total negociado de R\$ 304 bilhões. As transações à vista ${ }^{23}$, (lote-padrão), foram responsáveis por $89,8 \%$ das negociações, somando $\mathrm{R} \$ 273$ bilhões.

O valor de mercado das empresas da BOVESPA atingiu, em Dezembro de 2004, R\$ 904,9 bilhões, destacando-se cinco setores de atividade: Instituições financeiras $(17,3 \%)$; Petróleo e gás $(12,8 \%)$; Telefonia fixa $(11,6 \%)$; Mineração $(10,2 \%)$ e Energia elétrica $(9,6 \%)$.

A seguir, na tabela 4, será apresentada a evolução do número de empresas registradas em bolsa, as que tem ações negociadas na BOVESPA, o número de pontos do fechamento do pregão Ibovespa e o valor de mercado das empresas negociadas no período de 1999 a 2003.

Tabela 4 - Número de Empresas Registradas em Bolsa, Número de Empresas Negociadas na BOVESPA, Valor de Fechamento do Ibovespa e Valor de Mercado das Empresas Negociadas na BOVESPA

\begin{tabular}{|c|c|c|c|c|}
\hline Ano & $\begin{array}{c}N^{\circ} \text { de } \\
\text { empresas } \\
\text { registradas em } \\
\text { Bolsa }\end{array}$ & $\begin{array}{c}\text { Empresas com } \\
\text { açöes negociadas } \\
\text { na BOVESPA }\end{array}$ & $\begin{array}{c}\text { Valor de } \\
\text { fechamento } \\
\text { lbovespa* (em } \\
\text { pontos) }\end{array}$ & $\begin{array}{c}\text { Valor de Mercado das } \\
\text { empresas negociadas na } \\
\text { BOVESPA }\end{array}$ \\
\hline 1999 & 534 & 487 & nd & nd \\
\hline 2000 & 495 & 467 & 15.259 & $\mathrm{R} \$ 441$ bilhões \\
\hline 2001 & 468 & 439 & 13.577 & $\mathrm{R} \$ 430$ bilhões \\
\hline 2002 & 436 & 407 & 11.268 & $\mathrm{R} \$ 438$ bilhões \\
\hline 2003 & 410 & 383 & 22.236 & R\$ 677 bilhões \\
\hline
\end{tabular}

Embora o número de empresas tenha diminuído, o valor de mercado das empresas cresceu muito no período de análise. Esta evolução pode ser justificada pela fusão e

\footnotetext{
23 Mercado à vista representa a compra ou venda de uma determinada quantidade de ações, a um preço estabelecido em pregão.
} 
aquisição de várias empresas (provocando a diminuição do número de empresas) e pela forte entrada de capital estrangeiro; devido às privatizações que determinaram a quebra de monopólios nos setores de petróleo e telecomunicações, e a permissão do controle estrangeiro nos setores da energia elétrica e exploração mineral, que levou ao aumento do valor de mercado.

A evolução das operações efetuadas pela BOVESPA, no período em análise podem ser observadas na tabela 5 a seguir.

Tabela 5 - Evolução do Volume Total Negociado na BOVESPA de 1999 a 2003 por Tipo de Mercado (em RS bilhões)

\begin{tabular}{c|c|c|c|c}
\hline Ano & $\begin{array}{c}\text { Mercado à } \\
\text { Vista }\end{array}$ & $\begin{array}{c}\text { Mercado a } \\
\text { Termo }\end{array}$ & $\begin{array}{c}\text { Mercado de } \\
\text { Opções }\end{array}$ & $\begin{array}{c}\text { Volume } \\
\text { Total Negociado }\end{array}$ \\
\hline 1999 & nd & nd & nd & nd \\
\hline 2000 & nd & nd & nd & nd \\
\hline 2001 & 135,5 & 6,4 & 8,4 & 150,3 \\
\hline 2002 & 125,3 & 5,1 & 8,5 & 138,9 \\
\hline 2003 & 181,9 & 6,4 & 16,2 & 204,5 \\
\hline
\end{tabular}

Fonte: BOVESPA: www.bovespa.com.br. nd: dados não disponíveis. Elaboração própria.

A seguir, é apresentado, no gráfico 4, o perfil da participação percentual média dos investidores no período de 2001 a 2003. 


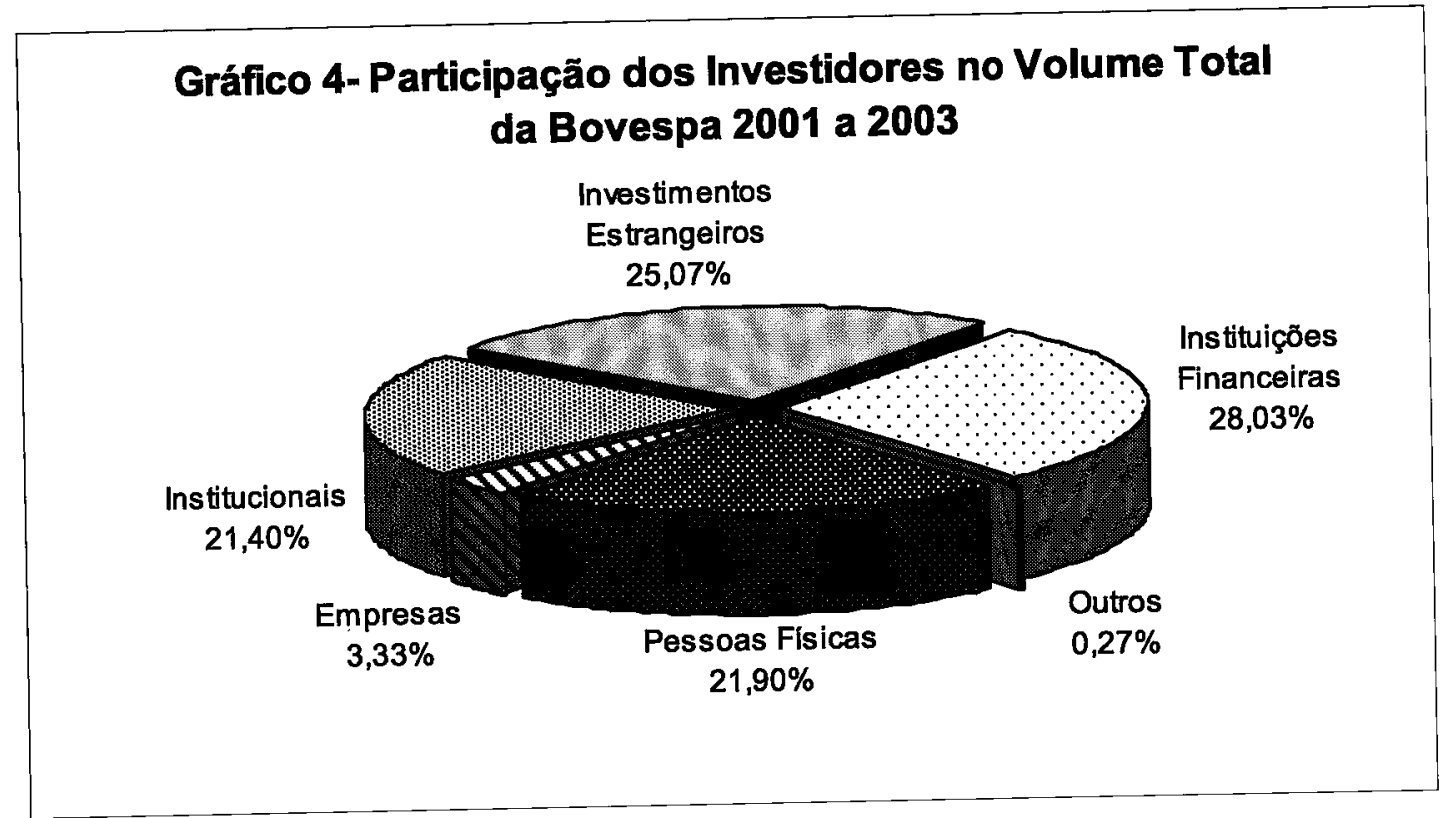

Fonte: BOVESPA: www.bovespa.com.br. Elaboração Própria

\subsection{Caracterização das Variáveis}

\subsubsection{Medidas do Endividamento}

Neste estudo serão utilizadas duas proxies para determinação da estrutura de capitais das empresas - as variáveis dependentes. A primeira fará a análise da alavancagem financeira, levando em consideração o endividamento total em relação ao valor contábil da empresa ${ }^{24}\left(\mathrm{Y}_{1}\right)$, e é definida pela expressão ET/(ET + PL), onde ET representa o endividamento de curto e o de longo prazo, e PL o patrimônio líquido. A segunda proxie apresenta o endividamento total em relação ao valor de mercado das ações da empresa $^{25}\left(\mathrm{Y}_{2}\right)$, definida por ET/(ET + VM), onde ET representa as dívidas de curto e longo prazo, e VM o valor de mercado das ações das empresas, com base na cotação do último dia de encerramento do exercício fiscal.

\footnotetext{
${ }^{24}$ Valor contábil representa o valor patrimonial da empresa. É o valor do Patrimônio Líquido constante no Balanço.

${ }^{25}$ Valor de mercado é o valor das empresas de capital aberto negociadas na bolsa de valores. Resulta da multiplicação do preço de suas ações no mercado bolsista pela quantidade de ações que compõem seu capital social, excluindo-se as ações em tesouraria.
} 
Segundo Pereira (2004), estas proxies de endividamento a serem utilizadas foram apontadas por Rajan e Zingales (1995) e Dorbetz e Fix (2003) como as melhores medidas para verificar a estrutura de capitais das empresas, sendo também utilizadas em diversos estudos internacionais. A primeira definição aponta o total de endividamento das empresas em relação ao seu patrimônio a preços contábeis. A segunda, mostra a relação entre o endividamento total da empresa em relação ao seu valor de mercado, com base nas cotações das ações na bolsa de valores, o que ajusta o valor das empresas a preços mais próximos à realidade atual.

A seguir, no gráfico 5, é apresentada a comparação do valor das empresas a valor contábil e a valor de mercado ${ }^{26}$. Observa-se que, estes valores no período de 1999 a 2002, estão muito próximos, com o valor contábil a superar o valor de mercado. Porém, em 2003, há um crescimento superior do valor de mercado em relação ao contábil.

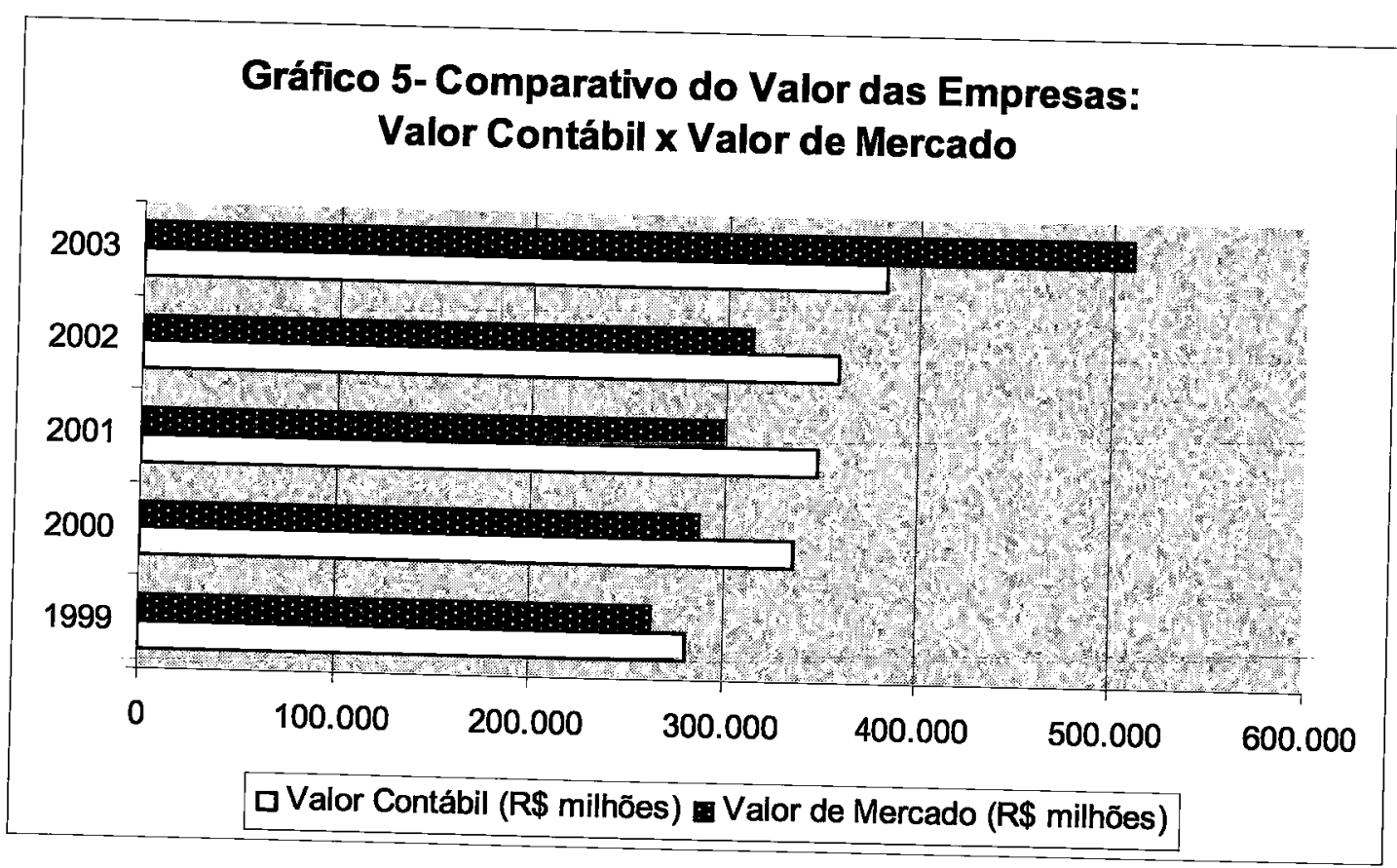

Fonte: Sabe e BOVESPA: www.bovespa.com.br. Elaboração Própria

\footnotetext{
${ }^{26}$ Ver relação do valor individual por empresa no Anexo D (valor contábil) e o no Anexo E (valor de
mercado).
} 


\subsubsection{Medidas dos Fatores Específicos das Empresas}

As medidas dos fatores específicos que determinam a estrutura de capitais das empresas - variáveis explicativas foram determinadas com base na teoria financeira. A literatura analisada permitiu a formulação de um conjunto de hipóteses, que identificam a existência de um aumento no endividamento das empresas, devido aos fatores como os ativos fixos, outros benefícios que não o de endividamento, oportunidade de crescimento e tamanho da empresa; e, um decréscimo ocasionado pela volatilidade, probabilidade de risco de falência, não expansão, rentabilidade e singularidade do produto.

Nove variáveis explicativas serão utilizadas neste estudo para determinação da estrutura de capital das empresas: Taxa média de Impostos, Outros Benefícios que Não o de Endividamento, Risco do Negócio, Composição dos Ativos, Oportunidades de Crescimento, Tamanho, Rentabilidade, Flexibilidade Financeira e Classificação do Ramo Econômico onde a empresa está inserida.

O resumo das variáveis dependentes e as variáveis explicativas dos modelos a serem testados neste estudo, com a suas respectivas proxies, estão representados na tabela 6 a seguir. 


\section{Tabela 6- Resumo das Variáveis Dependentes e Variáveis Explicativas dos Modelos}

\begin{tabular}{l|c|l}
\hline \multicolumn{1}{c|}{ Variáveis } & $\begin{array}{c}\text { Deno- } \\
\text { minação }\end{array}$ & \multicolumn{1}{|c}{ Proxies } \\
\hline - Variáveis Explicativas & $X_{1}$ & $\begin{array}{l}\text { Impostos sobre o Rendimento / Resultado } \\
\text { Antes do Imposto de Renda }\end{array}$ \\
\hline Taxa Média de Impostos & $X_{2}$ & (Depreciação + Amortização) / Ativo Total \\
\hline $\begin{array}{l}\text { Outros Benefícios que Não o de } \\
\text { Endividamento }\end{array}$ & $X_{3}$ & Desvio Padrão EBIT / Média EBIT \\
\hline Risco do Negócio (volatilidade) & $X_{4}$ & Desvio Padrão Vendas Liq./ Média Vendas Liq. \\
\hline $\begin{array}{l}\text { Composição dos Ativos Fixos } \\
\text { (tangibilidade) }\end{array}$ & $X_{5}$ & Imobilizado/Ativo Total \\
\hline Oportunidades de Crescimento & $X_{6}$ & $\begin{array}{l}\text { (Ativo Total - Patrimônio Líquido + Valor de } \\
\text { Mercado) / Ativo Total }\end{array}$ \\
\hline Tamanho (dimensão) & $X_{7}$ & lê (Ativo Total) \\
\hline Rentabilidade & $X_{8}$ & EBITA/Ativo Total \\
\hline Flexibilidade Financeira & $X_{9}$ & Disponível/ Ativo Circulante \\
\hline Setor de Atividade & $X_{10}$ & $\begin{array}{l}\text { Variável dummy para determinar o tipo de } \\
\text { setor onde atuam (secundário e terciário) }\end{array}$ \\
\hline
\end{tabular}

\subsubsection{Estatísticas Descritivas das Variáveis}

Os resultados das estatísticas descritivas das variáveis dos modelos estão descritos na tabela 7 a seguir. O nível médio de endividamento total das empresas, a valor contábil no período analisado, foi de $58 \%$, representando o percentual do ativo total financiado por capitais de terceiros. Já o endividamento total médio, calculado em relação ao valor de mercado das empresas, foi de $65 \%$ no mesmo período.

A rentabilidade média obtida pelas empresas foi de $11 \%$, medida através do EBITDA.

Os ativos tangíveis, que representam os valores que normalmente são oferecidos como garantia real aos credores, quando da contratação de empréstimos representam cerca de $42 \%$ do total do ativo.

A seguir, será apresentado na tabela 7 , as estatísticas descritivas das variáveis do modelo empírico: Mínimo, Máximo, Média, Mediana e o Desvio-Padrão. 
Tabela 7 - Estatística Descritivas das Variáveis Utilizadas nos Modelos

\begin{tabular}{c|r|r|r|r|r|r}
\hline Variável & \multicolumn{1}{|c|}{$\begin{array}{c}\mathbf{N}^{\circ} \\
\text { Observações }\end{array}$} & \multicolumn{1}{|c|}{ Mínimo } & Máximo & Média & Mediana & Desvio-Padrão \\
\hline Y1 & 207 & 0,01 & 0,99 & 0,58 & 0,58 & 0,20 \\
\hline Y2 & 207 & 0,07 & 0,99 & 0,65 & 0,65 & 0,20 \\
\hline $\mathbf{X 1}$ & 207 & $-4,95$ & 11,33 & 0,32 & 0,22 & 1,05 \\
\hline $\mathbf{X 2}$ & 207 & 0,00 & 0,15 & 0,04 & 0,03 & 0,03 \\
\hline $\mathbf{X 3}$ & 207 & $-43,06$ & 45,67 & 0,33 & 0,50 & 5,17 \\
\hline $\mathbf{X} 4$ & 207 & 0,02 & 2,22 & 0,31 & 0,26 & 0,24 \\
\hline $\mathbf{X 5}$ & 207 & 0,00 & 0,92 & 0,42 & 0,43 & 0,20 \\
\hline $\mathbf{X 6}$ & 207 & 0,11 & 4,43 & 0,97 & 0,91 & 0,40 \\
\hline $\mathbf{X 7}$ & 207 & 9,19 & 19,01 & 13,52 & 13,56 & 1,82 \\
\hline $\mathbf{X 8}$ & 207 & $-0,12$ & 0,33 & 0,11 & 0,11 & 0,07 \\
\hline $\mathbf{X 9}$ & 207 & 0,00 & 0,68 & 0,19 & 0,15 & 0,16 \\
\hline $\mathbf{X 1 0}$ & 207 & 0,00 & 1,00 & & & \\
\hline & & & & & &
\end{tabular}

\subsection{Metodologia de Análise de Dados}

\subsubsection{Análise de Correlação}

A análise do grau de associação entre as variáveis foi realizada com base na inferência estatística pela determinação dos coeficientes de correlação de Pearson. Esta análise indica que a intensidade de um fenômeno está tendencialmente acompanhada pela intensidade do outro, no mesmo sentido, ou, em sentido inverso (Murteira, 1993).

Os coeficientes de correlação de Pearson são obtidos através do Qui-quadrado ${ }^{27}$, onde o limite inferior deste coeficiente é zero, significando a independência das variáveis e o limite superior é igual a 1.

${ }^{27} X^{2}=\sqrt{\frac{X^{2}}{X^{2}+n}}=0,252$ 
Como este procedimento não indica que as variáveis estão indissoluvelmente ligadas, foram formulados modelos de regressão linear para estabelecer o tipo de relação causal entre o endividamento e os fatores específicos das empresas.

\subsubsection{Modelo de Regressão Linear Múltipla}

Para análise da amostra, optou-se pelo procedimento estatístico da regressão linear múltipla. Esta escolha, deu-se pelo fato da técnica de regressão múltipla estudar como as variáveis independentes, mencionadas anteriormente, influenciam a estrutura de capitais das empresas. Várias pesquisas empíricas têm-se focado na explicação da escolha da estrutura de capitais pelo uso de regressão linear para análise, como são exemplos os trabalhos de Titman e Wessels (1988), Alonso (2000), Rajan e Zingales (1995), Booth et al. (2001), Arias et al.(2000) Rita (2003) e Simões (2002).

Segundo Kmenta (1978), as relações que podem ser descritas com o modelo de regressão múltipla são muito comuns em economia, como por exemplo, na função de produção, onde a produção é função típica de vários insumos, e a função de demanda que tem como variáveis explicativas o preço do bem, o preço dos bens substitutos, a renda, entre outras.

O modelo de regressão linear que se pretende utilizar na análise dos dados é o Modelo da Regressão Múltipla Clássica, com dados seccionais (cross section $^{28}$ ). Este é utilizado, em estudos do gênero, por constituir um bom instrumento descritivo, à

\footnotetext{
${ }^{28}$ Permite a observação sobre várias empresas para um mesmo período de tempo, como, por exemplo:
vendas de um determinado ano de várias empresas. (Rita,2003:90).
} 
medida que permite evidenciar o poder explicativo de variáveis independentes, face a uma determinada variável dependente.

Este modelo pode ser descrito na seguinte forma ${ }^{29}$ :

$$
Y_{i}=\beta_{0}+\beta_{1} X_{i 1}+\beta_{2} X_{i 2}+\ldots+\beta_{k} X_{i k}+\varepsilon_{i}, \quad i=1, \ldots . n
$$

Onde $Y_{i}$ expressa a variável dependente ou explicada, os $X_{1}, \ldots, X_{k}$ expressam as variáveis independentes ou explicativas. A letra minúscula i refere-se a i-ésima observação, a segunda letra minúscula usada na descrição das variáveis independentes identifica a variável em questão. O número de variáveis é K-1. $\beta_{\mathrm{j}}$ são conhecidos como coeficientes parciais de regressão, isto é, os coeficientes das variáveis explicativas, ou declividades da regressão. $\beta_{0}$ é conhecido como intercepto ou constante da regressão. $\varepsilon$ é uma variável aleatória residual, na qual, procuram-se incluir todas as influências no comportamento da variável $\mathrm{Y}$ que não podem ser explicadas linearmente pelo comportamento das variáveis $\mathrm{X}_{1}, \ldots . ., \mathrm{X}_{\mathrm{k}}$, sendo considerado o erro do modelo.

Considerando as 9 variáveis previamente selecionadas e identificadas, os modelos sugeridos para o estudo dos determinantes da estrutura de capitais das empresas brasileiras de capital aberto são representados pelas seguintes equações ${ }^{30}$ :

${ }^{29}$ Para complementar a especificação do modelo de regressão foi acrescentado os seguintes pressupostos básicos a ser aplicado em todas as observações: (1) $\varepsilon_{\mathrm{i}}$ está normalmente distribuída; $(2) \mathrm{E}\left(\varepsilon_{\mathrm{i}}\right)=0 ;(3) \mathrm{E}$

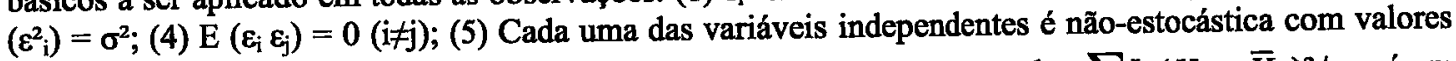
fixados em amostras repetitivas e tais que, para qualquer tamanho amostral, $\sum_{i=1}^{n}\left(X_{i k}-\bar{X}_{k}\right)^{2} / n$ é um número finito diferente de zero para cada $\mathrm{k}=2,3 \ldots \mathrm{K}$; (6) $\mathrm{O}$ número de observações excede o número de coeficientes a ser estimado e (7) não existe nenhuma relação linear exata entre qualquer das variáveis independentes. (Kmenta, 1978: 376).

30 Devido a variável risco do negócio ser calculada através de duas proxies, foram estipuladas 10 variáveis. 


\section{- Endividamento Total a Valores Contábeis}

$$
Y_{1}=\beta_{0}+\beta_{1} X_{1}+\beta_{2} X_{2}+\beta_{3} X_{3}+\beta_{4} X_{4}+\beta_{5} X_{5}+\beta_{6} X_{6}+\beta_{7} X_{7}+\beta_{8} X_{8}+\beta_{9} X_{9}+\beta_{10} X_{10}+\varepsilon
$$

\section{- Endividamento Total a Valores de Mercado}

$$
Y_{2}=\beta_{0}+\beta_{1} X_{1}+\beta_{2} X_{2}+\beta_{3} X_{3}+\beta_{4} X_{4}+\beta_{5} X_{5}+\beta_{6} X_{6}+\beta_{7} X_{7}+\beta_{8} X_{8}+\beta_{9} X_{9}+\beta_{10} X_{10}+\varepsilon
$$

Onde:

$Y_{1}=$ Endividamento Total ao valor contábil

$\mathrm{Y}_{2}=$ Endividamento Total ao valor de mercado

$\mathrm{X}_{1}=$ Taxa média de Impostos

$\mathrm{X}_{2}=$ Outros Benefícios que Não do Endividamento

$\mathrm{X}_{3}=$ Risco do Negócio medido através do desvio padrão do EBIT

$\mathrm{X}_{4}=$ Risco do Negócio medido através do Desvio Padrão das Vendas

$\mathrm{X}_{5}=$ Composição dos Ativos

$\mathrm{X}_{6}=$ Oportunidade de Crescimento

$\mathbf{X}_{7}=$ Tamanho

$\mathrm{X}_{\mathbf{8}}=$ Rentabilidade

$\mathrm{X}_{9}=$ Flexibilidade financeira

$\mathrm{X}_{10}=$ Dummy do setor (se setor secundário $=0 ;$ se não $=1$ ) 


\subsubsection{Estatísticas Utilizadas para Análise dos Modelos}

O método para estimação dos modelos de regressão linear múltipla com dados em cross section, usado foi o Stepwise.

"Sempre que, pelo procedimento Stepwise, entra uma variável nova no modelo analisa-se a significância de cada variável $X$, sendo eliminadas as variáveis que não tenham uma capacidade de explicação significativa. Este se repete até que as variáveis não introduzidas no modelo não tenham capacidade de explicação significativa e quando todas as que estão no modelo tenham" (Pestana e Gageiro, 2003: 614).

Tendo por objetivo verificar, estatisticamente, os modelos finais resultantes da regressão linear múltipla, e analisar o poder explicativo das variáveis independentes dos modelos, foram calculados e analisados os seguintes testes:

\subsubsection{Cálculo do Coeficiente de Determinação dos Modelos}

O cálculo do coeficiente de determinação dos modelos tem, por objetivo, avaliar a qualidade do modelo, ou seja, em que medida a variável dependente é explicada pelas variáveis independentes. Será calculado o coeficiente de determinação, (R Square ou $\left.R^{2}\right)^{31}$, e o Ajustamento do coeficiente de determinação do modelo, (Ajusted R Square ou

${ }^{31} R^{2}=\sum_{i=1}^{n}\left(\hat{y}_{i}-\bar{y}\right)^{2} / \sum_{i=1}^{n}\left(y_{i}-\bar{y}\right)^{2}$ 
$\mathrm{R}^{2}$ Ajustado) ${ }^{32}$, que corrige o $\mathrm{R}^{2}$ com base no número de graus de liberdade do problema.

\subsubsection{Teste de Aderência Global do Modelo (Estatística F)}

A estatística $F$ testa a hipótese nula que os coeficientes $\left(\beta_{\mathrm{i}}\right)$ de regressão, associados a cada uma das variáveis explicativas, são todos iguais a zero. Ou seja: $\mathrm{H}_{0}=\beta_{1}=\beta_{2}=\beta_{3}=$ $\beta_{\mathrm{k}}=0$. Este teste apresenta a aderência global da modelo estimado. Quanto maior for a variação explicada pela regressão, relativamente à variação residual, maior é a evidência contra a hipótese nula. Este teste é verificado utilizando-se a estatística $F^{33}$. Na tabela ANOVA deve se obter um nível de significância do teste $F$ inferior a 0,05 , para se poder rejeitar a hipótese nula $\left(\beta_{\mathrm{i}}=0\right)$.

\subsubsection{Teste $t$}

Este teste avalia a capacidade explicativa de cada variável independente. O objetivo é verificar se existe, ou não, uma relação linear entre cada uma das variáveis explicativas e a variável dependente. A hipótese nula consta em verificar se o coeficiente associado a cada variável é nulo. Será rejeitada a hipótese quando o nível de significância do teste apresenta valores superiores a 0,05 .

\footnotetext{
${ }^{32} R^{2}$ Ajustado $=1-\left(1-R^{2}\right) \frac{n-1}{n-k}$

${ }^{33} F=R^{2} /\left(1-R^{2}\right)(n-k-1) / k$
} 


\subsubsection{Independência das Variáveis Aleatórias Residuais}

Através do teste de Durbin-Watson ${ }^{34}$, será analisada a existência de independência entre as variáveis aleatórias residuais, ou seja, se a sua covariância é nula ${ }^{35}$. Se o resultado estiver entre o intervalo ds e 4-ds, não será rejeitada a hipótese nula, e, conclui-se que não existe autocorrelação entre os resíduos, sendo ds definido como o ponto superior. $O$ seu valor será definido pelo número de observações da amostra e o número de variáveis explicativas do modelo, com exceção do termo constante.

\subsubsection{Multicolinearidade}

Um dos pressupostos do modelo de regressão linear múltipla é que as variáveis explicativas são linearmente independentes, isto é, que não se verifica a multicolinearidade. "O método Stepwise permite detectar a multicolinearidade, pela observação de modificações significativas nos coeficientes estimados" (Pestana e Gageiro, 2003:625). A intensidade da multicolinearidade é analisada, neste estudo, através de três pontos: Correlação entre as variáveis independentes, da Tolerância e VIF e do Condition Index e proporção da variância.

$$
\begin{gathered}
34 \quad d=\frac{\sum_{t=2}^{t=n}\left(\hat{u}-\hat{u}_{t-1}\right)^{2}}{\sum_{i=2}^{t=n} \hat{u}_{t}^{2}} \\
35 E\left(\varepsilon_{i} \varepsilon_{j}\right)=0, i \neq j .
\end{gathered}
$$




\section{- Correlação entre as Variáveis Independentes}

A correlação entre as variáveis independentes será verificada na análise da matriz de correlação, onde se verifica a não existência de correlações elevadas entre as variáveis observadas.

\section{- Tolerância e VIF}

Este teste da tolerância ${ }^{36}$ mede o grau em que uma variável dependente é explicada por todas as outras variáveis explicativas. A tolerância da variável independente mede a proporção da sua variação, que não é explicada pelo restante das variáveis independentes. Segundo Pestana e Gageiro (2003), como a tolerância varia entre zero e um, quanto mais próximo de zero, maior será a multicolinearidade. $O$ valor normalmente considerado como o limite abaixo do qual há multicolinearidade é 0,1 , (onde $\mathrm{R}^{2}=0,9$ e $\mathrm{R}=0,95$ ). As variáveis com valores abaixo da tolerância devem ser excluídas do modelo.

O VIF (variance inflation factor) ${ }^{37}$ é o inverso da tolerância. Quanto mais próximo de zero estiver o VIF, menor será a multicolinearidade. Segundo Pestana e Gageiro (2003), o valor considerado como limite acima do qual existe multicolinearidade é 10 . Neste caso, as variáveis independentes serão analisadas e as que estiverem fora deste limite serão excluídās.

\footnotetext{
${ }^{36}$ Tolerância $=1-R_{i}^{2}$

${ }^{37} \mathrm{VIF}=1 /$ tolerância
} 


\section{- Condition Index e Proporção de Variância.}

O condition index calcula se existe multicolinearidade entre as variáveis do modelo. Este indicador é calculado através da raiz quadrada do quociente, entre o maior valor próprio, e cada valor próprio das variáveis. Os valores próprios dão uma indicação de quantas dimensões distintas, que incluem a constante e os termos independentes, existem entre as variáveis X's. A intensidade de multicolinearidade é considerada elevada, quando, o condition index é superior a 30. A variance proportion é a proporção de variância explicada por cada componente principal. 


\section{ANÁLISE DOS RESULTADOS DO TESTE EMPÍRICO}

Nesta seção será realizada a análise da validação, estatística e teórica, dos resultados do estudo empírico, realizado na amostra das empresas brasileiras não financeiras de capital aberto.

\subsection{Análise dos Resultados da Estimação dos Modelos - Validação Estatística}

Para realização da validação estatística dos modelos analisados, (modelo de endividamento total a valor contábil e modelo de endividamento total a valor de mercado), foi utilizado o software estatístico SPSS versão 11.0. A seguir será apresentada a análise dos resultados da estimação dos modelos, com base na metodologia adotada de análise dos resultados.

\subsubsection{Endividamento Total a Valor Contábil (EVC)}

A Regressão linear Cross Section, do modelo da medida de endividamento a valor contábil, pelo processo stepwise, que apresentou-se estatisticamente significativo e que não sofre de multicolinearidade, é representado pelo seguinte equação:

$$
\begin{aligned}
\mathrm{EVC}= & 0,424+0,154 \mathrm{X}_{5}+0,254 \mathrm{X}_{6}-0,787 \mathrm{X}_{8}-0,351 \mathrm{X}_{9} \quad \mathrm{R}^{2}=0,284 \\
& (0,044) \quad(0,062) \quad(0,033) \quad(0,179) \quad(0,081)
\end{aligned}
$$

Os resultados da estimação do modelo estão descritos a seguir, na tabela 8 , que apresenta os resultados da estimação, e, na tabela 9 , com a análise da variância. 
Tabela 8 - Resultados da Análise de Regressão Linear Múltipla - Modelo EVC

\begin{tabular}{l|l|r|r|r|r}
\hline \multicolumn{2}{c|}{ Variáveis Independentes } & Coeficiente & \multicolumn{1}{|c|}{$\begin{array}{l}\text { Desvio- } \\
\text { padrão }\end{array}$} & Estatística t & Valor p \\
\hline$B_{0}$ & Constante & 0,424 & 0,044 & 9,689 & 0,000 \\
$X_{5}$ & Tangibilidade & 0,154 & 0,062 & 2,462 & 0,015 \\
$X_{6}$ & Oportunidades de crescimento & 0,254 & 0,033 & 7,752 & 0,000 \\
$X_{8}$ & Rentabilidade & $-0,787$ & 0,179 & $-4,387$ & 0,000 \\
$X_{9}$ & Flexibilidade financeira & $-0,351$ & 0,081 & $-4,330$ & 0,000 \\
\hline$R^{2}=0,284, R^{2}$ ajustado= 0,270 e Durbin-Watson=1,792
\end{tabular}

Tabela 9 - Análise da Variância (ANOVA) - Modelo EVC

\begin{tabular}{l|r|c|r|r}
\hline Fonte de Variação & Variação & Graus de Liberdade & Quadrado Médio & Estatística F \\
\hline Explicada (SSR) & 2,408 & 4 & 0,602 & 20,044 \\
Residual (SSE) & 6,066 & 202 & 0,030 & \\
Total & 8,473 & 206 & & \\
\hline
\end{tabular}

A seguir, será apresentada a interpretação de dados da regressão linear.

\section{- Coeficiente de Determinação}

$O$ coeficiente de determinação do modelo, $R^{2}$ Ajustado, informa qual é a proporção da variância total da variável dependente, que é explicada pelo modelo linear, já considerando os graus de liberdade. Neste caso, o $\mathbf{R}^{2}$ ajustado foi igual a $27 \%$, o que representa o poder explicativo da regressão pelas variáveis independentes X's $\left(\mathrm{X}_{5}, \mathrm{X}_{6}, \mathrm{X}_{8}, \mathrm{X}_{9}\right)$. Embora, este resultado tenha um reduzido valor, de acordo com outros estudos empíricos da mesma natureza realizados, o mesmo, só por si, não é determinante de qualidade de modelo. 
- Análise Teste F

$\mathrm{O}$ teste $\mathrm{F}$ analisa se todos os parâmetros simultaneamente são iguais a zero: $\mathrm{Ho}=\beta_{1}=$ $\beta_{2}=\beta_{k}=0$, ou seja, nenhuma variável explica o modelo. Na tabela, $F_{(4, \infty)}=3,32$ para um nível de significância de $1 \%$. $O$ teste $\mathrm{F}$ calculado no modelo de estimação foi igual a 20,44. Como o resultado obtido foi superior a 3,32, então, a hipótese nula não se verifica e a variáveis independentes $\left(\mathrm{X}_{5}, \mathrm{X}_{6}, \mathrm{X}_{8}, \mathrm{X}_{9}\right)$, explicam o modelo. Conclui-se que o modelo tem aderência global.

\section{- Testet}

Testa a hipótese dos parâmetros individualmente explicarem o modelo. Ao aplicar o teste $\mathrm{t}$ de student com 202 graus de liberdade, verifica-se que os resultados obtidos foram satisfatórios. Estatisticamente, os coeficientes são significativos com nível de significância abaixo de $5 \%$. A análise dos sinais dos parâmetros economicamente consistentes com a teoria financeira será apresentada na próxima seção.

\section{- Independência das Variáveis Aleatórias Residuais}

O teste de Durbin-Watson analisa a existência de independência entre as variáveis aleatórias residuais, verificando se a covariância é nula. $\mathrm{O}$ resultado do teste foi de 1,792. Na tabela da estatística $d$, os pontos de significância a $1 \%$ do limite superior ds para $\mathrm{n}=200$ e $\mathrm{k}=4$ é de 1,715 . Como $\mathrm{D}-\mathrm{W}$ calculado é superior a ds e inferior a 4-ds, encontram-se na região onde se deve rejeitar a hipótese nula, conclui-se que não existe autocorrelação entre os resíduos. 
- Multicolinearidade

Para verificar se as variáveis explicativas são linearmente independentes, ou seja, não se verifica multicolinearidade foi observada a correlação entre as variáveis independentes, calculados os testes de tolerância, VIF e o condition index e variance proportion.

A matriz de correlação abaixo, calculada pelo Coeficiente de Pearson, apresenta a correlação das variáveis independentes, onde se verifica a não existência de correlações elevadas entre estas variáveis, sendo o valor limite da amostra de 0,282.

Tabela 10 - Matriz de Correlação entre as Variáveis Explicativas - Modelo EVC

\begin{tabular}{c|c|c|c|c}
\hline Variáveis Independentes & $\mathbf{X 5}$ & $\mathbf{X 6}$ & $\mathbf{X 8}$ & $\mathbf{X 9}$ \\
\hline $\mathbf{X 5}$ & 1,000 & $-0,132$ & 0,136 & 0,093 \\
X6 & $-0,132$ & 1,000 & 0,282 & 0,203 \\
X8 & 0,136 & 0,282 & 1,000 & 0,237 \\
X9 & 0,093 & 0,203 & 0,237 & 1,000 \\
\hline
\end{tabular}

O teste da tolerância (tolerance), onde foi medido o grau de explicação da variável dependente em relação às outras variáveis independentes, mostrou que todas as variáveis $\mathrm{X}$ 's $\left(\mathrm{X}_{5}, \mathrm{X}_{6}, \mathrm{X}_{8}, \mathrm{X}_{9}\right)$ significativas deste modelo apresentaram resultados acima de 0,1 ; e, analisando o VIF apresentou resultados abaixo do limite de 10 . O que representa a não existência de multicolinearidade, conforme, pode-se observar na tabela 11, a seguir.

Tabela 11 - Tolerância e VIF das Variáveis Explicativas - Modelo EVC

\begin{tabular}{c|c|c}
\hline Variáveis Independentes & Tolerance & VIF \\
\hline X5 & 0,942 & 1,061 \\
X6 & 0,868 & 1,152 \\
X8 & 0,863 & 1,159 \\
X9 & 0,916 & 1,092 \\
\hline
\end{tabular}


O condition index calculado foi de 9,164 , sendo este valor inferior a 30 , conclui-se a não existência de multicolinearidade. A proporção da variância explicada de cada variável é apresentada na tabela 12 a seguir.

Tabela 12 - Proporção da Variância da Constante e das Variáveis Explicativas Modelo EVC

\begin{tabular}{c|c|c|c|c}
\hline Constante & X5 & X6 & X8 & X9 \\
\hline 0,94 & 0,43 & 0,61 & 0,1 & 0,00 \\
\hline
\end{tabular}

\subsubsection{Endividamento Total a Valor de Mercado (EVM)}

O modelo de endividamento a valor de mercado, resultante da regressão linear Cross Section pelo processo stepwise, apresentou estatisticamente significativo, e que não sofre de multicolinearidade, é representado pelo seguinte equação:

$$
\begin{aligned}
& \mathrm{EVM}=0,862+0,131 \mathrm{X}_{5}-0,078 \mathrm{X}_{6}-1,129 \mathrm{X}_{8}-0,349 \mathrm{X}_{9} \quad \mathrm{R}^{2}=0373 \\
& \begin{array}{lllll}
(0,041) \quad(0,058) \quad(0,031) & (0,166) \quad(0,075)
\end{array}
\end{aligned}
$$

$\mathrm{Na}$ utilização da metodologia stepwise em modelo de endividamento a valor de mercado, após estimação, foi sugerido a eliminação de duas empresas existentes no cadastro por apresentarem problemas estatísticos, ficando a amostra com 205 observações. Após estimação do modelo de endividamento, têm-se como resultados da estimação do modelo as tabelas 13 e 14, que apresentam, respectivamente, os resultados da estimação e a análise da variância. 
Tabela 13 - Resultados da Análise de Regressão Linear Múltipla - Modelo EVM

\begin{tabular}{l|l|r|r|r|r}
\hline \multicolumn{2}{c|}{ Variáveis Independentes } & Coeficiente & $\begin{array}{r}\text { Desvio- } \\
\text { padrão }\end{array}$ & Estatística t & Valor p \\
\hline$B_{0}$ & Constante & 0,862 & 0,041 & 20,808 & 0,000 \\
$X_{5}$ & Tangibilidade & 0,131 & 0,058 & 2,247 & 0,026 \\
$X_{6}$ & Oportunidades de crescimento & $-0,078$ & 0,031 & $-2,539$ & 0,012 \\
$X_{8}$ & Rentabilidade & $-1,129$ & 0,166 & $-6,816$ & 0,000 \\
$X_{9}$ & Flexibilidade financeira & $-0,349$ & 0,075 & $-4,645$ & 0,000 \\
\hline
\end{tabular}

$R^{2}=0,373, R^{2}$ ajustado $=0,360$ e Durbin-Watson $=1,930$

Tabela 14 - Análise da Variância (ANOVA) - Modelo EVM

\begin{tabular}{l|c|c|r|r}
\hline Fonte de Variação & Variação & Graus de Liberdade & Quadrado Médio & Estatística F \\
\hline Explicada (SSR) & 3,030 & 4 & 0,757 & 29,714 \\
Residual (SSE) & 5,098 & 200 & 0,025 & \\
Total & 8,128 & 204 & & \\
\hline
\end{tabular}

A seguir, será apresentada a interpretação de dados obtidos do modelo de estimação.

\section{- Coeficiente de Determinação}

O coeficiente de determinação $\mathrm{R}^{2}$ ajustado foi igual a $36 \%$, o que representa o poder explicativo da regressão pelas variáveis independentes, $X$ 's $\left(X_{5}, X_{6}, X_{8}, X_{9}\right)$, um bom ajuste dos dados ao modelo estimado, de acordo com outros estudos empíricos da mesma natureza realizados.

\section{- Análise Teste F}

O teste $F$ calculado foi de 29,714 . Na tabela $F_{(4, \infty)}=3,32$. Como $F$ calculado foi superior ao valor apresentado na tabela de 3,32, então, não se verifica a hipótese nula, e conclui- 
se que o modelo tem aderência global, e as independentes $\left(X_{5}, X_{6}, X_{8}, X_{9}\right)$ explicam o modelo.

- Teste t

Ao aplicar o teste $\mathrm{t}$ de student com 200 graus de liberdade, verificamos que os resultados obtidos foram satisfatórios; estatisticamente os coeficientes são significativos com nível de significância abaixo de $5 \%$. Os sinais dos parâmetros economicamente, se são consistentes com a teoria financeira, serão analisados na próxima seção.

\section{- Independência das Variáveis Aleatórias Residuais}

Para verificar a existência de independência, entre as variáveis aleatórias residuais, foi utilizado o teste de Durbin-Watson, verificando se a covariância é nula. O resultado do teste foi de 1,930. Na tabela da estatística d, os pontos de significância a $1 \%$ do limite superior ds para $n=200$ e $k=4$ é de 1,715 . Sendo DW calculado superior a ds, e inferior a 4-ds, o resultado encontra-se na região onde se deve rejeitar a hipótese nula, ou seja, não existe autocorrelação entre os resíduos.

\section{- Multicolinearidade}

Para verificação se existe multicolinearidade foi observada a correlação entre as variáveis independentes, calculados os testes de tolerância, VIF e o condition index $e$ variance proportion. 
O teste da tolerância, onde foi medido o grau de explicação da variável dependente em relação às outras variáveis independentes, mostrou que todas as variáveis $\mathrm{X}$ $\left(\mathrm{X}_{5}, \mathrm{X}_{6}, \mathrm{X}_{8}, \mathrm{X}_{9}\right)$ significativas deste modelo apresentaram resultados acima de 0,1 , e analisando o VIF apresentou resultados abaixo do limite de 10. O que representa a não existência de multicolinearidade. Os resultados encontram-se na tabela 15, a seguir.

\section{Tabela 15- Tolerância e VIF das Variáveis Explicativas - Modelo EVM}

\begin{tabular}{c|c|c}
\hline Variáveis Independentes & Tolerance & VIF \\
\hline X5 & 0,939 & 1,065 \\
X6 & 0,864 & 1,157 \\
X8 & 0,872 & 1,147 \\
X9 & 0,912 & 1,097 \\
\hline
\end{tabular}

O condition index foi de 9,384 , onde se verifica que o mesmo foi inferior a 30 , demonstrando a não existência de multicolinearidade. A proporção da variância explicada de cada variável é apresentada na tabela 16, a seguir.

Tabela 16 - Proporção da Variância da Constante e das Variáveis Explicativas Modelo EVM

\begin{tabular}{c|c|c|c|c}
\hline Constante & X5 & X6 & X8 & X9 \\
\hline 0,95 & 0,45 & 0,62 & 0,00 & 0,00 \\
\hline
\end{tabular}

\subsection{Análise dos Resultados da Estimação dos Modelos - Validação Teórica}

Após proceder a análise estatística de resultados dos modelos de endividamento a valor contábil e valor de mercado, esta seção tem por objetivo validar os resultados de acordo com a teoria financeira, apresentada no capítulo 2 anterior; Serão confrontados os sinais 
dos coeficientes estimados das variáveis estudas, conforme demonstrados na tabela 17 a seguir, com as hipóteses formuladas no capítulo 3.

Tabela 17 - As Variáveis dos Modelos e Seus Resultados Estatísticos

\begin{tabular}{|c|c|c|c|c|}
\hline \multirow{2}{*}{\multicolumn{2}{|c|}{ Variáveis Dependentes }} & \multirow{3}{*}{$\begin{array}{c}\text { Hipóteses } \\
\text { Fórmu= } \\
\text { ladas }\end{array}$} & \multicolumn{2}{|c|}{$\begin{array}{c}\text { Resultado dos } \\
\text { Sinais dos Coeficientes } \\
\end{array}$} \\
\hline & & & \multirow{2}{*}{$\begin{array}{c}Y_{1} \\
\text { Endivida- } \\
\text { mento a Valor } \\
\text { Contábil }\end{array}$} & \multirow{2}{*}{$\begin{array}{c}\mathbf{Y}_{2} \\
\text { Endivida- } \\
\text { mento a Valor } \\
\text { de Mercado }\end{array}$} \\
\hline $\mathrm{X}_{1}$ & Taxa Média de Impostos & & & \\
\hline$\overline{X_{2}}$ & $\begin{array}{l}\text { Outros Benefícios que Não o de } \\
\text { Endividamento }\end{array}$ & $(-)$ & ns & $\mathrm{ns}$ \\
\hline $\mathrm{X}_{3}$ & $\begin{array}{l}\text { Risco do Negócio (medido através do } \\
\text { EBIT) }\end{array}$ & $(-)$ & ns & ns \\
\hline $\mathrm{X}_{4}$ & $\begin{array}{l}\text { Risco do Negócio (medido através } \\
\text { das vendas líquidas) }\end{array}$ & $(-)$ & ns & ns \\
\hline $\mathrm{X}_{5}$ & $\begin{array}{l}\text { Composição dos Ativos Fixos } \\
\text { (tangibilidade) }\end{array}$ & $(+)$ & $(+)$ & $(+)$ \\
\hline $\mathrm{X}_{6}$ & Oportunidades de Crescimento & $(-)$ & $(+)$ & $(-)$ \\
\hline $\mathrm{X}_{7}$ & Tamanho (dimensão) & $(+)$ & ns & ns \\
\hline $\mathrm{X}_{8}$ & Rentabilidade & $(-)$ & $(-)$ & $(-)$ \\
\hline$X_{9}$ & Flexibilidade Financeira & $(-)$ & $(-)$ & $(-)$ \\
\hline$X_{10}$ & Setor Econômico & $(\neq 0)$ & ns & ns \\
\hline
\end{tabular}

Observa-se que nos dois modelos analisados o valor das empresas cotadas a preços contábeis e a preços de mercado, os fatores determinantes da estrutura de capital que apresentaram significância foram os mesmos, (tangibilidade, oportunidades de crescimento, rentabilidade e flexibilidade financeira), e apresentam a mesma relação com o endividamento, com exceção da variável oportunidades de crescimento que possui resultados contraditórios, isto é, positivamente relacionada com o modelo a valor contábil e negativamente o modelo a valor de mercado.

Para validar a Teoria dos Efeitos Fiscais foram testadas as hipóteses 1 e 2, e analisada, respectivamente, duas proxies: Taxa média de impostos e outros benefícios que não o de endividamento. A hipótese 1, (o efeito da taxa média de impostos é positivamente 
relacionado com a estrutura de capitais das empresas), não apresentou significância em nenhum dos modelos estimados. Este resultado também foi encontrado por Rita (2003); Isto demonstra que os efeitos fiscais não estão explicando o endividamento das empresas brasileiras. A hipótese 2, (a existência de outros benefícios que não o de endividamento se constitui em um benefício), também não se mostrou significativa. Estes resultados também foram encontrados nos estudos de Titman e Wessls (1988) e El-Khouri (1989), onde a variável outros benefícios que não o de endividamento não foi significativa.

No teste da volatilidade, ou seja, o risco do negócio apresentada na hipótese $\mathbf{3}$, calculado por duas variáveis, uma em relação a variação do EBIT e outra em relação as vendas líquidas, não se apresentaram significativas em nenhum dos modelos estimados, não foram um fator explicativo da estrutura de capitais das empresas. Estes resultados também foram encontrados por Ferri e Jones (1979), Titman e Wessels(1988) e Canda (1991).

A hipótese 4, (a tangibilidade apresenta uma relação positiva com o endividamento), foi confirmada nos dois modelos de endividamento estudados: $\mathrm{O}$ de valor contábil e o de valor de mercado. Isto demonstra que, a existência de garantias reais assegura às empresas a possibilidade de conseguirem um prazo de pagamento maior, porque servem de colateral na concessão de empréstimos; e, que colaterais tangíveis reduzem os custos de insolvência, o que leva as empresas a maior acesso ao crédito. Estes resultados também foram encontrados nos trabalhos de Simões (2002), Gomes e Leal (2000), Rajan e Zingales (1995), Chung (1993), Klock e Thies (1992) e Brito e Lima (2004). 
A variável oportunidades de crescimento da empresa, apresentada na hipótese 5, apresentou-se estatisticamente significativa, porém com sinais contraditórios. No modelo de endividamento a valor mercado, esta se mostra negativa, confirmando a hipótese levantada, de que empresas com crescimento acelerado recorrem menos ao endividamento devido a estarem a investir constantemente em novos projetos, e não quererem incorrer em custos elevados de agenciamento e de falência. Este resultado também foi encontrado nos trabalhos de Bradley et al.(1984), Chung, K. (1993), Rajan e Zingales (1995), Kayo e Famá (1997). Já no modelo de endividamento a valor contábil, aquela variável apresenta um valor positivo entre o fator endividamento $\mathrm{e}$ as oportunidades de crescimento, contrariando o previsto na Teoria. Estes resultados também podem ser observados nos estudos de Brito e Lima (2004) e Toy et al. (1974). Isto mostra que a variável oportunidades de crescimento é um fator determinante da alavancagem financeira. Os sinais contraditórios levam a conclusão que, as empresas que têm crescimento rápido podem recorrer, ou não, para o endividamento a fim de captar de recursos.

A hipótese 6, (o tamanho apresenta uma relação positiva com o endividamento), apresentou-se não significativa nos modelos estimados. Embora a maioria das empresas do modelo seja de grande porte, o que indica terem acesso aos mecanismos de financiamento e ao acesso a taxas de juros atraentes na utilização dos mesmos, como possuem colateral para garantir tais empréstimos, era de esperar que esta variável se apresentasse significativa e com uma relação positiva com o endividamento, resultado verificado no estudo de Canda (1991) e El-Khouri (1989), e ainda leva a acreditar que esta variável é importante, porém não constitui em um fator determinante para a captação de recursos no mercado. Uma prática muito comum utilizada pelas empresas, 
para não ficarem com seu patrimônio "preso", para garantir operações de captação de recursos a longo prazo, levando ao impedimento da utilização deste patrimônio em outras operações e transações, é a utilização de garantias através dos Recebiveis e Fiança Bancária, o que leva a maior mobilidade da empresa.

A rentabilidade, testada na hipótese 7 , apresenta uma relação negativa com o endividamento confirmando o previsto na teoria financeira nos dois modelos estimados. As empresas que possuem lucros internos suficientes preferem a utilização destes à captação de fundos junto a terceiros, o que confirma a Teoria de Assimetria de Informação (pecking order), de que há prioridade na utilização dos recursos por meio de fundos gerados internamente ao financiamento, e este à captação no mercado bolsista. Esta prioridade aos recursos internos é justificada por proporcionar às empresas maior independência e flexibilidade financeira. Estes resultados também foram encontrados nos estudos de empresas brasileiras em: Gomes e Leal (2000), Eid (1996), Ferreira e Brasil (1997), Junior e Melo (1999), Moreira e Puga (2001) e os estudos realizados em outros países por Simões (2002), Titman e Wessels (1988) e Rajan e Zingales (1995).

A hipótese 8, (a flexibilidade financeira apresenta uma relação negativa com o endividamento), é confirmada pelos resultados de modelos estimados (endividamento a valor contábil e a valor de mercado). Isto confirma a Teoria de Assimetria de Informação, onde as empresas com ativos líquidos suficientes preferem o autofinanciamento ao endividamento, e este a emissão de ações no mercado. Isto é justificado porque as empresas, que têm em caixa recursos disponíveis para proporcionar o crescimento e operacionalização, não incorrerem em altos custos de 
agenciamento e de falência que ocorrem quando a captação de recursos é externa. Estes resultados também foram encontrados por Antoniou et al. (2002).

A hipótese 9 testou que o setor de atividade onde a empresa está inserida é um determinante de seu nível de endividamento. $\mathrm{O}$ efeito da teoria da estratégia nos modelos estimados não se apresentou significativo. Deste modo, o fato de uma empresa pertencer ao setor industrial, ou a outro setor, não exerce influência alguma no endividamento delas. 


\section{CONSIDERAÇÕES FINAIS E DESENVOLVIMENTOS FUTUROS.}

As empresas brasileiras utilizam à captação de recursos externos para financiar a sua operacionalização, crescimento e desenvolvimento, apresentando um nível médio de endividamento total em relação ao seu patrimônio, se comparado ao valor contábil de $58 \%$, e se comparado ao valor de mercado de $65 \%$.

Os coeficientes de determinação dos modelos, ( $\mathrm{R}^{2}$ ajustado), foram de $27 \%$ para o endividamento a valor contábil, e de $36 \%$ no endividamento a valor de mercado. Sugere-se que os modelos possam ser melhorados com a inclusão de novas variáveis, ou que as variáveis utilizadas possam ser operacionalizadas de forma diferente. Porém, acredita-se ser bastante significativos os resultados encontrados em regressão com dados contábeis, e dados de mercado de empresas brasileiras. Estes resultados foram semelhantes, e em alguns superiores, aos de outros estudos empíricos de abordagem do mesmo tema.

Utilizando-se o coeficiente de determinação do modelo tem-se que, o melhor resultado encontrado foi para o modelo de endividamento a valor de mercado. Isto pode ser justificado pelo processo de atualização das empresas, via mercado, ser mais eficiente do que os valores apresentados a valor contábil, não computados a valores históricos e que não acompanham a valorização do mercado.

Com a estabilização da economia brasileira, acontecida após 1995, e as grandes transformações ocorridas na década de 90, surgiu um ambiente macroeconômico favorável ao retorno do crescimento das empresas, refletindo no período analisado de 
1999 a 2003, onde os dados apresentam maior consistência, e produzem informações mais próximas da realidade nacional.

Os determinantes da estrutura de capitais das empresas brasileira não-financeiras, cotadas na bolsa de valores, que se apresentou significativo foram, a composição dos ativos fixos (tangibilidade), as oportunidades de crescimento, a rentabilidade e a flexibilidade financeira. Em análise as variáveis estudadas, através do teste empírico, verifica-se que algumas apresentam sinais dos coeficientes que confirmam as hipóteses previstas pela teoria financeira, e uma que contradiz estas hipóteses. Já as variáveis taxa média de impostos, outros benefícios que não o de endividamento, risco do negócio (volatilidade), tamanho e o setor econômico, onde a empresa está inserida, não se apresentaram significativas nos modelos estudados.

A seguir, será apresentado o resumo da análise das variáveis estudadas de acordo com as quatro correntes da teoria financeira, focadas na estrutura de capitais das empresas e seus fatores determinantes, isto é, Efeitos Fiscais e Custos de Insolvência, Teoria da Agência, Teoria da Assimetria de Informações e Outras Linhas de Investigação baseadas na Estratégia e no Controle.

\section{- Teoria dos Efeitos Fiscais e dos Custos de Insolvência (Trade-Off)}

Efeitos Fiscais: Esta teoria foi testada através das seguintes variáveis: taxa média de impostos e outros benefícios que não o de endividamento. O resultado do estudo empírico conclui que, estas variáveis quando da contratação das dívidas não apresentam 
significância em nenhum dos modelos analisados, não constituindo fatores determinantes da estrutura de capitais.

Custos de Insolvência: Os custos de insolvência foram testados através das variáveis: risco do negócio (volatilidade), composição dos ativos fixos (tangibilidade), oportunidades de crescimento e tamanho (dimensão). Os resultados apontaram que a volatilidade e o tamanho não se apresentam significativos, não constituindo determinantes de endividamento. A tangibilidade apresentou-se positivamente relacionada com o endividamento nos dois modelos analisados, confirmando o previsto pela teoria, de que empresas com maior grau de imobilização, têm maior acesso ao crédito, devido a corresponderem às exigências de colaterais para garantia, o que confirma o previsto pela teoria de trade-off. As oportunidades de crescimento apresentaram sinais contraditórios. $\mathrm{Na}$ análise do modelo de endividamento, a valor de mercado, o mesmo apresenta uma relação negativa confirmando o previsto pela teoria de empresas com crescimento rápido, tendem a recorrer menos ao endividamento. Já esta variável analisado com o endividamento, a valor contábil, apresenta uma relação positiva, contradizendo a hipótese teórica levantada.

\section{- Teoria da Agência}

Esta teoria foi testada através das seguintes variáveis: composição dos ativos fixos (tangibilidade) e as oportunidades de crescimento. É apresentado, nos resultados dos testes empíricos, que a variável tangibilidade se mostra significativa, apresentando resultado positivamente relacionado com o endividamento como o previsto pela teoria. O endividamento pode ser utilizado pela empresa para diminuir os custos de 
agenciamento dos conflitos de interesses gerados pelos interessados na empresa, (acionistas, gerentes e credores). A variável oportunidade de crescimento apresentou resultados contraditórios: negativamente relacionada com o endividamento a valor de mercado, e positivamente com o endividamento a valor contábil.

\section{- Teoria da Assimetria de Informacões}

O estudo empírico utilizou as variáveis tangibilidade, oportunidades crescimento, tamanho, rentabilidade e flexibilidade financeira para testar as hipóteses ligadas a esta teoria. Como resultado, obteve-se que a tangibilidade se mostrou positivamente relacionada com o endividamento nos dois modelos analisados, o que confirma o previsto na teoria. Quanto as variáveis rentabilidade e flexibilidade financeira apresentaram-se negativamente relacionadas, confirmando que, quanto maior os recursos internos disponíveis pela empresa, maior será o seu autofinanciamento, e menor o seu endividamento. Estes resultados confirmam o previsto na teoria do pecking order, a qual afirma, que as empresas preferem a utilização de recursos internos, ao financiamento externo e este à captação através do lançamento de ações no mercado. A variável oportunidade de crescimento da empresa apresenta resultado significativo, porém, contraditório. E, a variável tamanho, não se apresentou significância.

\section{- Teoria Baseada na Estratégia e no Controle}

Outras linhas de investigação baseadas na estratégia e no controle das empresas, foram testadas através do setor econômico, onde as empresas estavam inseridas. Os resultados se revelaram não significativos. 
Destaca-se, neste estudo empírico, que a maioria das empresas analisadas é de grande porte $(90,3 \%)$, o que leva a constatação de que o mercado de ações brasileiro, ainda é muito restrito e de dificuldade de acessibilidade às pequenas e médias empresas.

O teste empírico apresentou resultados significativos que, contribuem para o esclarecimento do comportamento atual da estrutura de capitais das empresas nacionais não-financeiras cotadas em bolsa de valores, e quais os seus principais determinantes. Porém, pesquisas futuras poderão incluir outras variáveis, como por exemplo, as taxas de juros cobrados nos empréstimos, visto que a do Brasil é uma das mais altas do mundo, interferindo diretamente no padrão de financiamento das empresas. 


\section{REFERÊNCIAS BIBLIOGRAFIAS}

Alonso, E. J. M., (2000) Debt Financing and Diversification Strategy: Some Evidence from Spanish Manufacturing Firms. VIII Foro de Finanzas - Associación Española de Finanzas (AEFIN), Madrid, 25 -27 Octubre. Disponível em: http:www.uc3m.es/uc3m/dpto/ECO/finanzas8/men05.pdf.

Antoniou, A., Yilmaz, G. e Krisha, P.(2002) Determinants of Corporate Capital Structure: Evidence from European Countries, University of Durham, Working Paper, March.

Arias, C. A., Martínes, A. C.e Gracia, J. L. (2000) Enfoques Emergentes en Torno en la Estrucutura de Capital: El caso de la Pyme, VII Foro de Finanzas - Associación Española de Finanzas (AEFIN), Madrid, 25-27, Ouctubre. Disponível em: http://www.uc3m.es/us3m/dpto/ECO/finanzas8/ayb74.pdf.

Balakrishan, S. e Fox, I. (1993) Asset Specifity, Firm Heterogeneity and Capital Structure, Strategic Management Journal, 14, 3-16.

Barcelos, Luiz Cláudio (2002) Determinantes do Acesso ao Crédito Empresarial no Brasil: Teoria e Evidências Empíricas. Dissertação de mestrado. Universidade de São Paulo.

Booth, L., Aivazian, V., Demirguc-Kunt, A., Maksimovic, V. (2001) Capital Structure in Developing Countries. The Journal of Finance, Vol. LVI, $\mathrm{n}^{\circ} 1,87-130$. February.

Bradley, M., Jarrel, G. e Kim, E. (1984) On The Exercise of na Optimal Capital Structe: Theory and Evidence. Journal of Finance, v. 39, nº3, p. 857-880.

Brealey, R. A., S. C. Myers (1998) Principios de Finanças Empresariais, Quinta Edição, McGraw-Hill de Portugal. 
Brito, R. D. e M. R. Lima (2004) A Escolha da Estrutura de Capital sob Franca Garantia Legal: o Caso do Brasil. IBMEC. FinanceLab Working paper - FLWP $-n^{\circ} 8$.

Canda, F. (1991) The Influence of Specified Determinants of Corporate Capital Structure. Dissertação (Ph. D.) Ohio State University, Ohio.

Carvalho, A. G. (2000) Ascensão e Declínio do Mercado de Capitais no Brasil - A Experiência dos Anos 90. Revista de Economia Aplicada, pg. 595-632.

Chung, K. (1993) Asset Characteristics and Corporate Debt Policy: An Empirical Test. Journal of Business Finance \& Accounting, v. 20, nº 1, p.83-98.

Diamond, Douglas W. (1989) Reputation Acquisition in Debt Markets, Journal of Political Economy, Vol. 97, $\mathrm{n}^{\circ} 4,828-862$.

Donaldson, G. (1961) Information Asymmetry and Equity Issues, Journal of Financial and Quantitative Analysis, Vol. 26, n 2, June, 181-199.

Drobetz, W. e Fix, R., (2003) What are The Determinants of the Capital Structure? Some Evidence for Switzerland, Working Paper no 4/03. WWZ/Departament of Finance. University of Basel.

Eid Junior W. (1996) Custo e Estrutura de Capital: o Comportamento das Empresas Brasileiras. Revista de Administração de Empresas, São Paulo, v.36, n.4, p 5159.

El-Kouri, R. (1989) Time-Series Cross-Section tests of the Determinants of Capital Structure.. Dissertação (Ph.D). University of Wisconin-Madison. 
Emery, D. R. e Finnerty, J. D. (1997) Corporate Financial Management, Prentice Hall Inc.

Ferreira, L. de S. e Brasil, H. G.(1997) Estrutura de Capital: um teste preliminar da "Pecking Order Hypotesis". $21^{\circ}$ Encontro da ANPAD, Rio de Janeiro.

Ferri, M. e Jones, W. (1979) Determinants of Financial Structure: A new Methodological Approch. Journal of Finance, v. 34, n³, 361-644.

Giambiagi, Fabio (2005) Estabilização, Reformas e Desequilíbrios Macroeconômicos: Os Anos FHC. Giambiangi, F. et al. Economia brasileira contemporânea, Rio de Janeiro: Elsevier. P. 166-195.

Gitman, L. (2002) Princípios de Administração Financeira. $7^{\mathrm{a}}$ Edição. Editora Harbra Ltda. São Paulo SP.

Gomes, G. e Leal, R.(2000) Determinantes da Estrutura de Capitais das Empresas Brasileiras com Ações Negociadas em Bolsa de Valores. In: Leal, R..; Costa Jr., N.; Lemgruber, E. Finanças Corporativas, São Paulo: Atlas.

Graham, J., Lemmon, M. e Schallheim, J. (1998) Debt, Leases, Taxes and Endogeneity of Corporate Tax Status. Journal of Finance 53, 131-162.

Graham, J. e Harvey, C (2001) The Theory and Practice of Corporate Finance: Evidence from the Field. Journal of Financial Economics 60, 187-243.

Guarita, S. A. D. (2002) Fusões e Aquisições no Brasil: evolução do processo. Revista FAE Business, n. 3, setembro. 
Guia para Elaboração de Dissertações de Mestrado (2002) Faculdade de Economia. Universidade do Algarve.

Harris, M. e Raviv, A. (1988) Corporate Control Contests and Capital Structure, Journal of Financial Economics, Vol. 20, 55-86.

Harris, M. e A. Raviv (1990) Capital Structure and the Informational Role of Debt, The Journal of Finance, Vol. XLV, n 2, June, 321-349.

Harris, M. e A. Raviv (1991) The theory of Capital Structure, The Journal of Finance, Vol. 46, n⿳⺈ 1; pp. 297-355.

Jensen, M. C. e Meckling, W. H. (1976) Theory of the Firm: Managerial Behavior, Agency Costs, and Ownership Structure, Journal of Financial Economics 3, $\mathrm{n}^{\circ} 4$, October, 305-360. Disponível em: http://papers.ssrn.com/sol3/paper.taf?abstract $\underline{\mathrm{id}=94043 .}$.

Jensen, M. C. (1986) Agency Cost of Free Cash Flow, Corporate Finance and Takeovers, The American Economic Review. Vol. 76, No 2, 323-329.

Júnior, W. R e Melo, G.M. Padrão de Financiamento das Empresas Privadas no Brasil. Texto para Discussão n 653 . IPEA, 1999.

Kayo, E. e Famá, R. (1997) Teoria da Agência e Crescimento:Evidências Empíricas dos Efeitos Positivos e Negativos do Endividamento. Caderno de Pesquisas em Administração, v.2, n.5, p.1-8.

Kim, E. H. (1978) A Mean Variance Theory of Optimal Capital Structure and Corporate Debt Capacity, The Journal of Finance, Vol. 32, no 1; 45-64.

Kim, W. S. e Sorensen, E. H. (1986) Evidence on the Impact of the Agency Costs of Debt on Corporate Debt Policy, Journal of Financial e Quantitative Analysis, Vol. 21, $\mathrm{n}^{\circ}$ 2, June, 131-144. 
Klock, S., Thies, F. (1992) Determinants of Capital Structure. Review of Financial Economics, p. 40-52.

Kmenta, J. (1978) Elementos de Econometria. Tradução de Carlos Roberto Vieira Araújo. São Paulo: Atlas.

Kraus, A. e Litzenberger, R. (1973) A State-Preference Model of Optimal Leverage, The Journal of Finance, Vol. 28, 911-920.

La Porta, R., Lopez-de-Silanes, F.e Shleifer, A. (1999) Corporate Ownership Around the World, The Journal of Finance, Vol. LIV, $\mathrm{n}^{\circ} 2$, April, 471-517.

Lacerda, A.C., Bocchi, J. I., Rego, J. M., Borges, M.A., Marques, E. M. (2001) Economia Brasileira. São Paulo: Saraiva.

Leland, H. E. e Pyle, D. H. (1977) Informational Asymmetries, Financial Structure, and Financial Intermediation, The Journal of Finance, Vol. 32, $\mathrm{n}^{\mathrm{o}} 2$, May, 371387.

Loureiro, A. L. J. Guia Prático de Economia Brasileira. Maceió: EDUFAL, 1995.

Manos, R., Green, C., Murinde, V. (2001) Business Groups and Capital Structure: Evidence on Indian Firms. Institute for Development Policy and Management University of Manchester, Finance and Development Research Programe. Working Paper Series, Paper $n^{\circ} 34$, December.

Miller, M. H. (1977) Debt and Taxes, The Journal of Finance, Vol. 32, $\mathrm{n}^{\circ} 2$, May, 261275.

Modigliani, F. e Miller, M. H. (1958) The Cost of Capital, Corporation Finance and The Theory of Investment, American Economic Review 3, Vol. XLVIII, June, 261-297. 
Modigliani, F. e Miller, M. H. (1963) Corporate Income Taxes and the Cost of Capital: A Correction by ..., American Economic Review, June, 437-447.

Moreira, M. e Puga, F. (2001) Como a Indústria Financia o seu Crescimento: Uma Análise do Brasil Pós-Plano Real. Revista Econômica Contemporânea, v.5, p.3567.

Motta, J.R.S.T. (2001) Uma Análise da Relação entre Mercado de Capitais e Desenvolvimento. Janeiro 2001. www.camara.gov.br

Murteira, B.J.F. (1993) Análise Exploratória de Dados - Estatística Descritiva. Lisboa. McGraw Hill.

Myers, S. C. (1977) Determinants of Corporate Borrowing, Journal of Financial Economics, Vol. 5, 147-175.

Myers, S. C. (1984) The Capital Structure Puzzle, The Journal of Finance, Vol. XXXIX, n 3, July, 575-592.

Myers, S. C. e Majluf, N. S. (1984) Corporate Financing and Investment Decision When Firms Have Information that Investors do not Have, Journal of Financial Economics, Vol. 13, 187-221.

Pereira, J.A. (2004) Capital Structure Determinants: The Case of Euronext Market Countries. Instituto Superior de Economia e Gestão. Universidade Técnica de Lisboa. Disponível em: http://pascoal.iseg.utl.pt/ depteco/sem0203 p.html.

Perobelli, F. e Fama, R. (2002) Determinantes da Estrutura de Capital: Aplicação a Empresas de Capital Aberto Brasileiras. Revista de Administração da Universidade de São Paulo, v. 37, jul/set. 
Pestana, M.H., Gageiro, J.N. (2003) Análise de Dados para Ciências Sociais - A Complementação do SPSS, Lisboa: Sílado.

Procianoy, J. L. e Schorrenberger, A. (2004) A Influência da Estrutura de Controle nas Decisões de Estrutura de Capital das Companhias Brasileiras. Revista Brasileira de Economia - RBE. Rio de Janeiro. Jan/Mar.

Rajan, R. e Zingales, L. (1995) What Do Know About Capital Structure? Some Evidence from International Data, The Journal of Finance, Vol. L, 1421-1460.

Ross, S. A. (1977) The Determination of Financial Structure: The Incentive-Signalling Approach, Bell Journal of Economics, Spring, Vol. 8, $\mathrm{n}^{\circ}$ 1, 23-40.

Rita, Rui. (2003) As teorias da Estrutura de Capitais: A Evidência Empírica das Empresas Portuguesas, Dissertação de Mestrado. Universidade de Évora.

Silva, J. V. (1991) Teoria das Estruturas de Capitais. Texto de apoio da Disciplina de Gestão Financeira. Évora.

Simões, J. S. N. F. (2002) Identificação de Variáveis Financeiras e Estratégicas que Determinam a Estrutura Financeira das Empresas em Portugal, Dissertação de Mestrado. Universidade de Évora.

Soctt, J. H. (1976) A Theory of Optimal Capital Structure, The Bell Journal of Economics and Management Science, $\mathrm{n}^{\circ}$ 7, 33-54.

Stlutz, R. (1988) Managerial Control of Voting Rights: Financing Polices and the Market for Corporate Control, The Journal of Financial Economics, 20, 25-54.

Stlutz, R. (1990) Managerial Discretion and Optimal Financing Polices, Journal of Financial Economics. Vol. 26, No 1 3-27. 
Titman, S. (1984) The Effect of Capital Structure on a Firm's Liquidation Decision, Journal of Financial Economics, Vol. 13, 137-151.

Titman, S.; Wessels, R. (1988). The Determinants of Capital Structure Choice. Journal of Finance, v. $43, n^{\circ} 1$, p. 1-19.

Warner, J. B. (1977) Bankruptcy Costs: Some Evidence, Journal of Finance, 237-348.

Zonenschain, C. (1998) Estrutura de Capital das Empresas no Brasil. Revista do BNDES, Rio de Janeiro, volume $5 \mathrm{n}^{\circ}$. 10, Páginas: 63-92, dezembro. 


\section{ANEXOS}

Anexo A - Nível de Endividamento das Empresas Estudadas e Análise Individual Anexo B - Classificação da Amostra por Empresa, segundo CNAE Anexo C - Classificação da Amostra por Porte, segundo BNDES Anexo D - Valor de Mercado por Empresa da Amostra: 1999 a 2003 (em R\$ Mil) Anexo E - Valor Contábil por Empresa da Amostra: 1999 a 2003 (em R\$ Mil) 
Anexo A - Nível de Endividamento das Empresas Estudadas e Análise Individual

\begin{tabular}{|c|c|c|c|c|c|c|}
\hline Empresa & 1999 & 2000 & 2001 & 2002 & 2003 & Médla \\
\hline ACESITA & $68,18 \%$ & $71,85 \%$ & $77,49 \%$ & $80,44 \%$ & $73,10 \%$ & $74,21 \%$ \\
\hline ACOS VILL & $109,99 \%$ & $90,10 \%$ & $89,57 \%$ & $93,94 \%$ & $83,95 \%$ & $93,51 \%$ \\
\hline ADUBOS TREVO & $177,07 \%$ & $86,82 \%$ & $54,15 \%$ & $59,36 \%$ & $54,93 \%$ & $86,47 \%$ \\
\hline AES TIETE & $77,57 \%$ & $66,62 \%$ & $71,14 \%$ & $80,69 \%$ & $80,16 \%$ & $75,24 \%$ \\
\hline ALBARUS & $29,88 \%$ & $27,50 \%$ & $25,29 \%$ & $27,69 \%$ & $26,80 \%$ & $27,43 \%$ \\
\hline ALL AMER LAT & $72,71 \%$ & $76,06 \%$ & $78,60 \%$ & $76,89 \%$ & $77,15 \%$ & $76,28 \%$ \\
\hline ALPARGATAS & $42,22 \%$ & $41,64 \%$ & $43,29 \%$ & $50,93 \%$ & $45,58 \%$ & $44,73 \%$ \\
\hline AMBEV & $80,92 \%$ & $62,14 \%$ & $69,26 \%$ & $66,43 \%$ & $70,56 \%$ & $69,86 \%$ \\
\hline ARACRUZ & $45,38 \%$ & $38,88 \%$ & $52,56 \%$ & $63,00 \%$ & $65,78 \%$ & $53,12 \%$ \\
\hline ARTHUR LANGE & $60,26 \%$ & $62,35 \%$ & $63,81 \%$ & $62,74 \%$ & $69,42 \%$ & $63,72 \%$ \\
\hline AVIPAL & $55,36 \%$ & $57,04 \%$ & $57,03 \%$ & $67,39 \%$ & $66,45 \%$ & $60,65 \%$ \\
\hline BAN ARMAZENS & $21,75 \%$ & $48,50 \%$ & $48,74 \%$ & $78,66 \%$ & $84,26 \%$ & $56,38 \%$ \\
\hline BARDELLA & $26,12 \%$ & $36,15 \%$ & $35,16 \%$ & $28,97 \%$ & $29,49 \%$ & $31,18 \%$ \\
\hline BAUMER & $53,74 \%$ & $55,63 \%$ & $53,05 \%$ & $51,39 \%$ & $46,01 \%$ & $51,96 \%$ \\
\hline BELGO MINEIR & $30,95 \%$ & $39,98 \%$ & $39,80 \%$ & $38,22 \%$ & $31,52 \%$ & $36,09 \%$ \\
\hline BIC MONARK & $16,89 \%$ & $13,27 \%$ & $15,41 \%$ & $21,66 \%$ & $15,92 \%$ & $16,63 \%$ \\
\hline BLUE TREE & $74,73 \%$ & $84,20 \%$ & $90,24 \%$ & $92,36 \%$ & $93,96 \%$ & $87,10 \%$ \\
\hline BRASIL T PAR & $22,00 \%$ & $48,02 \%$ & $51,39 \%$ & $54,68 \%$ & $56,37 \%$ & $46,49 \%$ \\
\hline BRASIL TELEC & $34,08 \%$ & $42,74 \%$ & $51,11 \%$ & $54,21 \%$ & $55,55 \%$ & $47,54 \%$ \\
\hline BRASKEM & $40,30 \%$ & $38,72 \%$ & $59,81 \%$ & $86,64 \%$ & $84,14 \%$ & $61,92 \%$ \\
\hline BRASMOTOR & $67,61 \%$ & $63,25 \%$ & $64,96 \%$ & $72,60 \%$ & $73,76 \%$ & $68,43 \%$ \\
\hline BRAZIL REALT & $46,52 \%$ & $45,87 \%$ & $49,17 \%$ & $49,19 \%$ & $45,73 \%$ & $47,30 \%$ \\
\hline BUETTNER & $98,96 \%$ & $98,74 \%$ & $98,29 \%$ & $98,52 \%$ & $99,67 \%$ & $98,84 \%$ \\
\hline CACIQUE & $69,58 \%$ & $63,29 \%$ & $53,31 \%$ & $59,63 \%$ & $36,99 \%$ & $56,56 \%$ \\
\hline CAEMI & $65,42 \%$ & $63,75 \%$ & $64,79 \%$ & $75,79 \%$ & $59,61 \%$ & $65,87 \%$ \\
\hline CAIUA & $85,34 \%$ & $86,82 \%$ & $81,11 \%$ & $88,33 \%$ & $92,50 \%$ & $86,82 \%$ \\
\hline CBC CARTUCHO & $48,96 \%$ & $52,16 \%$ & $45,65 \%$ & $56,44 \%$ & $52,25 \%$ & $51,09 \%$ \\
\hline CEB & $28,86 \%$ & $35,09 \%$ & $55,12 \%$ & $73,44 \%$ & $75,14 \%$ & $53,53 \%$ \\
\hline CEDRO & $39,20 \%$ & $45,52 \%$ & $47,98 \%$ & $56,18 \%$ & $54,36 \%$ & $48,65 \%$ \\
\hline CELESC & $51,65 \%$ & $54,92 \%$ & $63,52 \%$ & $75,75 \%$ & $73,97 \%$ & $63,96 \%$ \\
\hline CELPA & $54,71 \%$ & $58,27 \%$ & $53,63 \%$ & $55,47 \%$ & $60,24 \%$ & $56,46 \%$ \\
\hline CELPE & $42,65 \%$ & $51,12 \%$ & $49,96 \%$ & $59,63 \%$ & $58,16 \%$ & $52,31 \%$ \\
\hline CELUL IRANI & $46,15 \%$ & $51,37 \%$ & $53,63 \%$ & $58,43 \%$ & $54,10 \%$ & $52,74 \%$ \\
\hline CEMAT & $66,97 \%$ & $75,26 \%$ & $66,12 \%$ & $72,30 \%$ & $76,87 \%$ & $71,51 \%$ \\
\hline CEMIG & $33,84 \%$ & $34,23 \%$ & $47,41 \%$ & $58,17 \%$ & $55,84 \%$ & $45,90 \%$ \\
\hline CERJ & $89,67 \%$ & $86,28 \%$ & $94,73 \%$ & $89,46 \%$ & $\mathbf{9 1}, 46 \%$ & $90,32 \%$ \\
\hline CESP & $44,86 \%$ & $45,33 \%$ & $51,44 \%$ & $68,66 \%$ & $64,09 \%$ & $54,88 \%$ \\
\hline CHIARELLI & $35,18 \%$ & $40,69 \%$ & $45,47 \%$ & $47,61 \%$ & $70,75 \%$ & $47,94 \%$ \\
\hline CIA HERING & $72,86 \%$ & $75,75 \%$ & $86,50 \%$ & $99,01 \%$ & $97,19 \%$ & $86,26 \%$ \\
\hline COELBA & $57,79 \%$ & $45,52 \%$ & $55,02 \%$ & $60,22 \%$ & $59,29 \%$ & $55,57 \%$ \\
\hline COELCE & $30,04 \%$ & $35,08 \%$ & $48,66 \%$ & $53,31 \%$ & $52,41 \%$ & $43,90 \%$ \\
\hline COMGAS & $54,12 \%$ & $36,15 \%$ & $51,75 \%$ & $59,76 \%$ & $59,39 \%$ & $52,24 \%$ \\
\hline CONFAB & $38,16 \%$ & $40,61 \%$ & $54,27 \%$ & $59,26 \%$ & $61,17 \%$ & $50,69 \%$ \\
\hline CONST A LIND & $68,85 \%$ & $84,04 \%$ & $82,00 \%$ & $85,13 \%$ & $88,24 \%$ & $81,65 \%$ \\
\hline COPESUL & $64,73 \%$ & $65,30 \%$ & $65,98 \%$ & $71,48 \%$ & $64,81 \%$ & $66,46 \%$ \\
\hline COSERN & $63,84 \%$ & $51,89 \%$ & $55,75 \%$ & $62,50 \%$ & $59,36 \%$ & $58,67 \%$ \\
\hline COTEMINAS & $27,09 \%$ & $30,48 \%$ & $26,45 \%$ & $28,11 \%$ & $27,02 \%$ & $27,83 \%$ \\
\hline CRT CELULAR & $61,30 \%$ & $51,84 \%$ & $49,92 \%$ & $51,33 \%$ & $45,10 \%$ & $51,90 \%$ \\
\hline D F VASCONC & $87,12 \%$ & $86,96 \%$ & $86,93 \%$ & $100,65 \%$ & $113,97 \%$ & $95,13 \%$ \\
\hline
\end{tabular}




\begin{tabular}{|c|c|c|c|c|c|c|}
\hline Empresa & 1999 & 2000 & 2001 & 2002 & 2003 & Médla \\
\hline DIMED & $45,58 \%$ & $44,55 \%$ & $45,30 \%$ & $39,10 \%$ & $45,57 \%$ & $44,02 \%$ \\
\hline DIXIE TOGA & $61,62 \%$ & $59,84 \%$ & $75,04 \%$ & $78,21 \%$ & $68,06 \%$ & $68,56 \%$ \\
\hline DOC IMBITUBA & $86,63 \%$ & $89,65 \%$ & $91,30 \%$ & $95,48 \%$ & $113,21 \%$ & $95,26 \%$ \\
\hline DOCAS & $31,77 \%$ & $28,14 \%$ & $33,76 \%$ & $54,72 \%$ & $59,87 \%$ & $41,65 \%$ \\
\hline DOHLER & $23,46 \%$ & $21,66 \%$ & $23,40 \%$ & $19,07 \%$ & $28,07 \%$ & $23,13 \%$ \\
\hline DROGASIL & $35,94 \%$ & $36,68 \%$ & $36,70 \%$ & $39,80 \%$ & $41,73 \%$ & $38,17 \%$ \\
\hline DURATEX & $41,92 \%$ & $40,90 \%$ & $39,60 \%$ & $45,99 \%$ & $43,48 \%$ & $42,38 \%$ \\
\hline EBE & $77,20 \%$ & $75,05 \%$ & $76,06 \%$ & $71,86 \%$ & $70,23 \%$ & $74,08 \%$ \\
\hline ELDORADO & $43,12 \%$ & $51,60 \%$ & $60,72 \%$ & $70,21 \%$ & $68,28 \%$ & $58,79 \%$ \\
\hline ELECTROLUX & $55,68 \%$ & $68,32 \%$ & $75,55 \%$ & $48,03 \%$ & $57,88 \%$ & $61,09 \%$ \\
\hline ELEKEIROZ & $26,92 \%$ & $30,10 \%$ & $29,09 \%$ & $34,99 \%$ & $46,91 \%$ & $33,60 \%$ \\
\hline ELEKTRO & $49,73 \%$ & $53,01 \%$ & $79,84 \%$ & $108,97 \%$ & $97,15 \%$ & $\mathbf{7 7 , 7 4 \%}$ \\
\hline ELETROBRAS & $29,77 \%$ & $31,66 \%$ & $38,51 \%$ & $45,09 \%$ & $42,74 \%$ & $37,55 \%$ \\
\hline ELETROPAULO & $66,54 \%$ & $70,96 \%$ & $74,83 \%$ & $83,74 \%$ & $82,77 \%$ & $75,77 \%$ \\
\hline ELUMA & $61,13 \%$ & $68,23 \%$ & $57,22 \%$ & $55,57 \%$ & $46,76 \%$ & $57,78 \%$ \\
\hline EMAE & $17,13 \%$ & $16,66 \%$ & $23,76 \%$ & $22,04 \%$ & $21,60 \%$ & $20,24 \%$ \\
\hline EMBRACO & $60,51 \%$ & $58,75 \%$ & $59,82 \%$ & $65,24 \%$ & $63,63 \%$ & $61,59 \%$ \\
\hline EMBRAER & $79,86 \%$ & $69,73 \%$ & $68,12 \%$ & $70,35 \%$ & $70,83 \%$ & $71,78 \%$ \\
\hline EMBRATEL PAR & $39,48 \%$ & $46,83 \%$ & $55,74 \%$ & $62,24 \%$ & $61,34 \%$ & $53,13 \%$ \\
\hline ENCORPAR & $1,59 \%$ & $0,85 \%$ & $0,71 \%$ & $1,32 \%$ & $1,11 \%$ & $1,12 \%$ \\
\hline ENERSUL & $51,86 \%$ & $51,82 \%$ & $56,30 \%$ & $63,65 \%$ & $65,14 \%$ & $57,75 \%$ \\
\hline ESCELSA & $61,36 \%$ & $63,77 \%$ & $71,50 \%$ & $91,89 \%$ & $86,54 \%$ & $75,01 \%$ \\
\hline ESTRELA & $94,83 \%$ & $94,70 \%$ & $94,27 \%$ & $88,30 \%$ & $90,73 \%$ & $92,57 \%$ \\
\hline ETERNIT & $33,97 \%$ & $22,30 \%$ & $26,94 \%$ & $32,24 \%$ & $23,72 \%$ & $27,83 \%$ \\
\hline EUCATEX & $44,08 \%$ & $48,45 \%$ & $60,60 \%$ & $65,94 \%$ & $74,42 \%$ & $58,70 \%$ \\
\hline F CATAGUAZES & $69,21 \%$ & $79,41 \%$ & $83,42 \%$ & $87,37 \%$ & $87,29 \%$ & $81,34 \%$ \\
\hline FAB C RENAUXX & $54,54 \%$ & $58,10 \%$ & $69,07 \%$ & $90,95 \%$ & $96,36 \%$ & $73,80 \%$ \\
\hline FERBASA & $23,13 \%$ & $18,70 \%$ & $22,80 \%$ & $19,45 \%$ & $15,96 \%$ & $20,01 \%$ \\
\hline FERTIBRAS & $75,38 \%$ & $78,13 \%$ & $79,38 \%$ & $85,76 \%$ & $80,32 \%$ & $79,80 \%$ \\
\hline FIBAM & $81,88 \%$ & $83,53 \%$ & $84,51 \%$ & $84,20 \%$ & $85,94 \%$ & $84,01 \%$ \\
\hline FORJA TAURUS & $29,64 \%$ & $27,61 \%$ & $32,55 \%$ & $48,93 \%$ & $34,44 \%$ & $34,63 \%$ \\
\hline FOSFERTIL & $62,76 \%$ & $63,69 \%$ & $59,78 \%$ & $68,70 \%$ & $58,43 \%$ & $62,67 \%$ \\
\hline FRAS-LE & $56,82 \%$ & $51,69 \%$ & $51,77 \%$ & $62,66 \%$ & $59,32 \%$ & $56,45 \%$ \\
\hline GAZOLA & $68,53 \%$ & $86,34 \%$ & $90,64 \%$ & $93,74 \%$ & $91,09 \%$ & $86,07 \%$ \\
\hline GER PARANAP & $35,54 \%$ & $38,19 \%$ & $39,24 \%$ & $41,67 \%$ & $40,37 \%$ & $39,01 \%$ \\
\hline GERDAU & $66,71 \%$ & $65,33 \%$ & $68,54 \%$ & $75,30 \%$ & $69,46 \%$ & $69,07 \%$ \\
\hline GERDAU MET & $80,81 \%$ & $79,59 \%$ & $81,62 \%$ & $86,57 \%$ & $82,87 \%$ & $82,29 \%$ \\
\hline GLOBEX & $58,12 \%$ & $61,44 \%$ & $58,35 \%$ & $62,91 \%$ & $62,42 \%$ & $60,65 \%$ \\
\hline GPC PART & $15,32 \%$ & $40,72 \%$ & $54,37 \%$ & $68,63 \%$ & $67,20 \%$ & $49,25 \%$ \\
\hline GRADIENTE & $76,41 \%$ & $57,55 \%$ & $54,76 \%$ & $48,83 \%$ & $73,93 \%$ & $62,30 \%$ \\
\hline GRANOLEO & $13,74 \%$ & $7,70 \%$ & $8,26 \%$ & $47,01 \%$ & $42,26 \%$ & $23,80 \%$ \\
\hline GRAZZIOTIN & $33,94 \%$ & $33,00 \%$ & $31,09 \%$ & $28,26 \%$ & $27,82 \%$ & $30,82 \%$ \\
\hline GUARARAPES & $25,88 \%$ & $31,23 \%$ & $28,67 \%$ & $30,87 \%$ & $30,09 \%$ & $29,35 \%$ \\
\hline HOTEIS OTHON & $85,48 \%$ & $85,49 \%$ & $92,19 \%$ & $72,29 \%$ & $81,52 \%$ & $83,39 \%$ \\
\hline IGUACU CAFE & $33,59 \%$ & $34,21 \%$ & $33,81 \%$ & $45,10 \%$ & $28,30 \%$ & $35,00 \%$ \\
\hline INDS ROMI & $30,19 \%$ & $31,46 \%$ & $29,28 \%$ & $22,55 \%$ & $22,44 \%$ & $27,18 \%$ \\
\hline INEPAR & $61,76 \%$ & $72,70 \%$ & $80,94 \%$ & $96,48 \%$ & $102,95 \%$ & $82,97 \%$ \\
\hline IOCHP-MAXION & $72,54 \%$ & $74,41 \%$ & $64,96 \%$ & $60,72 \%$ & $64,85 \%$ & $67,50 \%$ \\
\hline IPIRANGA DIS & $62,60 \%$ & $62,76 \%$ & $69,46 \%$ & $75,09 \%$ & $75,57 \%$ & $69,09 \%$ \\
\hline IPIRANGA PET & $37,98 \%$ & $38,79 \%$ & $46,94 \%$ & $59,58 \%$ & $59,57 \%$ & $48,57 \%$ \\
\hline IPIRANGA REF & $84,05 \%$ & $83,98 \%$ & $87,84 \%$ & $99,89 \%$ & $95,78 \%$ & $90,31 \%$ \\
\hline
\end{tabular}




\begin{tabular}{|c|c|c|c|c|c|c|}
\hline Empresa & 1999 & 2000 & 2001 & 2002 & 2003 & Médla \\
\hline ITAUTEC & $59,97 \%$ & $61,79 \%$ & $66,75 \%$ & $67,28 \%$ & $68,10 \%$ & $64,78 \%$ \\
\hline IVEN & $81,45 \%$ & $83,10 \%$ & $87,22 \%$ & $96,62 \%$ & $93,64 \%$ & $88,41 \%$ \\
\hline J B DUARTE & $92,70 \%$ & $96,01 \%$ & $98,80 \%$ & $98,56 \%$ & $95,36 \%$ & $96,29 \%$ \\
\hline JOAO FORTES & $59,37 \%$ & $61,79 \%$ & $68,13 \%$ & $63,34 \%$ & $65,30 \%$ & $63,59 \%$ \\
\hline KARSTEN & $56,71 \%$ & $64,68 \%$ & $64,50 \%$ & $63,71 \%$ & $60,94 \%$ & $62,11 \%$ \\
\hline KEPLER WEBER & $98,12 \%$ & $49,32 \%$ & $58,33 \%$ & $62,49 \%$ & $59,04 \%$ & $65,46 \%$ \\
\hline KLABIN S/A & $52,81 \%$ & $46,43 \%$ & $70,49 \%$ & $76,85 \%$ & $52,48 \%$ & $59,81 \%$ \\
\hline LA FONTE PAR & $67,71 \%$ & $75,57 \%$ & $80,37 \%$ & $82,44 \%$ & $85,81 \%$ & $78,38 \%$ \\
\hline LA FONTE TEL & $72,34 \%$ & $81,55 \%$ & $88,62 \%$ & $89,09 \%$ & $91,35 \%$ & $84,59 \%$ \\
\hline LECO & $33,74 \%$ & $33,90 \%$ & $44,80 \%$ & $52,16 \%$ & $53,88 \%$ & $43,70 \%$ \\
\hline LF TEL & $90,74 \%$ & $80,96 \%$ & $77,84 \%$ & $78,41 \%$ & $80,65 \%$ & $81,72 \%$ \\
\hline LIGHT & $72,39 \%$ & $76,03 \%$ & $100,99 \%$ & $91,22 \%$ & $95,01 \%$ & $87,13 \%$ \\
\hline LIX DA CUNHA & $76,84 \%$ & $73,88 \%$ & $73,39 \%$ & $72,65 \%$ & $73,24 \%$ & $74,00 \%$ \\
\hline LOJAS AMERIC & $78,38 \%$ & $82,93 \%$ & $84,06 \%$ & $85,23 \%$ & $88,40 \%$ & $83,80 \%$ \\
\hline LOJAS HERING & $37,47 \%$ & $99,47 \%$ & $108,13 \%$ & $121,30 \%$ & $126,52 \%$ & $98,58 \%$ \\
\hline LOJAS RENNER & $61,24 \%$ & $67,43 \%$ & $74,49 \%$ & $93,41 \%$ & $85,06 \%$ & $76,33 \%$ \\
\hline MAGNESITA & $26,86 \%$ & $28,31 \%$ & $29,83 \%$ & $36,35 \%$ & $39,75 \%$ & $32,22 \%$ \\
\hline MANASA & $83,47 \%$ & $79,28 \%$ & $76,37 \%$ & $79,47 \%$ & $89,25 \%$ & $81,57 \%$ \\
\hline MANGELS INDL & $57,71 \%$ & $59,49 \%$ & $58,40 \%$ & $61,12 \%$ & $58,99 \%$ & $59,14 \%$ \\
\hline MARCOPOLO & $58,77 \%$ & $64,70 \%$ & $74,64 \%$ & $67,57 \%$ & $64,66 \%$ & $66,07 \%$ \\
\hline MARISOL & $43,01 \%$ & $39,96 \%$ & $40,08 \%$ & $40,47 \%$ & $42,94 \%$ & $41,29 \%$ \\
\hline MELPAPER & $73,56 \%$ & $76,23 \%$ & $71,62 \%$ & $73,85 \%$ & $72,75 \%$ & $73,60 \%$ \\
\hline MENDES JR & $74,46 \%$ & $71,59 \%$ & $70,73 \%$ & $75,45 \%$ & $78,47 \%$ & $74,14 \%$ \\
\hline MET DUQUE & $20,73 \%$ & $19,32 \%$ & $22,67 \%$ & $36,76 \%$ & $33,94 \%$ & $26,68 \%$ \\
\hline METAL LEVE & $44,30 \%$ & $40,41 \%$ & $37,67 \%$ & $34,20 \%$ & $34,73 \%$ & $38,26 \%$ \\
\hline METISA & $21,84 \%$ & $21,06 \%$ & $26,10 \%$ & $38,93 \%$ & $25,44 \%$ & $26,67 \%$ \\
\hline MICHELETTO & $51,98 \%$ & $63,34 \%$ & $67,98 \%$ & $74,15 \%$ & $79,90 \%$ & $67,47 \%$ \\
\hline MILLENNIUM & $35,33 \%$ & $36,77 \%$ & $27,99 \%$ & $29,94 \%$ & $21,44 \%$ & $30,29 \%$ \\
\hline MULTIBRAS & $54,60 \%$ & $49,38 \%$ & $51,44 \%$ & $60,08 \%$ & $61,74 \%$ & $55,45 \%$ \\
\hline NADIR FIGUEI & $26,51 \%$ & $30,31 \%$ & $29,68 \%$ & $31,20 \%$ & $31,77 \%$ & $29,89 \%$ \\
\hline P.ACUCAR-CBD & $55,08 \%$ & $55,72 \%$ & $53,25 \%$ & $60,90 \%$ & $57,85 \%$ & $56,56 \%$ \\
\hline PARANAPANEMA & $84,53 \%$ & $88,61 \%$ & $96,44 \%$ & $95,25 \%$ & $103,10 \%$ & $93,58 \%$ \\
\hline PARMALAT & $37,78 \%$ & $32,51 \%$ & $40,05 \%$ & $57,04 \%$ & $68,52 \%$ & $47,18 \%$ \\
\hline PAUL FLUZ & $30,01 \%$ & $31,86 \%$ & $51,42 \%$ & $63,99 \%$ & $61,28 \%$ & $47,71 \%$ \\
\hline PERDIGAO S/A & $71,83 \%$ & $74,99 \%$ & $72,24 \%$ & $77,53 \%$ & $72,54 \%$ & $73,83 \%$ \\
\hline PET MANGUINH & $47,79 \%$ & $34,76 \%$ & $43,14 \%$ & $43,79 \%$ & $45,30 \%$ & $42,96 \%$ \\
\hline PETROBRAS & $68,76 \%$ & $62,60 \%$ & $61,19 \%$ & $64,78 \%$ & $63,24 \%$ & $64,11 \%$ \\
\hline PETROFLEX & $73,42 \%$ & $78,47 \%$ & $80,24 \%$ & $77,54 \%$ & $75,27 \%$ & $76,99 \%$ \\
\hline PETROPAR & $59,05 \%$ & $54,20 \%$ & $48,29 \%$ & $44,38 \%$ & $35,63 \%$ & $48,31 \%$ \\
\hline PETROQ UNIAO & $42,28 \%$ & $42,05 \%$ & $41,02 \%$ & $58,11 \%$ & $59,68 \%$ & $48,63 \%$ \\
\hline PETTENATI & $49,24 \%$ & $44,84 \%$ & $43,39 \%$ & $50,27 \%$ & $51,60 \%$ & $47,87 \%$ \\
\hline PLASCAR PART & $54,47 \%$ & $74,88 \%$ & $79,01 \%$ & $104,93 \%$ & $75,54 \%$ & $77,76 \%$ \\
\hline POLIALDEN & $13,47 \%$ & $20,68 \%$ & $27,33 \%$ & $27,47 \%$ & $32,31 \%$ & $24,25 \%$ \\
\hline POLIPROPILEN & $47,58 \%$ & $46,41 \%$ & $53,19 \%$ & $65,14 \%$ & $61,59 \%$ & $54,78 \%$ \\
\hline POLITENO & $44,84 \%$ & $40,02 \%$ & $53,14 \%$ & $22,51 \%$ & $19,13 \%$ & $35,93 \%$ \\
\hline PORTOBELLO & $59,41 \%$ & $76,51 \%$ & $74,79 \%$ & $84,43 \%$ & $82,94 \%$ & $75,62 \%$ \\
\hline PRONOR & $85,64 \%$ & $86,08 \%$ & $78,09 \%$ & $56,01 \%$ & $56,81 \%$ & $72,53 \%$ \\
\hline RANDON PART & $70,91 \%$ & $73,76 \%$ & $72,47 \%$ & $77,59 \%$ & $73,04 \%$ & $73,55 \%$ \\
\hline RASIP AGRO & $36,27 \%$ & $44,89 \%$ & $42,17 \%$ & $36,88 \%$ & $41,18 \%$ & $40,28 \%$ \\
\hline RECRUSUL & $37,64 \%$ & $46,08 \%$ & $55,43 \%$ & $81,50 \%$ & $123,69 \%$ & $68,87 \%$ \\
\hline RHODIA-STER & $110,04 \%$ & $83,05 \%$ & $83,16 \%$ & $91,34 \%$ & $75,26 \%$ & $88,57 \%$ \\
\hline
\end{tabular}




\begin{tabular}{|c|c|c|c|c|c|c|}
\hline Empresa & 1999 & 2000 & 2001 & 2002 & 2003 & Médla \\
\hline RIO GDE ENER & $40,88 \%$ & $48,32 \%$ & $53,10 \%$ & $62,95 \%$ & $57,37 \%$ & $52,52 \%$ \\
\hline RIOSULENSE & $81,36 \%$ & $81,69 \%$ & $80,63 \%$ & $81,08 \%$ & $84,35 \%$ & $81,82 \%$ \\
\hline RIPASA & $41,86 \%$ & $28,02 \%$ & $40,88 \%$ & $55,63 \%$ & $52,70 \%$ & $43,82 \%$ \\
\hline ROSSI RESID & $59,88 \%$ & $54,52 \%$ & $51,98 \%$ & $54,29 \%$ & $62,20 \%$ & $56,57 \%$ \\
\hline SABESP & $45,28 \%$ & $45,57 \%$ & $49,76 \%$ & $55,63 \%$ & $54,16 \%$ & $50,08 \%$ \\
\hline SADIA S/A & $74,15 \%$ & $71,09 \%$ & $67,55 \%$ & $75,41 \%$ & $72,90 \%$ & $72,22 \%$ \\
\hline SANSUY & $81,18 \%$ & $78,98 \%$ & $78,35 \%$ & $80,18 \%$ & $79,65 \%$ & $79,67 \%$ \\
\hline SANTANENSE & $61,56 \%$ & $63,26 \%$ & $53,00 \%$ & $60,23 \%$ & $74,87 \%$ & $62,58 \%$ \\
\hline SARAIVA LIVR & $59,19 \%$ & $66,42 \%$ & $63,75 \%$ & $61,42 \%$ & $63,60 \%$ & $62,88 \%$ \\
\hline SCHLOSSER & $90,58 \%$ & $97,23 \%$ & $77,04 \%$ & $93,00 \%$ & $106,83 \%$ & $92,94 \%$ \\
\hline SCHULZ & $32,09 \%$ & $36,89 \%$ & $49,03 \%$ & $54,57 \%$ & $53,55 \%$ & $45,23 \%$ \\
\hline SEARA ALM & $64,76 \%$ & $65,91 \%$ & $67,54 \%$ & $70,15 \%$ & $63,70 \%$ & $66,41 \%$ \\
\hline SEMP & $99,71 \%$ & $98,30 \%$ & $97,10 \%$ & $93,39 \%$ & $91,94 \%$ & $96,09 \%$ \\
\hline SERGEN & $20,22 \%$ & $24,47 \%$ & $26,07 \%$ & $20,93 \%$ & $19,40 \%$ & $22,22 \%$ \\
\hline SID NACIONAL & $53,19 \%$ & $62,68 \%$ & $61,90 \%$ & $68,28 \%$ & $67,05 \%$ & $62,62 \%$ \\
\hline SID TUBARAO & $41,78 \%$ & $42,43 \%$ & $44,84 \%$ & $51,23 \%$ & $41,15 \%$ & $44,28 \%$ \\
\hline SONDOTECNICA & $29,15 \%$ & $22,68 \%$ & $17,43 \%$ & $20,64 \%$ & $22,47 \%$ & $22,47 \%$ \\
\hline SOUZA CRUZ & $52,48 \%$ & $47,35 \%$ & $42,49 \%$ & $49,39 \%$ & $51,01 \%$ & $48,55 \%$ \\
\hline SPRINGER & $22,90 \%$ & $20,93 \%$ & $22,79 \%$ & $16,53 \%$ & $20,54 \%$ & $20,74 \%$ \\
\hline SULTEPA & $46,16 \%$ & $48,69 \%$ & $48,84 \%$ & $56,79 \%$ & $62,88 \%$ & $52,67 \%$ \\
\hline SUPERGASBRAS & $50,28 \%$ & $54,02 \%$ & $60,44 \%$ & $64,29 \%$ & $58,55 \%$ & $57,52 \%$ \\
\hline SUZANO & $54,48 \%$ & $49,04 \%$ & $71,52 \%$ & $71,34 \%$ & $60,58 \%$ & $61,39 \%$ \\
\hline SUZANO PAPEL & $47,76 \%$ & $41,71 \%$ & $49,71 \%$ & $52,37 \%$ & $42,43 \%$ & $46,80 \%$ \\
\hline TAM S/A & $80,65 \%$ & $82,26 \%$ & $83,50 \%$ & $94,22 \%$ & $98,49 \%$ & $87,82 \%$ \\
\hline TEC BLUMENAU & $56,92 \%$ & $65,85 \%$ & $64,19 \%$ & $63,12 \%$ & $68,48 \%$ & $63,71 \%$ \\
\hline TECHNOS REL & $3,63 \%$ & $3,85 \%$ & $7,82 \%$ & $13,92 \%$ & $11,49 \%$ & $8,14 \%$ \\
\hline TECNOSOLO & $40,33 \%$ & $51,15 \%$ & $46,99 \%$ & $49,97 \%$ & $49,69 \%$ & $47,63 \%$ \\
\hline TEKA & $94,92 \%$ & $82,64 \%$ & $83,17 \%$ & $93,88 \%$ & $95,55 \%$ & $90,03 \%$ \\
\hline TEKNO & $22,45 \%$ & $20,95 \%$ & $18,81 \%$ & $19,31 \%$ & $18,32 \%$ & $19,97 \%$ \\
\hline TELE CL SUL & $45,21 \%$ & $41,62 \%$ & $40,23 \%$ & $43,20 \%$ & $36,47 \%$ & $41,35 \%$ \\
\hline TELE CTR OES & $27,07 \%$ & $47,07 \%$ & $49,35 \%$ & $47,94 \%$ & $40,82 \%$ & $42,45 \%$ \\
\hline TELE LEST CL & $74,10 \%$ & $50,58 \%$ & $48,28 \%$ & $53,75 \%$ & $51,75 \%$ & $55,69 \%$ \\
\hline TELE NORD CL & $59,42 \%$ & $49,30 \%$ & $45,68 \%$ & $43,22 \%$ & $33,95 \%$ & $46,31 \%$ \\
\hline TELE NORT CL & $40,45 \%$ & $66,47 \%$ & $66,94 \%$ & $69,27 \%$ & $61,10 \%$ & $60,85 \%$ \\
\hline TELE SUDESTE & $49,81 \%$ & $39,82 \%$ & $35,49 \%$ & $36,71 \%$ & $32,59 \%$ & $38,88 \%$ \\
\hline TELEFONICA & $72,14 \%$ & $68,55 \%$ & $67,40 \%$ & $72,82 \%$ & $74,12 \%$ & $71,01 \%$ \\
\hline TELEMAR & $26,33 \%$ & $38,95 \%$ & $59,43 \%$ & $64,17 \%$ & $68,47 \%$ & $51,47 \%$ \\
\hline TELEMAR N L & $25,81 \%$ & $34,91 \%$ & $50,22 \%$ & $47,18 \%$ & $57,29 \%$ & $43,08 \%$ \\
\hline TELEMIG CL & $53,70 \%$ & $61,78 \%$ & $63,34 \%$ & $66,50 \%$ & $52,43 \%$ & $59,55 \%$ \\
\hline TELEMIG PART & $31,07 \%$ & $51,30 \%$ & $54,34 \%$ & $57,86 \%$ & $45,07 \%$ & $47,93 \%$ \\
\hline TELESP & $22,85 \%$ & $27,60 \%$ & $35,61 \%$ & $35,23 \%$ & $38,98 \%$ & $32,05 \%$ \\
\hline TELESP CL PA & $55,03 \%$ & $37,83 \%$ & $60,09 \%$ & $58,46 \%$ & $72,53 \%$ & $56,79 \%$ \\
\hline TEX RENAUX & $69,46 \%$ & $68,77 \%$ & $71,03 \%$ & $95,25 \%$ & $95,95 \%$ & $80,09 \%$ \\
\hline TRAFO & $46,98 \%$ & $58,08 \%$ & $52,52 \%$ & $54,82 \%$ & $49,38 \%$ & $52,36 \%$ \\
\hline TRAN PAULIST & $11,53 \%$ & $13,93 \%$ & $15,56 \%$ & $17,84 \%$ & $18,68 \%$ & $15,51 \%$ \\
\hline TREVISA & $126,98 \%$ & $45,92 \%$ & $39,14 \%$ & $51,51 \%$ & $47,55 \%$ & $62,22 \%$ \\
\hline TUPY & $76,21 \%$ & $81,69 \%$ & $84,38 \%$ & $89,63 \%$ & $90,67 \%$ & $84,52 \%$ \\
\hline ULTRAPAR & $46,37 \%$ & $44,01 \%$ & $47,10 \%$ & $43,20 \%$ & $41,52 \%$ & $44,44 \%$ \\
\hline UNIPAR & $39,93 \%$ & $37,48 \%$ & $38,29 \%$ & $52,94 \%$ & $57,15 \%$ & $45,16 \%$ \\
\hline USIMINAS & $69,93 \%$ & $71,60 \%$ & $75,53 \%$ & $80,35 \%$ & $74,13 \%$ & $74,31 \%$ \\
\hline VCP & $39,64 \%$ & $33,51 \%$ & $50,52 \%$ & $61,93 \%$ & $57,04 \%$ & $48,53 \%$ \\
\hline
\end{tabular}




\begin{tabular}{|l|c|c|c|c|c|c|}
\hline Empresa & $\mathbf{1 9 9 9}$ & $\mathbf{2 0 0 0}$ & $\mathbf{2 0 0 1}$ & $\mathbf{2 0 0 2}$ & $\mathbf{2 0 0 3}$ & Média \\
\hline VALER DOCE & $46,32 \%$ & $\mathbf{5 5 , 2 8} \%$ & $55,16 \%$ & $61,50 \%$ & $58,43 \%$ & $\mathbf{5 5 , 3 4 \%}$ \\
\hline VICUNHA TEXT & $63,37 \%$ & $66,82 \%$ & $63,58 \%$ & $63,82 \%$ & $64,13 \%$ & $\mathbf{6 4 , 3 4 \%}$ \\
\hline VIGOR & $53,71 \%$ & $55,59 \%$ & $60,50 \%$ & $72,26 \%$ & $72,92 \%$ & $\mathbf{6 2 , 9 9 \%}$ \\
\hline WEG & $56,49 \%$ & $61,04 \%$ & $56,49 \%$ & $60,73 \%$ & $55,20 \%$ & $57,99 \%$ \\
\hline WEMBLEY & $60,91 \%$ & $63,79 \%$ & $59,65 \%$ & $62,14 \%$ & $58,64 \%$ & $61,03 \%$ \\
\hline MEDIA & $54,52 \%$ & $54,94 \%$ & $57,70 \%$ & $62,53 \%$ & $61,84 \%$ & $58,31 \%$ \\
\hline
\end{tabular}

Fonte: Sabe. Balanço Patrimonlal. Elaboraçăo Própria.

Calculado através da seguinte fórmula: Endividamento a valor contábil $(\mathrm{PC}+\mathrm{ELP}) /(\mathrm{PC}+\mathrm{ELP}+\mathrm{PL})$ 
Anexo B- Classificação da Amostra por Empresa, segundo CNAE

\begin{tabular}{|c|c|c|c|}
\hline $\begin{array}{c}\text { Empresa } \\
\text { (Nome Pregão) }\end{array}$ & Seção & Divisão & Grupo \\
\hline ACESITA & $\begin{array}{l}\text { INDÚSTRIAS DE } \\
\text { TRANSFORMACÃO }\end{array}$ & METALURGIA BASICA & SIDERURGIA \\
\hline Acos VILL & $\begin{array}{l}\text { INDĹSTRIAS DE } \\
\text { TRANSFORMAÇÃo }\end{array}$ & METALURGIA BÁSICA & SIDERURGIA \\
\hline ADUBOS TREVO & $\begin{array}{l}\text { INDÚSTRIAS DE } \\
\text { TRANSFORMAÇAO } \\
\end{array}$ & $\begin{array}{l}\text { FABRICACĀOO DE PRODUTOS } \\
\text { QUIMICOS }\end{array}$ & $\begin{array}{l}\text { FABRICACÃO DE PRODUTOS QUIMICOS } \\
\text { INORGÁNICOS }\end{array}$ \\
\hline AES TIETE & $\begin{array}{l}\text { PRODUGAOE DISTRIBUICCAO } \\
\text { DE ELLTRICIDADE, GAS E } \\
\text { AGUA }\end{array}$ & $\begin{array}{l}\text { ELETRICIDADE, GAS E AGUA } \\
\text { QUENTE }\end{array}$ & $\begin{array}{l}\text { PRODUCCÃO E DISTRIBUIÇÃO DE ENERGIA } \\
\text { ELE'TRICA }\end{array}$ \\
\hline ALBARUS & $\begin{array}{l}\text { INDÚSTRIAS DE } \\
\text { TRANSFORMACGAOO }\end{array}$ & $\begin{array}{l}\text { FABRICACCAOO E MONTAGEM DE } \\
\text { VEECULOS } \\
\text { AUTOMOTORES,REBOQUES E } \\
\text { CARROCERIAS, }\end{array}$ & $\begin{array}{l}\text { FABRICACAOO DE PECAS E ACESSORIOS } \\
\text { PARA VEICULOS }\end{array}$ \\
\hline ALL AMER LAT & $\begin{array}{l}\text { INDÚSTRIAS DE } \\
\text { TRANSFORMAÇÄO }\end{array}$ & $\begin{array}{l}\text { FABRICACAO DE OUTROS } \\
\text { EQUPAMENTOS DE } \\
\text { TRANSPORTE }\end{array}$ & $\begin{array}{l}\text { CONSTRUÇÃO, MONTAGEM E REPARAÇÃO } \\
\text { DE VEICULOS FERROVIÁRIOS }\end{array}$ \\
\hline ALPARGATAS & $\begin{array}{l}\text { INDÚSTRIAS DE } \\
\text { TRANSFORMAČÃO }\end{array}$ & $\begin{array}{l}\text { PREPARACÃO DE COUROS E } \\
\text { FABRICACÁO DE ARTEFATOS DE }\end{array}$ & FABRICAÇÃO DE CALCCADOS \\
\hline AMBEV & $\begin{array}{l}\text { INDÚSTRIAS DE } \\
\text { TRANSFORMAÇÄO } \\
\end{array}$ & $\begin{array}{l}\text { FABRICACAO DE PRODUTOS } \\
\text { ALIMENTICIOS E BEBIDAS }\end{array}$ & FABRICAÇÃO DE BEBIDAS \\
\hline ARACRUZ & $\begin{array}{l}\text { INDÜSTRIAS DE } \\
\text { TRANSFORMAÇĀO }\end{array}$ & $\begin{array}{l}\text { FABRICAÇÃO DE CELULOSE, } \\
\text { PAPELE PRODUTOS DE PAPEL } \\
\end{array}$ & $\begin{array}{l}\text { FABRICAÇĀO DE CELULOSE E OUTRAS } \\
\text { PASTAS PARA A FABRICAÇĀO DE PAPEL }\end{array}$ \\
\hline ARTHUR LANGE & $\begin{array}{l}\text { INDÚSTRIAS DE } \\
\text { TRANSFORMAC,ĀO }\end{array}$ & $\begin{array}{l}\text { PREPARACẢO DE COUROS E } \\
\text { FABRICACÁAO DE ARTEFATOS DE } \\
\end{array}$ & $\begin{array}{l}\text { CURTIMENTO E OUTRAS PREPARAÇÓES } \\
\text { DE COURO }\end{array}$ \\
\hline AVIPAL & $\begin{array}{l}\text { INDÚSTRIAS DE } \\
\text { TRANSFORMACAOO }\end{array}$ & $\begin{array}{l}\text { FABRICACÃO DE PRODUTOS } \\
\text { ALMMENTICIOS E BEBIDAS }\end{array}$ & $\begin{array}{l}\text { ABATE E PREPARACĀO DE PRODUTOS DE } \\
\text { CARNE E DE PESCADO } \\
\end{array}$ \\
\hline BAN ARMAZENS & $\begin{array}{l}\text { TRANSPORTE, ARMAZENAGEM } \\
\text { E COMUNICACOOES }\end{array}$ & $\begin{array}{l}\text { ATIVIDADES ANEXAS E } \\
\text { AUXILIARES DOS TRANSPORTES } \\
\text { EAGEENCIAS DE VIAGEM } \\
\end{array}$ & $\begin{array}{l}\text { MOVIMENTACĀO E ARMAZENAMENTO DE } \\
\text { CARGAS }\end{array}$ \\
\hline BARDELLA & $\begin{array}{l}\text { INDÚSTRIAS DE } \\
\text { TRANSFORMACÃO }\end{array}$ & $\begin{array}{l}\text { FABRICACĀO DE MAQUINAS E } \\
\text { EQUIPAMENTOS }\end{array}$ & $\begin{array}{l}\text { FABRICACAROO DE MÁQUINAS E } \\
\text { EQUIPAMENTOS DE USO GERAL }\end{array}$ \\
\hline BAUMER & $\begin{array}{l}\text { INDÚSTRIAS DE } \\
\text { TRANSFORMACCAO }\end{array}$ & \begin{tabular}{|l|} 
FABRICACAAO DE \\
EQUIPAMENTOS DE \\
INSTRUMENTACAO \\
MEDICOHOSPITALARES,INSTRU \\
MENTOS DE PRECISAO E \\
OPTICOS, EQUIPAMENTOS PARA \\
AUTOMACAO INDUSTRIAL, \\
CRONOMETROS E RELOGIOS \\
\end{tabular} & $\begin{array}{l}\text { FABRICACÃO DE APARELHOS E } \\
\text { INSTRUMENTOS PARAA USOS } \\
\text { MEDICOHOSPITALARES,ODONTOLOGICOS } \\
\text { E DE LABORATORIOS A APARELHOS } \\
\text { ORTOPEDICOS } \\
\end{array}$ \\
\hline BELGO MINEIR & $\begin{array}{l}\text { INDÚSTRIAS DE } \\
\text { TRANSFORMAC,Ão }\end{array}$ & METALURGIA BÁSICA & SIDERURGIA \\
\hline BIC MONARK & $\begin{array}{l}\text { INDÚSTRIAS DE } \\
\text { TRANSFORMAÇĀO }\end{array}$ & $\begin{array}{l}\text { FABRICACAODE OUTROS } \\
\text { EQUPAMENTOS DE } \\
\text { TRANSPORTE } \\
\end{array}$ & $\begin{array}{l}\text { FABRICACẢO DE OUTROS EQUIPAMENTOS } \\
\text { DE TRANSPORTE }\end{array}$ \\
\hline BLUE TREE & $\begin{array}{l}\text { ALOJAMENTOE } \\
\text { ALIMENTACÄOO }\end{array}$ & ALOJAMENTO E ALIMENTAÇÃO & $\begin{array}{l}\text { ESTABELECIMENTOS HOTELEIROS } \bar{E} \\
\text { OUTROS TPOS DE ALOJAMENTO } \\
\text { TEMPORARIO }\end{array}$ \\
\hline BRASIL T PAR & $\begin{array}{l}\text { TRANSPORTE, ARMAZENAGEM } \\
\text { E COMUNICACOEES }\end{array}$ & \begin{tabular}{|l|} 
CORREIOE \\
TELECOMUNICAÇÖES \\
\end{tabular} & TELECOMUNICAÇÖES \\
\hline BRASIL TELEC & $\begin{array}{l}\text { TRANSPORTE, ARMAZENAGEM } \\
\text { E COMUNICACOEES }\end{array}$ & $\begin{array}{l}\text { CORREIO E } \\
\text { TELECOMUNICAÇÖES } \\
\end{array}$ & TELECOMUNICACÖES \\
\hline BRASKEM & $\begin{array}{l}\text { INDÚSTRIAS DE } \\
\text { TRANSFORMAGAOO }\end{array}$ & $\begin{array}{l}\text { FABRICAÇÃO DE PRODUTOS } \\
\text { QUIMICOS }\end{array}$ & $\begin{array}{l}\text { FABRICACÃO DE PRODUTOS QUIMICOS } \\
\text { ORGÁNICOS }\end{array}$ \\
\hline BRASMOTOR & $\begin{array}{l}\text { INDÚSTRIAS DE } \\
\text { TRANSFORMAC,ĀO }\end{array}$ & $\begin{array}{l}\text { FABRICACÃOO DE MAQUINAS E } \\
\text { EQUIPAMENTOS }\end{array}$ & FABRICAÇ̄OO DE ELETRODOMÉSTICOS \\
\hline BRAZIL REALT & CONSTRUGÃO & CONSTRUÇÃO & $\begin{array}{l}\text { CONSTRUCRAO DE EDIFICIOS E OBRAS DE } \\
\text { ENGENHARAA CIVIL }\end{array}$ \\
\hline BUETTNER & $\begin{array}{l}\text { INDÚSTRIAS DE } \\
\text { TRANSFORMAÇÃO }\end{array}$ & $\begin{array}{l}\text { FABRICACĀOO DE PRODUTOS } \\
\text { TEXXTEIS }\end{array}$ & $\begin{array}{l}\text { FABRICACAO DE ARTEFATOS TÉXTEIS A } \\
\text { PARTR DE TELIDOS - EXCETO VESTUARIO } \\
\text {-E DE OUTROS ARTIGOS TEXXTEIS } \\
\end{array}$ \\
\hline CACIQUE & $\begin{array}{l}\text { INDÚSTRIAS DE } \\
\text { TRANSFORMAÇĀO }\end{array}$ & $\begin{array}{l}\text { FABRICACÁO DE PRODUTOS } \\
\text { ALIMENTICIOS E BEBIDAS } \\
\end{array}$ & TORRAFAÇĀO E MOAGEM DE CAFÉ \\
\hline CAEMI & INDÚSTRIAS EXTRATIVAS & $\begin{array}{l}\text { EXTRACÃO DE MINERAS } \\
\text { METALICOS }\end{array}$ & EXTRAÇÃO DE MINÉRIO DE FERRO \\
\hline CAIUA & $\begin{array}{l}\text { PRODUÇAOE EISTRIBUICÇAO } \\
\text { DE ELETRICIDADE, GAS E } \\
\text { AGUA }\end{array}$ & $\begin{array}{l}\text { ELETRICIDADE, GÁS E AGUA } \\
\text { QUENTE }\end{array}$ & $\begin{array}{l}\text { PRODUCCAO E DISTRIBUIÇÃO DE ENERGIA } \\
\text { ELETTRICA }\end{array}$ \\
\hline CBC CARTUCHO & 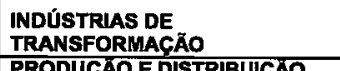 & $\begin{array}{l}\text { FABRICACĀO DE MAQUINAS E } \\
\text { EQUIPAMENTOS }\end{array}$ & $\begin{array}{l}\text { FABRICACĀO DE ARMAS, MUNIÇŐES E } \\
\text { EQUIPAMENTOS MILTARES }\end{array}$ \\
\hline CEB & $\begin{array}{l}\text { PRODUGGAOE DISTRIBUICAXO } \\
\text { DE ELETRICIDADE, GAS E } \\
\text { AGUA }\end{array}$ & $\begin{array}{l}\text { ELETRIGIDADE, GAS E AGUA } \\
\text { QUENTE }\end{array}$ & $\begin{array}{l}\text { PRODUCCÃO E DISTRIBUIÇÃO DE ENERGIA } \\
\text { ELÉTRICA }\end{array}$ \\
\hline CEDRO & $\begin{array}{l}\text { INDÚSTRIAS DE } \\
\text { TRANSFORMAC̆O }\end{array}$ & $\begin{array}{l}\text { FABRICAÇÃO DE PRODUTOS } \\
\text { TEXXTEIS }\end{array}$ & $\begin{array}{l}\text { TECELAGEM - INCLUSIVE FIACĀO E } \\
\text { TECELLAGEM }\end{array}$ \\
\hline CELESC & $\begin{array}{l}\text { PRODUCCAO E DISTRIBUICGAO } \\
\text { DE ELLERICIDADE, GÁS E } \\
\text { AGUA }\end{array}$ & $\begin{array}{l}\text { ELETRICIDADE, GÁS E AGUA } \\
\text { QUENTE }\end{array}$ & $\begin{array}{l}\text { PRODUÇÃO E DISTRIBUIÇÃO DE ENERGIA } \\
\text { ELÉTRICA }\end{array}$ \\
\hline CELPA & $\begin{array}{l}\text { PRODUCAO E DISTRIBUICAXO } \\
\text { DE ELETRICIDADE, GAS E } \\
\text { AGUA }\end{array}$ & $\begin{array}{l}\text { ELETRICIDADE, GAS E ÁGUA } \\
\text { QUENTE }\end{array}$ & $\begin{array}{l}\text { PRODUČÃO E DISTRIBUIÇÃO DE ENERGIA } \\
\text { ELÉTRICAA }\end{array}$ \\
\hline
\end{tabular}




\begin{tabular}{|c|c|c|c|}
\hline $\begin{array}{c}\text { Empresa } \\
\text { (Nome Pregão) }\end{array}$ & Seção & Divisâo & Grupo \\
\hline CELPE & $\begin{array}{l}\text { PRODUCÁXO E DISTRIBUICAÁO } \\
\text { DE ELETRICIDADE, GAS E } \\
\text { AGUA }\end{array}$ & $\begin{array}{l}\text { ELETRICIDADE, GÁS E AGUA } \\
\text { QUENTE }\end{array}$ & $\begin{array}{l}\text { PRODUÇÃO E DISTRIBUIÇÃO DE ENERGIA } \\
\text { ELÉTRICA }\end{array}$ \\
\hline CELUL IRANI & $\begin{array}{l}\text { INDÚSTRIAS DE } \\
\text { TRANSFORMAC̆AOO }\end{array}$ & $\begin{array}{l}\text { FABRICAÇAOO DE CELULOSE, } \\
\text { PAPELE PRODUTOS DE PAPEL }\end{array}$ & $\begin{array}{l}\text { FABRICAÇÃO DE CELULOSE E OUTRAS } \\
\text { PASTAS PARA A FABRICACÁO DE PAPEL }\end{array}$ \\
\hline CEMAT & $\begin{array}{l}\text { PROODUGAO EDISTRIBUICAO } \\
\text { DEELETRICIDADE, GASE } \\
\text { AGUA }\end{array}$ & $\begin{array}{l}\text { ELETRICIDADE, GÁS E AGUA } \\
\text { QUENTE }\end{array}$ & $\begin{array}{l}\text { PRODUÇĀO E DISTRIBUIÇAOO DE ENERGIA } \\
\text { ELÉTRICA }\end{array}$ \\
\hline CEMIG & $\begin{array}{l}\text { PRODUCCAO E DISTRIBUICAAOO } \\
\text { DE ELETRICIDADE, GASE } \\
\text { AGUA }\end{array}$ & $\begin{array}{l}\text { ELETRICIDADE, GÁS E AGUA } \\
\text { QUENTE }\end{array}$ & $\begin{array}{l}\text { PRODUÇÃO E DISTRIBUIÇÃO DE ENERGIA } \\
\text { ELÉTRICA }\end{array}$ \\
\hline CERJ & $\begin{array}{l}\text { PRODUCCAO E DISTRIBUICCAO } \\
\text { DE ELETRICIDADE, GAS E } \\
\text { AGUA }\end{array}$ & $\begin{array}{l}\text { ELETRICIDADE, GÁS E ÁGUA } \\
\text { QUENTE }\end{array}$ & $\begin{array}{l}\text { PRODUÇAOO E DISTRIBUIÇAOO DE ENERGIA } \\
\text { ELLETRICA }\end{array}$ \\
\hline CESP & $\begin{array}{l}\text { PRODUCGAOE DISTRIBUICAO } \\
\text { DEELTTRICIDADE, GAS E } \\
\text { AGUA }\end{array}$ & $\begin{array}{l}\text { ELETRICIDADE, GAS E ÁGUA } \\
\text { QUENTE }\end{array}$ & $\begin{array}{l}\text { PRODUÇĀO E DISTRIBUIÇÃO DE ENERGIA } \\
\text { ELÉTRICA }\end{array}$ \\
\hline CHIARELLI & $\begin{array}{l}\text { INDU์STRIAS DE } \\
\text { TRANSFORMAÇAOO } \\
\end{array}$ & $\begin{array}{l}\text { FABRICACAXOO DE PRODUTOS DE } \\
\text { MANERAAS NÃO-METÁLICOS }\end{array}$ & FABRICAĞ̈̌O DE PRODUTOS CERÁMICOS \\
\hline CIA HERING & $\begin{array}{l}\text { INDÚSTRIAS DE } \\
\text { TRANSFORMAC̆AOO } \\
\end{array}$ & $\begin{array}{l}\text { CONFECCX̃O DE ARTICOS DO } \\
\text { VESTUARIO EACESSORIOS }\end{array}$ & $\begin{array}{l}\text { CONFECÇÃO DE ARTIEOS DO VESTUARIO } \\
\text { EACESSORIOS }\end{array}$ \\
\hline COELBA & $\begin{array}{l}\text { PRODUÇÁO E DISTRIBUICAOO } \\
\text { DE ELETRICIDADE, GÁS E } \\
\text { AGUA }\end{array}$ & $\begin{array}{l}\text { ELETRIGIDADE, GAS E AGUA } \\
\text { QUENTE }\end{array}$ & $\begin{array}{l}\text { PRODUÇÃO E DISTRIBUIÇÃO DE ENERGIA } \\
\text { ELÉTRICA }\end{array}$ \\
\hline COELCE & $\begin{array}{l}\text { PRODUCGÁO E DISTRIBUICCAO } \\
\text { DE ELETRICIDADE, GÁS E } \\
\text { AGUA }\end{array}$ & $\begin{array}{l}\text { ELETRICIDADE, GÁS E AGUA } \\
\text { QUENTE }\end{array}$ & $\begin{array}{l}\text { PRODUC̆ẢO E DISTRIBUIÇÃO DE ENERGIA } \\
\text { ELÉTRICA }\end{array}$ \\
\hline COMGAS & $\begin{array}{l}\text { PRODUCCAOOE DISTRIBUICAAO } \\
\text { DE ELETRICIDADE, GÁS E } \\
\text { AGUA }\end{array}$ & $\begin{array}{l}\text { ELETRICIDADE, GAS E AGUA } \\
\text { QUENTE }\end{array}$ & $\begin{array}{l}\text { PRODUĢĀOE DISTRIBUICĀO DE GAS } \\
\text { ATRAVES DE TUBULAGÖES } \\
\end{array}$ \\
\hline CONFAB & $\begin{array}{l}\text { INDÚSTRIAS DE } \\
\text { TRANSFORMAÇĀO }\end{array}$ & METALURGIA BÁSICA & $\begin{array}{l}\text { FABRICACZZOO DE TUBOS - EXCETO EM } \\
\text { SADERÚRGICAS }\end{array}$ \\
\hline CONST A LIND & CONSTRUCÃ̃o & CONSTRUÇĀO & $\begin{array}{l}\text { construgfio DE EDIFICIOS E OBRAS DE } \\
\text { ENGENHARIA CIVLL }\end{array}$ \\
\hline COPESUL & $\begin{array}{l}\text { INDÚSTRIAS DE } \\
\text { TRANSFORMAC,ĀO } \\
\end{array}$ & $\begin{array}{l}\text { FABRICAÇÃO DE PRODUTOS } \\
\text { QUIMICOS }\end{array}$ & $\begin{array}{l}\text { FABRICACÃO DE PRODUTOS QUIMICOS } \\
\text { ORGÁNICOS }\end{array}$ \\
\hline COSERN & $\begin{array}{l}\text { PRODUGAOO E DISTRIBUIÇAO } \\
\text { DE ELETRICIDADE, GAS E } \\
\text { AGUA }\end{array}$ & $\begin{array}{l}\text { ELETRICIDADE, GAS E AGUA } \\
\text { QUENTE }\end{array}$ & $\begin{array}{l}\text { PRODUCC̆̃O E DISTRIBUIÇÃO DE ENERGIA } \\
\text { ELÉTRICA }\end{array}$ \\
\hline COTEMINAS & $\begin{array}{l}\text { INDÚSTRIAS DE } \\
\text { TRANSFORMAC,AO } \\
\end{array}$ & $\begin{array}{l}\text { FABRICAÇAO DE PRODUTOS } \\
\text { TÉXTEIS }\end{array}$ & $\begin{array}{l}\text { TECELAGEM - INCLUSIVE FIAÇAO E } \\
\text { TECELAGEM }\end{array}$ \\
\hline CRT CELLULAR & $\begin{array}{l}\text { TRANSPORTE, ARMAZENAGEM } \\
\text { ECOMUNICAGOES }\end{array}$ & $\begin{array}{l}\text { CORREIOE } \\
\text { TELECOMUNICACOOES } \\
\end{array}$ & TELECOMUNICAÇÓES \\
\hline DF VASCONC & $\begin{array}{l}\text { INDÚSTRIAS DE } \\
\text { TRANSFORMACAO }\end{array}$ & $\begin{array}{l}\text { FABRICAGAO DE } \\
\text { EQUIPAMENTOS DE } \\
\text { INSTRUMENTACÁ } \\
\text { MEDICOHOSPITALARES,INSTRU } \\
\text { MENTOS DE PRECISAO E } \\
\text { OPTICOS, EQUIPAMENTOS PARA } \\
\text { AUTOMACAO INDUSTRIIL, } \\
\text { CRONOMETROS E RELÓGIOS }\end{array}$ & $\begin{array}{l}\text { FABRICACÃO DE APARELHOS E } \\
\text { INSTRUMENTOS PARAA USOS } \\
\text { MEDICOHOSPITALARES,ODONTOLOGICOS } \\
\text { EDE LAABRATORIOS E APARELHOS } \\
\text { ORTOPÉDICOS }\end{array}$ \\
\hline DIMED & $\begin{array}{l}\text { COMERCIO; REPARAGAO DE } \\
\text { VEICULOS AUTOMOTORES, } \\
\text { OBJETOS PESSOAS E } \\
\text { DOMESTIICOS }\end{array}$ & $\begin{array}{l}\text { COMÉRCIO VAREJISTA E } \\
\text { REPARACAO DE OBJETOS } \\
\text { PESSOAS EDOMESTICOS } \\
\end{array}$ & $\begin{array}{l}\text { COMÉRCIO VAREJISTA DE OUTROS } \\
\text { PRODUTOS }\end{array}$ \\
\hline DIXIE TOGA & $\begin{array}{l}\text { INDÚSTRIAS DE } \\
\text { TRANSFORMACÃO } \\
\end{array}$ & $\begin{array}{l}\text { FABRICACARO DE CELULOSE, } \\
\text { PAPELE PRODUTOS DE PAPEL }\end{array}$ & $\begin{array}{l}\text { FABRICACAO DE EMBALAGENS DE PAPEL } \\
\text { OU PAPELAO }\end{array}$ \\
\hline DOC IMBITUBA & $\begin{array}{l}\text { TRANSPORTE, ARMAZENAGEM } \\
\text { E COMUNICACOES }\end{array}$ & $\begin{array}{l}\text { ATIVDADES ANEXASE } \\
\text { AUXILARES DOS TRANSPORTES } \\
\text { EAGENCIAS DE VAGEM } \\
\end{array}$ & $\begin{array}{l}\text { MOVIMENTAÇZO E ARMAZENAMENTO DE } \\
\text { CARGAS }\end{array}$ \\
\hline DOCAS & $\begin{array}{l}\text { INDÚSTRIAS DE } \\
\text { TRANSFORMAC,ÃO }\end{array}$ & \begin{tabular}{|l} 
EDIÇÃO, IMPRESSÃO E \\
REPRODUCCAOO DE GRAVACÖES
\end{tabular} & $\begin{array}{l}\text { IMPRRESSĀO E SERVIGOS CONEXOS PARA } \\
\text { TERCEROS }\end{array}$ \\
\hline DOHLER & $\begin{array}{l}\text { INDÚSTRIAS DE } \\
\text { TRANSFORMAC̆OO }\end{array}$ & $\begin{array}{l}\text { FABRICAÇÃO DE PRODUTOS } \\
\text { TERTIEIS }\end{array}$ & $\begin{array}{l}\text { TECELAGEM - INCLUSIVE FIAÇĀO E } \\
\text { TECELAGEM }\end{array}$ \\
\hline DROGASIL & $\begin{array}{l}\text { COMERCIO; REPARACAAO DE } \\
\text { VEICULOS AUTOMOTORES, } \\
\text { OBJETOS PESSOAIS E } \\
\text { DOMÉSTICOS } \\
\end{array}$ & $\begin{array}{l}\text { COMÉRCIO VAREJISTAE } \\
\text { REPARACAO DE OBJETOS } \\
\text { PESSOAIS E DOMÉSTICOS } \\
\end{array}$ & $\begin{array}{l}\text { COMÉRCIO VAREJISTA DE OUTROS } \\
\text { PRODUTOS }\end{array}$ \\
\hline DURATEX & $\begin{array}{l}\text { INDÚSTRIAS DE } \\
\text { TRANSFORMACXXO }\end{array}$ & $\begin{array}{l}\text { FABRICACÃO DE PRODUTOS DE } \\
\text { MADEIRA }\end{array}$ & $\begin{array}{l}\text { FABRICACAOO DE PRODUTOS DE MADEIRA, } \\
\text { CORTGA E MATERIAL TRANCADO- } \\
\text { EXCLUSIYE MÓVEIS }\end{array}$ \\
\hline EBE & $\begin{array}{l}\text { PRODUCAOE DISTRIBUICAOO } \\
\text { DE ELETRICIDADE, GAS E } \\
\text { AGUA } \\
\end{array}$ & $\begin{array}{l}\text { ELETRICIDADE, GAS E AGUA } \\
\text { QUENTE }\end{array}$ & $\begin{array}{l}\text { PRODUCAOO E DISTRIBUICAOO DE ENERGIA } \\
\text { ELÉTRICA }\end{array}$ \\
\hline ELDORADO & $\begin{array}{l}\text { ALOJANENTO E } \\
\text { ALIMENTAC,ÄO }\end{array}$ & ALOSAMENTO E ALIMENTAÇ̄O & $\begin{array}{l}\text { ESTABELECIMENTOS HOTELEROS E } \\
\text { OUTROS TPOS DE ALOJAMENTO } \\
\text { TEMPORARJO }\end{array}$ \\
\hline ELECTROLUX & $\begin{array}{l}\text { INDÚSTRIAS DE } \\
\text { TRANSFORMAC,ÃO }\end{array}$ & $\begin{array}{l}\text { FABRICACAZOO DE MAQQUINAS E } \\
\text { EQUIPAMENTOS }\end{array}$ & FABRICACÃO DE ELETRODOMÉSTICOS \\
\hline ELEKEIROZ & $\begin{array}{l}\text { INDÚSTRIAS DE } \\
\text { TRANSFORMAC̆AO }\end{array}$ & $\begin{array}{l}\text { FABRIGACÁO DE PRODUTOS } \\
\text { QUUlMICOS }\end{array}$ & $\begin{array}{l}\text { FABRICACARO DE PRODUTOS QUIMICOS } \\
\text { ORGÁNICOS }\end{array}$ \\
\hline ELEKTRO & $\begin{array}{l}\text { PRODUCARO E DISTRIBUICCAO } \\
\text { DE ELETRICIDADE, GAS E } \\
\text { AGUA }\end{array}$ & $\begin{array}{l}\text { ELETRICIDADE, GAS E AGUA } \\
\text { QUENTE }\end{array}$ & $\begin{array}{l}\text { PRODUCÃO E DISTRIBUIÇÃO DE ENERGIA } \\
\text { ELÉTRICA }\end{array}$ \\
\hline ELETROBRAS & $\begin{array}{l}\text { PRODUGAOE DISTRIBUICAOA } \\
\text { DE ELETRICIDADE, GAS E } \\
\text { AGUA }\end{array}$ & $\begin{array}{l}\text { ELETRICIDADE, GÁS E AGUA } \\
\text { QUENTE }\end{array}$ & $\begin{array}{l}\text { PRODUÇÃO E DISTRIBUICÅO DE ENERGIA } \\
\text { ELÉTRICA }\end{array}$ \\
\hline
\end{tabular}




\begin{tabular}{|c|c|c|c|}
\hline $\begin{array}{c}\text { Empresa } \\
\text { (Nome Pregão) }\end{array}$ & Seção & Divisão & Grupo \\
\hline ELETROPAULO & $\begin{array}{l}\text { PRODUÇAOOE DISTRIBUICÁO } \\
\text { DE ELETRICIDADE, GÁS E } \\
\text { AGUA }\end{array}$ & $\begin{array}{l}\text { ELETRICIDADE, GAS E ÁGUA } \\
\text { QUENTE }\end{array}$ & $\begin{array}{l}\text { PRODUÇÃO E DISTRIBUIÇÃO DE ENERGIA } \\
\text { ELÉTRICA }\end{array}$ \\
\hline $\begin{array}{c}\text { Empresa (Nome } \\
\text { Pregão) }\end{array}$ & Seção & Divisão & Grupo \\
\hline ELUMA & $\begin{array}{l}\text { INDÚSTRIAS DE } \\
\text { TRANSFORMAÇAO }\end{array}$ & METALURGIA BÁSICA & $\begin{array}{l}\text { METALURGIA DOS METAIS NÃO- } \\
\text { FERROSOS }\end{array}$ \\
\hline EMAE & $\begin{array}{l}\text { PRODUCCAO E DISTRIBUICCAO } \\
\text { DE ELETRICIDADE, GASE E } \\
\text { AGUAA }\end{array}$ & $\begin{array}{l}\text { ELETRICIDADE, GAS E AGUA } \\
\text { QUENTE }\end{array}$ & $\begin{array}{l}\text { CAPTAČOO, TRATAMENTO E } \\
\text { DISTRBUICARO DE AGUA }\end{array}$ \\
\hline EMBRACO & $\begin{array}{l}\text { INDÚSTRIAS DE } \\
\text { TRANSFORMAÇÃO }\end{array}$ & $\begin{array}{l}\text { FABRICACĀO DE MÁQUINAS E } \\
\text { EQUIPAMENTOS }\end{array}$ & $\begin{array}{l}\text { FABRICACAAO DE MOTORES, BOMIBAS, } \\
\text { COMPRESSORES E EQUIPAMENTOS DE } \\
\text { TRANSMISSÃOO }\end{array}$ \\
\hline EMBRAER & $\begin{array}{l}\text { INDÚSTRIAS DE } \\
\text { TRANSFORMAC,ĀO }\end{array}$ & $\begin{array}{l}\text { FABRICACAOO DE OUTROS } \\
\text { EQUIPAMENTOS DE } \\
\text { TRANSPORTE } \\
\end{array}$ & $\begin{array}{l}\text { CONSTRUÇĀO, MONTAGEM E REPARAÇÃO } \\
\text { DE AERONAVES }\end{array}$ \\
\hline EMBRATEL PAR & $\begin{array}{l}\text { TRANSPORTE, ARMAZENAGEM } \\
\text { ECOMUNICAGOES }\end{array}$ & $\begin{array}{l}\text { CORREIO E } \\
\text { TELECOMUNICACÓES }\end{array}$ & TELECOMUNICAÇOESS \\
\hline ENCORPAR & $\begin{array}{l}\text { INDÚSTRIAS DE } \\
\text { TRANSFORMACĀO } \\
\end{array}$ & $\begin{array}{l}\text { FABRICAÇÃO DE PRODUTOS } \\
\text { TÉXTEIS }\end{array}$ & $\begin{array}{l}\text { TECELAGEM - INCLUSIVE FIAÇÃO E } \\
\text { TECELAGEM }\end{array}$ \\
\hline ENERSUL & $\begin{array}{l}\text { PRODUGCAO E DISTRIBUICCAOO } \\
\text { DE ELETRICIDADE, GAS E } \\
\text { AGUA }\end{array}$ & $\begin{array}{l}\text { ELETRICIDADE, GÁS E AGUA } \\
\text { QUENTE }\end{array}$ & $\begin{array}{l}\text { PRODUCC̄̃O E DISTRIBUIÇÃO DE ENERGIA } \\
\text { ELĹETRICA }\end{array}$ \\
\hline ESCELSA & $\begin{array}{l}\text { PRODUÇÃO E DISTRIBUICCĀO } \\
\text { DE ELETRICIDADE, GAS E } \\
\text { AGUA }\end{array}$ & $\begin{array}{l}\text { ELETRICIDADE, GAS E AGUA } \\
\text { QUENTE }\end{array}$ & $\begin{array}{l}\text { PRODUÇĀO E DISTRIBUIÇÃO DE ENERGIA } \\
\text { ELÉTRRICA }\end{array}$ \\
\hline ESTRELA & $\begin{array}{l}\text { INDÚSTRIAS DE } \\
\text { TRANSFORMAÇĀO }\end{array}$ & $\begin{array}{l}\text { FABRICAÇÃO DE MÓVEESS E } \\
\text { INDÚSTRIAS DIVERSAS }\end{array}$ & FABRICAÇÃO DE PRODUTOS DIVERSOS \\
\hline ETERNIT & $\begin{array}{l}\text { INDÚSTRIAS DE } \\
\text { TRANSFORMACĀO }\end{array}$ & $\begin{array}{l}\text { FABRICACACAO DE PRODUTOS DE } \\
\text { MINERAAS NAOO-METALLICOS }\end{array}$ & $\begin{array}{l}\text { FABRICACÁAO DE ARTEFATOS DE } \\
\text { CONCRETO, CIMENTO, } \\
\text { FIBROGIMENTO,GESSO E ESTUQUE }\end{array}$ \\
\hline EUCATEX & $\begin{array}{l}\text { INDÚSTRIAS DE } \\
\text { TRANSFORMAC̆ÁO } \\
\end{array}$ & $\begin{array}{l}\text { FABRICACC̄̃O DE PRODUTOS DE } \\
\text { MADEIRA }\end{array}$ & $\begin{array}{l}\text { FABRICACAOO DE PRODUTOS DE MADEIRA, } \\
\text { CORTLA E MATERIAL TRANCAADO- } \\
\text { EXCLUSIVE MOVVEIS }\end{array}$ \\
\hline F CATAGUAZES & $\begin{array}{l}\text { PRODUÇĀO E DISTRIBUICGAOO } \\
\text { DE ELETRICIDADE, GAS E } \\
\text { AGUA }\end{array}$ & $\begin{array}{l}\text { ELETRICIDADE, GAS E AGUA } \\
\text { QUENTE }\end{array}$ & $\begin{array}{l}\text { PRODUÇÃO E DISTRIBUIÇÃO DE ENERGIA } \\
\text { ELÉTRICA }\end{array}$ \\
\hline FAB C RENAUX & $\begin{array}{l}\text { INDÚSTRIAS DE } \\
\text { TRANSFORMACAO }\end{array}$ & $\begin{array}{l}\text { FABRICAÇÃO DE PRODUTOS } \\
\text { TÉXTEIS }\end{array}$ & $\begin{array}{l}\text { TECELAGEM - INCLUSIVE FIAÇÃO E } \\
\text { TECELAGEM }\end{array}$ \\
\hline FERBASA & $\begin{array}{l}\text { INDÚSTRIAS DE } \\
\text { TRANSFORMAG,AO } \\
\end{array}$ & METALURGIA BÁSICA & SIDERURGIA \\
\hline FERTIBRAS & $\begin{array}{l}\text { INDÚSTRIAS DE } \\
\text { TRANSFORMACAOO }\end{array}$ & $\begin{array}{l}\text { FABRICACCAOO DE PRODUTOS } \\
\text { QUIMICOS }\end{array}$ & $\begin{array}{l}\text { FABRICACÃO DE PRODUTOS QUIMICOS } \\
\text { INORGANICOS }\end{array}$ \\
\hline FIBAM & $\begin{array}{l}\text { INDÚSTRIAS DE } \\
\text { TRANSFORMAÇÃO }\end{array}$ & METALURGIA BASICA & SIDERURGIA \\
\hline FORJA TAURUS & $\begin{array}{l}\text { INDÚSTRIAS DE } \\
\text { TRANSFORMAG,ÃO }\end{array}$ & $\begin{array}{l}\text { FABRICACARO DE MAQUINAS E } \\
\text { EQUIPAMENTOS }\end{array}$ & $\begin{array}{l}\text { FABRICACĀO DE ARMAS, MUNIÇŐES E } \\
\text { EQUIPAMENTOS MILITARES }\end{array}$ \\
\hline FOSFERTIL & $\begin{array}{l}\text { INDÚSTRIAS DE } \\
\text { TRANSFORMAÇĀO }\end{array}$ & $\begin{array}{l}\text { FABRICAÇÃO DE PRODUTOS } \\
\text { QÚMICOS }\end{array}$ & $\begin{array}{l}\text { FABRICACÃO DE PRODUTOS OUIMICOS } \\
\text { INORGANICOS }\end{array}$ \\
\hline FRAS-LE & $\begin{array}{l}\text { INDÚSTRIAS DE } \\
\text { TRANSFORMAĢÃO }\end{array}$ & $\begin{array}{l}\text { FABRICACCÁO E MONTAGEM DE } \\
\text { VEICULOS } \\
\text { AUTOMOTORES,REBOQUES E } \\
\text { CARROCERIAS }\end{array}$ & $\begin{array}{l}\text { FABRICACCAOO DE PECAS E ACESSORIOS } \\
\text { PARA VEICULOS AUTOMOTORES }\end{array}$ \\
\hline GAZOLA & $\begin{array}{l}\text { INDÚSTRIAS DE } \\
\text { TRANSFIRMAC̆ÄO }\end{array}$ & $\begin{array}{l}\text { FABRICACAODE PRODUTOS DE } \\
\text { METAL - EXCETO MAQUINAS E } \\
\text { EQUIPAMENTOS } \\
\end{array}$ & $\begin{array}{l}\text { FABRICACGAO DE ARTIGOS DE CUTELARIA, } \\
\text { DE SERRALHERIA E FERRAMENTAS } \\
\text { MANUAS }\end{array}$ \\
\hline GER PARANAP & $\begin{array}{l}\text { PRODUĢÅO E DISTRIBUICCAO } \\
\text { DE ELETRICIDADE, GAS E } \\
\text { AGUA }\end{array}$ & $\begin{array}{l}\text { ELETRICIDADE, GÁS E AGUA } \\
\text { QUENTE }\end{array}$ & $\begin{array}{l}\text { PRODUÇÃO E DISTRIBUIÇÃO DE ENERGIA } \\
\text { ELÉTRICA }\end{array}$ \\
\hline GERDAU & $\begin{array}{l}\text { INDÚSTRIAS DE } \\
\text { TRANSFORMAGĀO }\end{array}$ & METALURGIA BÁSICA & SIDERURGIA \\
\hline GERDAU MET & $\begin{array}{l}\text { INDÚSTRLAS DE } \\
\text { TRANSFORMACAO } \\
\text { COMERCIO; REPARACÁODEE }\end{array}$ & METALURGIA BÁSICA & SIDERURGIA \\
\hline GLOBEX & $\begin{array}{l}\text { COMERCIO; REPARACAAO DE } \\
\text { VEICULOS AUTOMOTORES, } \\
\text { OBJETOS PESSOAS E } \\
\text { DOMESTICOS } \\
\end{array}$ & $\begin{array}{l}\text { COMÉRCIO VAREJISTAE } \\
\text { REPARACÃO DE OBJETOS } \\
\text { PESSOAIS EOMÉSTICOS } \\
\end{array}$ & $\begin{array}{l}\text { COMÉRCIO VAREJISTA DE OUTROS } \\
\text { PRODUTOS }\end{array}$ \\
\hline GPC PART & $\begin{array}{l}\text { INDÚSTRIAS DE } \\
\text { TRANSFORMAC,ÃO }\end{array}$ & $\begin{array}{l}\text { FABRICAÇĂO DE PRODUTOS } \\
\text { QUIMICOS }\end{array}$ & $\begin{array}{l}\text { FABRICAÇẢO DE PRODUTOS QUIMICOS } \\
\text { ORGÁNICOS }\end{array}$ \\
\hline GRADIENTE & $\begin{array}{l}\text { INDUSSTRIAS DE } \\
\text { TRANSFORMAC,AOO }\end{array}$ & $\begin{array}{l}\text { FABRICACAX̃O DE MÁQUINAS E } \\
\text { EQUIPAMENTOS }\end{array}$ & FABRICAÇĀO DE ELETRODOMÉSTICOS \\
\hline GRANOLEO & $\begin{array}{l}\text { INDÚSTRIAS DE } \\
\text { TRANSFORMAC̆̊AO }\end{array}$ & $\begin{array}{l}\text { FABRICACĀAO DE PRODUTOS } \\
\text { ALIMENTICIOS E BEBIDAS }\end{array}$ & $\begin{array}{l}\text { PRODUCAZO DE OLEOS E GORDURAS } \\
\text { VEGETAS E ANIMANS } \\
\end{array}$ \\
\hline GRAZZIOTIN & $\begin{array}{l}\text { COMERCIO; REPARAÇAO DE } \\
\text { VÉCULOS AUTOMOTORES, } \\
\text { OBJETOS PESSOAIS E } \\
\text { DOMÉSTICOS } \\
\text { COMERCIO: REPARACAOODE }\end{array}$ & $\begin{array}{l}\text { COMÉRCIO VAREJISTA E } \\
\text { REPARACAO DE OBJETOS } \\
\text { PESSOAIS E DOMÉSTICOS }\end{array}$ & $\begin{array}{l}\text { COMÉRCIO VAREJISTA DE OUTROS } \\
\text { PRODUTOS }\end{array}$ \\
\hline GUARARAPES & $\begin{array}{l}\text { COMGERCIO; REPARACÁAO DE } \\
\text { VEICULOS AUTOMOTORES, } \\
\text { OBJETOS PESSOAIS E } \\
\text { DOMÉSTICOS }\end{array}$ & $\begin{array}{l}\text { COMÉRCIO VAREJISTAE } \\
\text { REPARACAOO DE OBJETOS } \\
\text { PESSOAS E DOMÉSTICOS }\end{array}$ & $\begin{array}{l}\text { COMERCIO VAREJISTA DE TECIDOS, } \\
\text { ARTIGOS DE ARMARINHO, VESTUARIO, } \\
\text { CALCADOS }\end{array}$ \\
\hline HOTEIS OTHON & $\begin{array}{l}\text { ALOJAMENTOE E } \\
\text { ALIMENTACAAO }\end{array}$ & ALOSAMENTO E ALIMENTACC̄OO & $\begin{array}{l}\text { ESTABELECIMENTOS HOTELEIROS E } \\
\text { OUTROS TIPOS DE ALOJAMENTO } \\
\text { TEMPORARIO }\end{array}$ \\
\hline IGUACU CAFE & $\begin{array}{l}\text { INDÚSTRIAS DE } \\
\text { TRANSFORMAČAOO }\end{array}$ & $\begin{array}{l}\text { FABRICACAZOO DE PRODUTOS } \\
\text { ALIMENTICIOS E BEBIDAS }\end{array}$ & TORRAFAC,ÃO E MOAGEM DE CAFE \\
\hline
\end{tabular}




\begin{tabular}{|c|c|c|c|}
\hline $\begin{array}{c}\text { Empresa } \\
\text { (Nome Pregão) }\end{array}$ & Seção & Divisão & Grupo \\
\hline INDS ROMI & $\begin{array}{l}\text { INDÚSTRIAS DE } \\
\text { TRANSFORMACAOO }\end{array}$ & $\begin{array}{l}\text { FABRICACĂO DE MÁQUINAS E } \\
\text { EQUIPAMENTOS }\end{array}$ & $\begin{array}{l}\text { FABRICACAOO DE MÁQUUINAS E } \\
\text { EQUIPAMENTOS DE USO GERAL }\end{array}$ \\
\hline INEPAR & $\begin{array}{l}\text { INDÚSTRIAS DE } \\
\text { TRANSFORMAÇAO } \\
\end{array}$ & $\begin{array}{l}\text { FABRICACAZO DE MAQUINAS E } \\
\text { EQUIPAMENTOS }\end{array}$ & $\begin{array}{l}\text { FABRICACAAO DE MAQUUINAS E } \\
\text { EQUIPAMENTOS DE USOS NA EXTRAÇAO } \\
\text { MINERAL E CONSTRUACAOO }\end{array}$ \\
\hline $\begin{array}{l}\text { Empresa (Nome } \\
\text { Pregão) }\end{array}$ & Seção & Divisão & Grupo \\
\hline IOCHP-MAXION & $\begin{array}{l}\text { INDÚSTRIAS DE } \\
\text { TRANSFORMAÇAOO } \\
\end{array}$ & $\begin{array}{l}\text { FABRICACAAO E MONTAGEM DE } \\
\text { VEICULOS } \\
\text { AUTOMOTORES, REBOQUUS E } \\
\text { CARROCERIAS }\end{array}$ & $\begin{array}{l}\text { FABRICACÃO DE PECAS E ACESSORIOS } \\
\text { PARA VEICULOS }\end{array}$ \\
\hline IPIRANGA DIS & $\begin{array}{l}\text { COMERCIO; REPARACAO DE } \\
\text { VEICULOS AUTOMOTORES, } \\
\text { OBJETOS PESSOAIS E } \\
\text { DOMESTICOS }\end{array}$ & $\begin{array}{l}\text { COMÉRCIO POR ATACADO, } \\
\text { REPRESENTANTES COMERCIAIS } \\
\text { EAGENTES DO COMÉRCIO }\end{array}$ & $\begin{array}{l}\text { COMERCIOATACADISTA DE PRODUTOS } \\
\text { INTERMEDIARIOS } \\
\text { NAROAGROPECUARIOS,RESIDUOS E } \\
\text { SUCATAS }\end{array}$ \\
\hline IPIRANGA PET & $\begin{array}{l}\text { COMERCIO; REPARACAOD DE } \\
\text { VEECULOS AUTOMOTORES, } \\
\text { OBNEOS PESSOAS E } \\
\text { DOMESTICOS } \\
\end{array}$ & $\begin{array}{l}\text { COMERCIO POR ATACADO, } \\
\text { REPRESENTANTES COMERCIAIS } \\
\text { EAGENTES DO COMERECIO }\end{array}$ & $\begin{array}{l}\text { COMERCIOATACADISTA DE PRODUTOS } \\
\text { INTERMEDIARIOS } \\
\text { NAOOAGROPECUAAIOS,RESIDUOS E } \\
\text { SUCATAS }\end{array}$ \\
\hline IPIRANGA REF & $\begin{array}{l}\text { INDÚSTRIAS DE } \\
\text { TRANSFORMAÇĀO }\end{array}$ & $\begin{array}{l}\text { FABRICACÁ DE COQUE, } \\
\text { REFINO DE PETROLEO, } \\
\text { ELABORAGAO DE } \\
\text { COMBUSTIVEIS NUCLEARES E } \\
\text { PRODUCAAO DE ALCOOL } \\
\end{array}$ & $\begin{array}{l}\text { FABRICACAOO DE PRODUTOS DERIVADOS } \\
\text { DO PETROLEO }\end{array}$ \\
\hline ITAUTEC & $\begin{array}{l}\text { INDÚSTRIAS DE } \\
\text { TRANSFORMAC̆AO }\end{array}$ & $\begin{array}{l}\text { FABRCACÁOD DE MAQUINAS } \\
\text { PARA ESCRITORIO E } \\
\text { EQUIPAMENTOS DE } \\
\text { INFORMÁTICA }\end{array}$ & $\begin{array}{l}\text { FABRICACAO DE MAQUINASE } \\
\text { EQUIPAMENTOS DE SISTEMAS } \\
\text { ELERRONICOS PARA PROCESSAMENTO DE } \\
\text { DADOS }\end{array}$ \\
\hline IVEN & $\begin{array}{l}\text { PRODUCGAOOE DISTRIBUICÁOO } \\
\text { DE ELETRICIDADE, GÁS E } \\
\text { AGUA }\end{array}$ & $\begin{array}{l}\text { ELETRICIDADE, GAS E AGUA } \\
\text { QUENTE }\end{array}$ & $\begin{array}{l}\text { PRODUÇÃO E DISTRIBUIÇÃO DE ENERGIA } \\
\text { ELÉTRICA }\end{array}$ \\
\hline J B DUARTE & $\begin{array}{l}\text { INDÚSTRIAS DE } \\
\text { TRANSFORMACAOO }\end{array}$ & $\begin{array}{l}\text { FABRICACAOO DE PRODUTOS } \\
\text { ALIMENTICIOS E EEBIDAS } \\
\end{array}$ & $\begin{array}{l}\text { PRODUCAOO DE OLEOS E GORDURAS } \\
\text { VEGETASS EANIMASS }\end{array}$ \\
\hline JOAO FORTES & CONSTRUÇÃO & CONSTRUÇĂO & $\begin{array}{l}\text { construģáo DE EDIFICIOS E OBRAS DE } \\
\text { ENGENHARIA GIVIL }\end{array}$ \\
\hline KARSTEN & $\begin{array}{l}\text { INDÚSTRIAS DE } \\
\text { TRANSFORMACÄOO }\end{array}$ & $\begin{array}{l}\text { FABRICAGÃO DE PRODUTOS } \\
\text { IEXTEIS }\end{array}$ & $\begin{array}{l}\text { TECELAGEM - INCLUSIVE FIACÃO E } \\
\text { TECELAGEM }\end{array}$ \\
\hline KEPLER WEBER & $\begin{array}{l}\text { INDÚSTRIAS DE } \\
\text { TRANSFORMAG,ÃO }\end{array}$ & $\begin{array}{l}\text { FABRICACCÃO DE MAQUINAS E } \\
\text { EQUIPAMENTOS }\end{array}$ & $\begin{array}{l}\text { FABRICAÇÃO DE MÁQQUINAS E } \\
\text { EQUIPAMENTOS DE USO GERAL }\end{array}$ \\
\hline KLABIN S/A & $\begin{array}{l}\text { INDÚSTRIAS DE } \\
\text { TRANSFORMAÇÃO } \\
\end{array}$ & $\begin{array}{l}\text { FABRICACAOO DE CELULOSE, } \\
\text { PAPEL E PRODUTOS DE PAPEL } \\
\end{array}$ & $\begin{array}{l}\text { FABRICAÇÃO DE CELULOSE E OUTRAS } \\
\text { PASTAS PARA A FABRICACAOO DE PAPEL }\end{array}$ \\
\hline LA FONTE PAR & $\begin{array}{l}\text { TRANSPORTE, ARMAZENAGEM } \\
\text { ECOMUNICACOES }\end{array}$ & $\begin{array}{l}\text { CORREIOE } \\
\text { TELECOMUNICACÓES } \\
\end{array}$ & TELECOMUNICACÓES \\
\hline LA FONTE TEL & $\begin{array}{l}\text { TRANSPORTE, ARMAZENAGEM } \\
\text { E COMUNICACOCOES }\end{array}$ & $\begin{array}{l}\text { CORREIO E } \\
\text { TELECOMUNICAÇOESS }\end{array}$ & TELECOMUNICACCỎES \\
\hline LECO & $\begin{array}{l}\text { INDÚSTRIAS DE } \\
\text { TRANSFORMACAOO }\end{array}$ & $\begin{array}{l}\text { FABRICACĀO DE PRODUTOS } \\
\text { ALIMENTICIOS E BEBIDAS }\end{array}$ & $\begin{array}{l}\text { PRODUCAOO DE OLEOS E GORDURAS } \\
\text { VEGETASS EANIMAIS }\end{array}$ \\
\hline LF TEL & $\begin{array}{l}\text { TRANSPORTE, ARMAZENAGEM } \\
\text { ECOMUNICACOCES }\end{array}$ & $\begin{array}{l}\text { CORREIOE } \\
\text { TELECOMUNICACODES } \\
\end{array}$ & TELECOMUNICAÇŌES \\
\hline LIGHT & $\begin{array}{l}\text { PRODUUCAOO E DISTRIBUICÁAO } \\
\text { DE ELETRICIDADE, GAS E } \\
\text { AGUA }\end{array}$ & $\begin{array}{l}\text { ELETRICIDADE, GAS E AGUA } \\
\text { QUENTE }\end{array}$ & $\begin{array}{l}\text { PRODUÇÃO E DISTRIBUIÇ̊̃O DE ENERGIA } \\
\text { ELÉTRICA }\end{array}$ \\
\hline LIX DA CUNHA & CONSTRUCCĀO & CONSTRUCĀAO & $\begin{array}{l}\text { CONSTRUÇÃO DE EDIFICIOS E OBRAS DE } \\
\text { ENGENHARIA CIVIL }\end{array}$ \\
\hline LOJAS AMERIC & $\begin{array}{l}\text { COMGERCIO; REPARAGAO DE } \\
\text { VEICULOS AUTOMOTORES, } \\
\text { OBETOS PESSOAIS E } \\
\text { DOMESTICOS } \\
\end{array}$ & $\begin{array}{l}\text { COMÉRCIO VAREJISTA E } \\
\text { REPARACAO DE OBJETOS } \\
\text { PESSOAS E DOMESTIICOS }\end{array}$ & $\begin{array}{l}\text { COMÉRCIO VAREJISTA DE OUTROS } \\
\text { PRODUTOS }\end{array}$ \\
\hline LOJAS HERING & $\begin{array}{l}\text { COMERGIO; REPARACAOODE } \\
\text { VEICULOS AUTOMOTORES, } \\
\text { OBNETOS PESSOAIS E } \\
\text { DOMESTICOS }\end{array}$ & $\begin{array}{l}\text { COMÉRCIO VAREJISTAE } \\
\text { REPARACAO DE OBJETOS } \\
\text { PESSOAS E DOMESTICOS } \\
\end{array}$ & $\begin{array}{l}\text { COMÉRCIO VAREJISTA DE TECIDOS, } \\
\text { ARTIGOS DE ARMARINHO, VESTUARIO, } \\
\text { CALCADOS }\end{array}$ \\
\hline LOJAS RENNER & $\begin{array}{l}\text { COMERGIO; REPARACAO DE } \\
\text { VEICULOS AUTOMOTORES, } \\
\text { OBJETOS PESSOASE } \\
\text { DOMESTICOS }\end{array}$ & $\begin{array}{l}\text { COMÉRCIO VAREJISTAE } \\
\text { REPARACAO DE OBJETOS } \\
\text { PESSOAS E DOMESTICOS } \\
\end{array}$ & $\begin{array}{l}\text { COMÉRCIO VAREJISTA DE TECIDOS, } \\
\text { ARTIGOS DE ARMARINHO, VESTUARIO, } \\
\text { CALCADOS }\end{array}$ \\
\hline MAGNESITA & $\begin{array}{l}\text { INDÚSTRIAS DE } \\
\text { TRANSFORMAC,̃O } \\
\end{array}$ & $\begin{array}{l}\text { FABRICAGAOO DE PRODUTOS DE } \\
\text { MINERAIS NAO-METALICOS } \\
\end{array}$ & FABRICACÃO DE PRODUTOS CERÁMICOS \\
\hline MANASA & $\begin{array}{l}\text { INDÚSTRIAS DE } \\
\text { TRANSFORMAÇÃO }\end{array}$ & $\begin{array}{l}\text { FABRICAÇÃO DE PRODUTOS DE } \\
\text { MADEIRA }\end{array}$ & $\begin{array}{l}\text { FABRICACGAO DE PRODUTOS DE MADEIRA, } \\
\text { CORTLAE MATERIAL TRANGADO- } \\
\text { EXCLUSIVE MOVEIS }\end{array}$ \\
\hline MANGELS INDL & $\begin{array}{l}\text { INDÚSTRIAS DE } \\
\text { TRANSFORMACÃO }\end{array}$ & METALURGIA BASICA & SIDERURGIA \\
\hline MARCOPOLO & $\begin{array}{l}\text { INDÚSTRIAS DE } \\
\text { TRANSFORMAC,AO }\end{array}$ & $\begin{array}{l}\text { FABRCACÁ E MONTAGEM DE } \\
\text { VEICULOS } \\
\text { AUTOMOTORES, REBOQUES E } \\
\text { CARROCERAAS }\end{array}$ & $\begin{array}{l}\text { FABRICACÃO DE CABINES, CARROCERIAS } \\
\text { EREBOQUES }\end{array}$ \\
\hline MARISOL & $\begin{array}{l}\text { INDÚSTRIAS DE } \\
\text { IRANSFORMACAOO }\end{array}$ & $\begin{array}{l}\text { CONFECCAO DE ARTICOS DO } \\
\text { VESTUAARO E ACESSORIOS } \\
\end{array}$ & $\begin{array}{l}\text { CONFECCAO DE ARTIGOS DO VESTUARIO } \\
\text { EACESSORIOS }\end{array}$ \\
\hline MELPAPER & $\begin{array}{l}\text { INDÚSTRIAS DE } \\
\text { TRANSFORMACAO }\end{array}$ & $\begin{array}{l}\text { FABRICACAXO DE CELULOSE, } \\
\text { PAPEL E PRODUTOS DE PAPEL } \\
\end{array}$ & $\begin{array}{l}\text { FABRICACAOO DE CELULOSE E OUTRAS } \\
\text { PASTAS PARA A FABRICACAOO DE PAPEL }\end{array}$ \\
\hline MENDES JR & CONSTRUCÅOO & CONSTRUC,ÃO & $\begin{array}{l}\text { construçä DE EDIFicIOS E OBRAS DE } \\
\text { ENGENHARIA CIVIL }\end{array}$ \\
\hline MET DUQUE & $\begin{array}{l}\text { INDÚSTRIAS DE } \\
\text { TRANSFORMACĀO }\end{array}$ & METALURGIA BASICA & SIDERURGIA \\
\hline
\end{tabular}




\begin{tabular}{|c|c|c|c|}
\hline $\begin{array}{c}\text { Empresa } \\
\text { (Nome Pregão) }\end{array}$ & Seção & Divisão & Grupo \\
\hline METAL LEVE & $\begin{array}{l}\text { INDÚSTRIAS DE } \\
\text { TRANSFORMAÇÃO }\end{array}$ & $\begin{array}{l}\text { FABRICACÁAO E MONTAGEM DE } \\
\text { VEICULOS } \\
\text { AUTOMOTORES,REBOQUUES E } \\
\text { GARROCERIAS }\end{array}$ & $\begin{array}{l}\text { FABRICACARO DE PECAS E ACESSÓRIOS } \\
\text { PARA VEICULOS AUTOMOTORES } \\
\end{array}$ \\
\hline METISA & $\begin{array}{l}\text { INDÚSTRIAS DE } \\
\text { TRANSFORMAÇAOO }\end{array}$ & METALURGIA BÁSICA & SIDERURGIA \\
\hline MICHELETTO & $\begin{array}{l}\text { INDÚSTRIAS DE } \\
\text { TRANSFORMACAXO } \\
\end{array}$ & METALURGIA BÁSICA & SIDERURGIA \\
\hline $\begin{array}{l}\text { Empresa (Nome } \\
\text { Pregão) }\end{array}$ & Seção & Divisão & Grupo \\
\hline MILLENNIUM & $\begin{array}{l}\text { INDÚSTRIAS DE } \\
\text { TRANSFORMAČAOO } \\
\end{array}$ & $\begin{array}{l}\text { FABRICAÇAOA DE PRODUTOS } \\
\text { QUIMICOS } \\
\end{array}$ & $\begin{array}{l}\text { FABRICACAAO DE PRODUTOS QUIMICOS } \\
\text { ORGANICOS }\end{array}$ \\
\hline MULTIBRAS & $\begin{array}{l}\text { INDÚSTRIAS DE } \\
\text { TRANSFORMAČÃO } \\
\end{array}$ & $\begin{array}{l}\text { FABRICAÇÃO DE MAQQUINAS E } \\
\text { EQUIPAMENTOS }\end{array}$ & FABRICACĂO DE ELETRODOMÉSTICOS \\
\hline NADIR FIGUEI & $\begin{array}{l}\text { INDÜSTRIAS DE } \\
\text { TRANSFORMAC̆OOO } \\
\text { COMERCIO; REPARACAOODE }\end{array}$ & $\begin{array}{l}\text { FABRICAÇÃO DE PRODUTOS DE } \\
\text { MINERAAS NAOO-METÁLICOS } \\
\end{array}$ & $\begin{array}{l}\text { FABRICAÇĀO DE VIDRO E DE PRODUTOS } \\
\text { DO VIDRO }\end{array}$ \\
\hline P.ACUCAR-CBD & $\begin{array}{l}\text { COMERCIO; RRPARACAO DE } \\
\text { VEICUULOS AUTOMOTORES, } \\
\text { OBJETOS PESSOAIS E } \\
\text { DOMÉSTICOS } \\
\end{array}$ & $\begin{array}{l}\text { COMÉRCIO VAREJISTAE } \\
\text { REPARAGÃO DE OBJEIOS } \\
\text { PESSOAS E DOMÉSTICOS } \\
\end{array}$ & $\begin{array}{l}\text { COMÉRCIO VAREJISTA NÃO } \\
\text { ESPECLALIZADO }\end{array}$ \\
\hline $\begin{array}{l}\text { PARANAPANEM } \\
\text { A }\end{array}$ & \begin{tabular}{|l|} 
INDÚSTRIAS DE \\
TRANSFORMAÇAOO \\
\end{tabular} & METALURGIA BÁSICA & SIDERURGIA \\
\hline PARMALAT & \begin{tabular}{|l|} 
INDÚSTRIAS DE \\
TRANSFORMACÃO \\
PRODUCAOOE DISTRIBU
\end{tabular} & $\begin{array}{l}\text { FABRICACÃO DE PRODUTOS } \\
\text { ALIMENTICIOS E BEBIDAS } \\
\end{array}$ & LATICINIOS \\
\hline PAUL F LUZ & $\begin{array}{l}\text { DE ELETRICIDADE, GAS E } \\
\text { AGUA } \\
\end{array}$ & $\begin{array}{l}\text { ELETRICIDADE, GAS E AGUA } \\
\text { QUENTE }\end{array}$ & $\begin{array}{l}\text { PRODUÇĀO E DISTRIBUIÇÃO DE ENERGIA } \\
\text { ELÉETRICA }\end{array}$ \\
\hline PERDIGAO S/A & \begin{tabular}{|l} 
INDÚSTRIAS DE \\
TRANSFORMACXAO \\
\end{tabular} & $\begin{array}{l}\text { FABRICACX̃O DE PRODUTOS } \\
\text { ALIMENTIGIOS E BEBIDAS } \\
\text { FABRICACAO DEE COIIS }\end{array}$ & $\begin{array}{l}\text { ABATE E PREPAARACAOA DE PRODUTOS DE } \\
\text { CARNEE DE PESCADO }\end{array}$ \\
\hline PET MANGUINH & $\begin{array}{l}\text { INDÚSTRIAS DE } \\
\text { TRANSFORMAC̆ĀO } \\
\end{array}$ & \begin{tabular}{|l|} 
FABRICACGAO DE COQUE, \\
REFINO OE PETROLLEO, \\
ELABORAGAO DE \\
COMBUSTIVEIS NUCLEARES E \\
PRODUCAOO DE ALCOOLL \\
FABRICACABO DE COOLE \\
\end{tabular} & $\begin{array}{l}\text { FABRICACÃO DE PRODUTOS DERIVADOS } \\
\text { DO PETROLLEO }\end{array}$ \\
\hline PETROBRAS & $\begin{array}{l}\text { INDÚSTRIAS DE } \\
\text { TRANSFORMAÇĀO } \\
\end{array}$ & $\begin{array}{l}\text { FABRICACAAO DE COQUE, } \\
\text { REFINO DE PETRÓLEO, } \\
\text { ELABORACAO DE } \\
\text { COMBUSTIVEIS NUCLEARES E } \\
\text { PRODUCGAO DE ALCOOL } \\
\end{array}$ & $\begin{array}{l}\text { FABRICACCÃO DE PRODUTOS DERIVADOS } \\
\text { DO PETROLLO }\end{array}$ \\
\hline PETROFLEX & $\begin{array}{l}\text { INDÚSTRIAS DE } \\
\text { TRANSFORMACAOAO }\end{array}$ & $\begin{array}{l}\text { FABRICACCĀO DE PRODUTOS } \\
\text { QUIMICOS }\end{array}$ & $\begin{array}{l}\text { FABRICACCÃO DE PRODUTOS QUIMICOS } \\
\text { ORGÁNICOS }\end{array}$ \\
\hline PETROPAR & $\begin{array}{l}\text { INDÚSTRIAS DE } \\
\text { TRANSFORMAÇĀO } \\
\end{array}$ & $\begin{array}{l}\text { FABRICACAXO DE CELULOSE, } \\
\text { PAPEL E PRODUTTOS DE PAPEL }\end{array}$ & $\begin{array}{l}\text { FABRICACĀO DE EMBALAGENS DE PAPEL } \\
\text { OU PAPELAO }\end{array}$ \\
\hline PETROQ UNIAO & $\begin{array}{l}\text { INDÚSTRIAS DE } \\
\text { TRANSFORMAÇAOO }\end{array}$ & $\begin{array}{l}\text { FABRICAÇĀO DE PRODUTOS } \\
\text { QUIMICOS }\end{array}$ & $\begin{array}{l}\text { FABRICACAZAO DE PRODUTOS QUIMICOS } \\
\text { ORGÁNICOS }\end{array}$ \\
\hline PETTENATI & $\begin{array}{l}\text { INDÚSTRIAS DE } \\
\text { TRANSFORMAÇÄO } \\
\end{array}$ & $\begin{array}{l}\text { FABRICACGAOO DE PRODUTOS } \\
\text { TEXTEIS }\end{array}$ & $\begin{array}{l}\text { TECELAGEM - INCLUSIVE FIAGĀO E } \\
\text { TECELAGEM }\end{array}$ \\
\hline PLASCAR PART & $\begin{array}{l}\text { INDÚSTRIAS DE } \\
\text { TRANSFORMAC,ÃO }\end{array}$ & $\begin{array}{l}\text { FABRICACCAO E MONTAGEM DE } \\
\text { VEICULOS } \\
\text { AUTOMOTORES,REBOQUES E } \\
\text { CARROCERIAS }\end{array}$ & $\begin{array}{l}\text { FABRICAÇÃO DE PECAS E ACESSÓRIOS } \\
\text { PARA VEICULOS AUTOMOTORES }\end{array}$ \\
\hline POLIALDEN & $\begin{array}{l}\text { INDÚSTRIAS DE } \\
\text { TRANSFORMAČAO }\end{array}$ & REBOQUES E CARROCERIAS & AUTOMOTORES \\
\hline POLIPROPILEN & $\begin{array}{l}\text { INDÚSTRIAS DE } \\
\text { TRANSFORMAGĀO }\end{array}$ & $\begin{array}{l}\text { FABRICAGÃO DE PRODUTOS } \\
\text { QUIMICOS }\end{array}$ & $\begin{array}{l}\text { FABRICACADO DE RESINAS E } \\
\text { ELASTOMIEROS }\end{array}$ \\
\hline POLITENO & $\begin{array}{l}\text { INDÚSTRIAS DE } \\
\text { TRANSFORMACAOO }\end{array}$ & $\begin{array}{l}\text { FABRICAÇÃO DE PRODUTOS } \\
\text { QUIMICOS }\end{array}$ & $\begin{array}{l}\text { FABRICACGÃO DE RESINAS E } \\
\text { ELASTÓMEROS }\end{array}$ \\
\hline PORTOBELLO & $\begin{array}{l}\text { INDÚSTRIAS DE } \\
\text { TRANSFORMACAAO } \\
\end{array}$ & $\begin{array}{l}\text { FABRICAÇAO DE PRODUTOS DE } \\
\text { MINERAIS NAO-METALLICOS } \\
\end{array}$ & FABRICAÇÃO DE PRODUTOS CERÁMICOS \\
\hline PRONOR & $\begin{array}{l}\text { INDÚSTRIAS DE } \\
\text { TRANSFORMAÇĀO }\end{array}$ & $\begin{array}{l}\text { FABRICACCAO DE PRODUTOS } \\
\text { QUUMICOS }\end{array}$ & $\begin{array}{l}\text { FABRICAÇĀO DE PRODUTOS QUIMICOS } \\
\text { ORGANICOS }\end{array}$ \\
\hline RANDON PART & $\begin{array}{l}\text { INDÚSTRIAS DE } \\
\text { TRANSFORMAÇÃO } \\
\end{array}$ & $\begin{array}{l}\text { FABRICACAAO E MONTAGEM DE } \\
\text { VEICULOS } \\
\text { AUTOMOTORES,REBOQUES E } \\
\text { CARROCERIAS }\end{array}$ & $\begin{array}{l}\text { FABRICACÃO DE PECAS E ACESSÓRIOS } \\
\text { PARA VEICULOS AUTOMOTORES }\end{array}$ \\
\hline RASIP AGRO & $\begin{array}{l}\text { INDÚSTRIAS DE } \\
\text { TRANSFORMAC,AOO }\end{array}$ & $\begin{array}{l}\text { FABRICACĀO DE PRODUTOS } \\
\text { ALIMENTICIOS E BEBIDAS }\end{array}$ & $\begin{array}{l}\text { FABRICACAOO DE OUTROS PRODUTOS } \\
\text { ALIMENTICIOS } \\
\end{array}$ \\
\hline RECRUSUL & $\begin{array}{l}\text { INDÚSTRIAS DE } \\
\text { TRANSFORMAC,ĀO }\end{array}$ & $\begin{array}{l}\text { FABRICACAO E MONTAGEM DE } \\
\text { VEICULOS } \\
\text { AUTOMOTORES,REBOQUES E } \\
\text { CARROCERIAS }\end{array}$ & $\begin{array}{l}\text { FABRICACAOO DE CABINES, CARROCERIAS } \\
\text { EREBOQUES }\end{array}$ \\
\hline RHODIA-STER & $\begin{array}{l}\text { INDÚSTRIAS DE } \\
\text { TRANSFORMACĀO } \\
\end{array}$ & $\begin{array}{l}\text { FABRICAÇÃO DE PRODUTOS } \\
\text { QUIMICOS }\end{array}$ & $\begin{array}{l}\text { FABRICACĀO DE PRODUTOS QUIMICOS } \\
\text { ORGANICOS }\end{array}$ \\
\hline RIO GDE ENER & $\begin{array}{l}\text { PRODUCAOA EDISTRIBUICCAOO } \\
\text { DE ELETRICIDADE, GAS E } \\
\text { AGUA } \\
\end{array}$ & $\begin{array}{l}\text { ELETRICIDADE, GÁS E AGUA } \\
\text { QUENTE }\end{array}$ & $\begin{array}{l}\text { PRODUÇÃO E DISTRIBUIÇÃO DE ENERGLA } \\
\text { ELÉTRICA }\end{array}$ \\
\hline RIOSULENSE & $\begin{array}{l}\text { INDÚSTRIAS DE } \\
\text { TRANSFORMAÇÃO }\end{array}$ & $\begin{array}{l}\text { FABRICACCĀO E MONTAGEM DE } \\
\text { VEECULOS } \\
\text { AUTOMOTORES,REBOQUES E } \\
\text { CARROCERIAS } \\
\end{array}$ & $\begin{array}{l}\text { FABRICACCAOO DE PECAS E ACESSÓRIOS } \\
\text { PARA VEICULOS AUTOMOTORES }\end{array}$ \\
\hline RIPASA & $\begin{array}{l}\text { INDÚSTRIAS DE } \\
\text { TRANSFORMAGAXO }\end{array}$ & $\begin{array}{l}\text { FABRICACÁO DE CELULOSE, } \\
\text { PAPEL E PRODUTOS DE PAPEL }\end{array}$ & $\begin{array}{l}\text { FABRICAÇĀO DE CELULOSE E OUTRAS } \\
\text { PASTAS PARA A FABRICAC,ĀO DE PAPEL }\end{array}$ \\
\hline
\end{tabular}




\begin{tabular}{|c|c|c|c|}
\hline $\begin{array}{c}\text { Empresa } \\
\text { (Nome Pregão) }\end{array}$ & Seção & Divisão & Grupo \\
\hline ROSSI RESID & CONSTRUCGĀO & CONSTRUC,AO & $\begin{array}{l}\text { construghia DE EDIFICIOS E OBRAS DE } \\
\text { ENGENHARIA CIVL }\end{array}$ \\
\hline SABESP & $\begin{array}{l}\text { PRODUGAOO E DISTRIBUICAAO } \\
\text { DE ELLTRICIDADE, GAS E } \\
\text { AGUA }\end{array}$ & $\begin{array}{l}\text { CAPTACÃO, TRATAMENTO E } \\
\text { DISTRIBUICACAO DE AGUA }\end{array}$ & $\begin{array}{l}\text { CAPTACAOO, TRATAMENTO E } \\
\text { DISTRIBUICGAO DE AGUA }\end{array}$ \\
\hline SADIA S/A & \begin{tabular}{|l|} 
INDÚSTRIAS DE \\
TRANSFORMAG,ĀO \\
\end{tabular} & $\begin{array}{l}\text { FABRICACÁOO DE PRODUTOS } \\
\text { ALIMENTIGIOS E BEBIDAS }\end{array}$ & $\begin{array}{l}\text { ABATE E PREPARACĀO DE PRODUTOS DE } \\
\text { CARNE E DE PESCADO }\end{array}$ \\
\hline SANSUY & $\begin{array}{l}\text { INDÚSTRIAS DE } \\
\text { TRANSFORMACXAO }\end{array}$ & $\begin{array}{l}\text { FABRICACA AO DE ARTIGOS DE } \\
\text { BORRACHA E MATERIAL } \\
\text { PLASTICO }\end{array}$ & $\begin{array}{l}\text { FABRICAÇÃO DE PRODUTOS DE MATERIAL } \\
\text { PLASTICO }\end{array}$ \\
\hline SANTANENSE & $\begin{array}{l}\text { INDUSTRIAS DE } \\
\text { TRANSFORMAÇĀO }\end{array}$ & $\begin{array}{l}\text { FABRICAGAOO DE PRODUTOS } \\
\text { TEXTEIS } \\
\end{array}$ & $\begin{array}{l}\text { TECELAGEM - INCLUSIVE FIACAXOO E } \\
\text { TECELAGEM }\end{array}$ \\
\hline $\begin{array}{l}\text { Empresa (Nome } \\
\text { Pregão) } \\
\end{array}$ & Seção & Divisão & Grupo \\
\hline SARAIVA LIVR & $\begin{array}{l}\text { COMERCIO; REPARACÁAO DE } \\
\text { VEICULOS AUTOMOTORES, } \\
\text { OBJETOS PESSOAS E } \\
\text { DOMESTICOS } \\
\end{array}$ & $\begin{array}{l}\text { COMÉRCIO VAREJISTA E } \\
\text { REPARAÇAO DE OBJETOS } \\
\text { PESSOAS E DOMÉSTICOS } \\
\end{array}$ & $\begin{array}{l}\text { COMÉRCIO VAREJISTA DE OUTROS } \\
\text { PRODUTOS }\end{array}$ \\
\hline SCHLOSSER & $\begin{array}{l}\text { INDÚSTRIAS DE } \\
\text { TRANSFORMAÇAO }\end{array}$ & $\begin{array}{l}\text { FABRICAÇÃO DE PRODUTOS } \\
\text { TEXTTEIS }\end{array}$ & $\begin{array}{l}\text { TECELAGEM - INCLUSIVE FIAÇAO E } \\
\text { TECELAGEM }\end{array}$ \\
\hline SCHULZ & $\begin{array}{l}\text { INDÚSTRIAS DE } \\
\text { TRANSFORMAGĀO }\end{array}$ & $\begin{array}{l}\text { FABRICACZ̃O DE MAQUINAS E } \\
\text { EQUIPAMMENTOS }\end{array}$ & $\begin{array}{l}\text { FABRICACAO DE MOTORES, BOMBAS, } \\
\text { COMPRESSORES E EQUIPAMENTOS DE } \\
\text { TRANSMISSÁO }\end{array}$ \\
\hline SEARA ALM & $\begin{array}{l}\text { INDÚSTRIAS DE } \\
\text { TRANSFORMAC,AOO }\end{array}$ & $\begin{array}{l}\text { FABRICACÄO DE PRODUTOS } \\
\text { ALIMENTICIOS E BEBIDAS } \\
\end{array}$ & $\begin{array}{l}\text { ABATE E PREPARACÅ̄O DE PRODUTOS DE } \\
\text { CARNEE DE PESCADO }\end{array}$ \\
\hline SEMP & \begin{tabular}{|l|} 
INDÚSTRIAS DE \\
TRANSFORMAGÃO \\
\end{tabular} & $\begin{array}{l}\text { FABRICACAOO DE MAQUINAS E } \\
\text { EQUIPAMENTOS }\end{array}$ & FABRICACÁAO DE ELETRODOMÉSTICOS \\
\hline SERGEN & CONSTRUÇÃO & CONSTRUC,AO & $\begin{array}{l}\text { construçä DE EDIFICIOS E OBRAS DE } \\
\text { ENGENHARIA CIVIL }\end{array}$ \\
\hline SID NACIONAL & $\begin{array}{l}\text { INDÚSTRIAS DE } \\
\text { IRANSFORMACAOO }\end{array}$ & METALURGIA BASICA & SIDERURGIA \\
\hline SID TUBARAO & $\begin{array}{l}\text { INDÚSTRIAS DE } \\
\text { TRANSFORMAGÃO } \\
\end{array}$ & METALURGIA BASICA & SIDERURGIA \\
\hline SONDOTECNICA & CONSTRUÇÃO & CONSTRUCCAO & $\begin{array}{l}\text { construçáa DE EDIFICIOS E OBRAS DE } \\
\text { ENGENHARIA CIVL }\end{array}$ \\
\hline SOUZA CRUZ & $\begin{array}{l}\text { INDÚSTRIAS DE } \\
\text { TRANSFORMAÇĀO }\end{array}$ & $\begin{array}{l}\text { FABRICAÇĀO DE PRODUTOS DO } \\
\text { FUMO }\end{array}$ & FABRICAÇÃO DE PRODUTOS DO FUMO \\
\hline SPRINGER & $\begin{array}{l}\text { INDÚSTRIAS DE } \\
\text { TRANSFORMAÇÃO }\end{array}$ & $\begin{array}{l}\text { FABRICACGAO DE MAQUINAS E } \\
\text { EQUIPAMENTOS }\end{array}$ & FABRICAÇĀO DE ELETRODOMÉSTICOS \\
\hline SULTEPA & CONSTRUÇĀO & CONSTRUCAAOO & $\begin{array}{l}\text { construcfáo DE EDIFICIOS E OBRAS DE } \\
\text { ENGENHARIA CIVIL }\end{array}$ \\
\hline $\begin{array}{l}\text { SUPERGASBRA } \\
\text { S }\end{array}$ & $\begin{array}{l}\text { PRODUÇÁO E DISTRIBUICCÁO } \\
\text { DE ELETRICIDADE, GAS E } \\
\text { AGUA }\end{array}$ & $\begin{array}{l}\text { ELETRICIDADE, GÁS E AGUA } \\
\text { QUENTE }\end{array}$ & $\begin{array}{l}\text { PRODUCĀO E DISTRIBUICAAO DE GAS } \\
\text { ATRAVES DE TUBULACÓES } \\
\end{array}$ \\
\hline SUZANO & $\begin{array}{l}\text { INDÚSTRIAS DE } \\
\text { TRANSFORMAGAO }\end{array}$ & $\begin{array}{l}\text { FABRICACÃO DE CELULOSE, } \\
\text { PAPEL PRODUTOS DE PAPEL } \\
\end{array}$ & $\begin{array}{l}\text { FABRICACCAO DE CELULOSE E OUTRAS } \\
\text { PASTAS PARA A FABRICACAO DE PAPEL }\end{array}$ \\
\hline SUZANO PAPEL & $\begin{array}{l}\text { INDÚSTRIAS DE } \\
\text { TRANSFORMACAAO } \\
\end{array}$ & \begin{tabular}{|l} 
FABRICACÃO DE CELULOSE, \\
PAPELE PRODUTOS DE PAPEL \\
\end{tabular} & $\begin{array}{l}\text { FABRICAC̆R̃O DE CELULOSE E OUTRAS } \\
\text { PASTAS PARA A FABRICACÃOO DE PAPEL } \\
\end{array}$ \\
\hline TAM S/A & $\begin{array}{l}\text { TRANSPORTE, ARMIAZENAGEM } \\
\text { ECOMUNICACOOOES }\end{array}$ & TRANSPORTE AÉREO & TRANSPORTE AEREO, REGULAR \\
\hline TEC BLUMENAU & $\begin{array}{l}\text { INDÚSTRIAS DE } \\
\text { TRANSFORMAG,AO } \\
\end{array}$ & $\begin{array}{l}\text { FABRICACAOO DE PRODUTOS } \\
\text { TÉXTEIS }\end{array}$ & $\begin{array}{l}\text { TECELAGEM - INCLUSIVE FIAĢ̄o E } \\
\text { TECELAGEM }\end{array}$ \\
\hline TECHNOS REL & $\begin{array}{l}\text { INDÚSTRIAS DE } \\
\text { TRANSFORMAGĂOO }\end{array}$ & $\begin{array}{l}\text { FABRICACAOO DE } \\
\text { EQUIPAMENTOS DE } \\
\text { INSTRUMENTACAOO } \\
\text { MEDICOHOSPTALARES,INSTRU } \\
\text { MENTOS DE PRECISAOE } \\
\text { OPTICOS, EQUIPAMENTOS PARA } \\
\text { AUTOMACAO INDUSTRIAL, } \\
\text { CRONOMETROS E RELÓGIOS } \\
\end{array}$ & $\begin{array}{l}\text { FABRICACAO DE CRONOMETROS E } \\
\text { RELOGIOS }\end{array}$ \\
\hline TECNOSOLO & CONSTRUG,ĀO & CONSTRUCÅ̄O & $\begin{array}{l}\text { construchio DE EDIFICIOS E OBRAS DE } \\
\text { ENGENHARIA CIVL }\end{array}$ \\
\hline TEKA & $\begin{array}{l}\text { INDÚSTRIAS DE } \\
\text { TRANSFORMACAOO }\end{array}$ & $\begin{array}{l}\text { FABRICACAOO DE PRODUTOS } \\
\text { TÉXTES }\end{array}$ & $\begin{array}{l}\text { TECELAGEM - INCLUSIVE FIAGÅO E } \\
\text { TECELAGEM }\end{array}$ \\
\hline TEKNO & $\begin{array}{l}\text { INDÚSTRIAS DE } \\
\text { IRANSFORMACAOA } \\
\end{array}$ & METALURGIA BÁSICA & SIDERURGIA \\
\hline TELE CL SUL & $\begin{array}{l}\text { TRANSPORTE, ARMAZENAGEM } \\
\text { E COMUNICACOES } \\
\end{array}$ & $\begin{array}{l}\text { CORREIOE } \\
\text { TELECOMUNICACÉEES }\end{array}$ & TELECOMUNICACÖES \\
\hline TELE CTR OES & $\begin{array}{l}\text { TRANSPORTE, ARMAZENAGEM } \\
\text { ECOMUNICACOES }\end{array}$ & $\begin{array}{l}\text { CORREIO E } \\
\text { TELECOMUNICACÓEES } \\
\end{array}$ & TELECOMUNICACOESS \\
\hline TELE LEST CL & $\begin{array}{l}\text { TRANSPORTE, ARMAZENAGEM } \\
\text { E COMUNICACOES } \\
\end{array}$ & $\begin{array}{l}\text { CORREIO E } \\
\text { TELECOMUNICAÇÓES }\end{array}$ & TELECOMUNICACÓES \\
\hline TELE NORD CL & $\begin{array}{l}\text { TRANSPORTE, ARMAZENAGEM } \\
\text { ECOMUNICACOES }\end{array}$ & $\begin{array}{l}\text { CORREIO E } \\
\text { TELECOMUNICACŌES }\end{array}$ & TELECOMUNICACÖOS \\
\hline TELE NORT CL & $\begin{array}{l}\text { TRANSPORTE, ARMAZENAGEM } \\
\text { ECOMUNICACOES }\end{array}$ & $\begin{array}{l}\text { CORREIO E } \\
\text { TELECOMUNICACÓES }\end{array}$ & TELECOMUNICACÓEES \\
\hline TELE SUDESTE & $\begin{array}{l}\text { TRANSPORTE, ARMAZENAGEM } \\
\text { E COMUNICAGOESS }\end{array}$ & $\begin{array}{l}\text { CORREIO E } \\
\text { TELECOMUUNICACEOEES }\end{array}$ & TELECOMUNICACÖES \\
\hline
\end{tabular}




\begin{tabular}{|c|c|c|c|}
\hline $\begin{array}{c}\text { Empresa } \\
\text { (Nome Pregão) }\end{array}$ & \begin{tabular}{|c|} 
Seção \\
\end{tabular} & \begin{tabular}{|r} 
Divisão \\
\end{tabular} & Grupo \\
\hline TELEFONICA & $\begin{array}{l}\text { TRANSPORTE, ARMAZENAGEM } \\
\text { ECOMUNICACÓES }\end{array}$ & $\begin{array}{l}\text { CORREIO E } \\
\text { TELECOMUNICAÇÓES }\end{array}$ & TELECOMUNICAÇÖES \\
\hline TELEMAR & $\begin{array}{l}\text { TRANSPORTE, ARMAZENAGEM } \\
\text { E COMUNICAÇOES }\end{array}$ & $\begin{array}{l}\text { CORREIO E } \\
\text { TELECOMUNICACÓEES }\end{array}$ & TELECOMUNICAC̈̈ES \\
\hline TELEMAR N L & $\begin{array}{l}\text { TRANSPORTE, ARMAZENAGEM } \\
\text { E COMUNICACÖES }\end{array}$ & $\begin{array}{l}\text { CORREIO E } \\
\text { TELECOMUNICAÇÓES }\end{array}$ & TELECOMUNICACCÓES \\
\hline TELEMIG CL & $\begin{array}{l}\text { TRANSPORTE, ARMAZENAGEM } \\
\text { E COMUNICACOEES }\end{array}$ & $\begin{array}{l}\text { CORREIO E } \\
\text { TELECOMUNICAÇÓES }\end{array}$ & TELECOMUNICAÇÖES \\
\hline TELEMIG PART & $\begin{array}{l}\text { TRANSPORTE, ARMAZENAGEM } \\
\text { E COMUNICACÖES }\end{array}$ & $\begin{array}{l}\text { CORREIOE } \\
\text { IELECOMUNICAÇÖES }\end{array}$ & TELECOMUNICAÇÓSS \\
\hline TELESP & $\begin{array}{l}\text { TRANSPORTE, ARMAZENAGEM } \\
\text { ECOMUNICACOOES }\end{array}$ & $\begin{array}{l}\text { CORREIOE } \\
\text { TELECOMUNICACÓES }\end{array}$ & TELECOMUNICAÇÓES \\
\hline TELESP CL PA & $\begin{array}{l}\text { TRANSPORTE, ARMAZENAGEM } \\
\text { ECOMUNICACOES }\end{array}$ & $\begin{array}{l}\text { CORREIO E } \\
\text { TELECOMUNICACÉES } \\
\end{array}$ & TELECOMUNICAÇÖES \\
\hline TEX RENAUX & $\begin{array}{l}\text { INDÚSTRIAS DE } \\
\text { TRANSFORMAÇĀO } \\
\end{array}$ & $\begin{array}{l}\text { FABRICACCAOO DE PRODUTOS } \\
\text { TÉXTEIS }\end{array}$ & $\begin{array}{l}\text { TECELAGEM - INCLUSIVE FIACÃO E } \\
\text { TECELAGEM }\end{array}$ \\
\hline $\begin{array}{c}\text { Empresa (Nome } \\
\text { Pregão) } \\
\end{array}$ & Seção & \begin{tabular}{|r|} 
Divisão \\
\end{tabular} & Grupo \\
\hline TRAFO & $\begin{array}{l}\text { INDÚSTRIAS DE } \\
\text { TRANSFORMAÇĀO } \\
\end{array}$ & $\begin{array}{l}\text { FABRICACCAO DE MAQUINAS, } \\
\text { APARELHOS E MATERIAIS } \\
\text { ELERTRICOS }\end{array}$ & $\begin{array}{l}\text { FABRICACGOD DE GERADORES, } \\
\text { TRANSFORMADORES E MOTORES } \\
\text { ELÉTRICOS }\end{array}$ \\
\hline TRAN PAULIST & $\begin{array}{l}\text { PRODUCGÁO E DISTRIBUUIÇÁO } \\
\text { DE ELETRICIDADE, GÁS E } \\
\text { AGUA } \\
\end{array}$ & $\begin{array}{l}\text { ELETRICIDADE, GÁS E AGUA } \\
\text { QUENTE }\end{array}$ & $\begin{array}{l}\text { PRODUCÃO E DISTRIBUIÇÃO DE ENERGIA } \\
\text { ELÉTRRICA }\end{array}$ \\
\hline TREVISA & $\begin{array}{l}\text { TRANSPORTE, ARMAZENAGEM } \\
\text { E COMUNICACOES }\end{array}$ & TRANSPORTE AQUAVIARIO & OUTROS TRANSPORTES AQUAVIÁRIOS \\
\hline TUPY & $\begin{array}{l}\text { INDÚSTRIAS DE } \\
\text { TRANSFORMAGAO } \\
\end{array}$ & METALURGIA BÁSICA & FUNDIÇĀO \\
\hline ULTRAPAR & $\begin{array}{l}\text { PRODUCGAO E DISTRIBUICACO } \\
\text { DE ELETRICIDADE, GAS E } \\
\text { AGUA }\end{array}$ & $\begin{array}{l}\text { ELETRIGIDADE, GAS E AGUA } \\
\text { QUENTE } \\
\end{array}$ & $\begin{array}{l}\text { PRODUÇÃO E DISTRIBUICĀO DE GAS } \\
\text { ATRAVES DE TUBULAÇOOES } \\
\end{array}$ \\
\hline UNIPAR & $\begin{array}{l}\text { INDÚSTRIAS DE } \\
\text { TRANSFORMAÇÃO } \\
\end{array}$ & $\begin{array}{l}\text { FABRICACCÃO DE PRODUTOS } \\
\text { QUIMICOS }\end{array}$ & $\begin{array}{l}\text { FABRICAÇAOO DE PRODUTOS QUIMICOS } \\
\text { ORGÁNICOS }\end{array}$ \\
\hline USIMINAS & $\begin{array}{l}\text { INDÚSTRIAS DE } \\
\text { TRANSFORMAÇÄO }\end{array}$ & METALURGIA BÁSICA & SIDERURGIA \\
\hline VCP & \begin{tabular}{|l} 
INDÚSTRIAS DE \\
TRANSFORMACÅOO \\
\end{tabular} & \begin{tabular}{|l|} 
FABRICACAXOO DE CELULOSE, \\
PAPEL E PRODUTOS DE PAPEL
\end{tabular} & $\begin{array}{l}\text { FABRICAÇĀO DE CELULOSE E OUTRAS } \\
\text { PASTAS PARA A FABRICAGÁO DE PAPEL } \\
\end{array}$ \\
\hline VALE R DOCE & INDÚSTRIAS EXTRATIVAS & $\begin{array}{l}\text { EXTRAÇÃO DE MINERAIS } \\
\text { METALICOS }\end{array}$ & EXTRAÇÃO DE MINÉRIO DE FERRO \\
\hline VICUNHA TEXT & $\begin{array}{l}\text { INDÚSTRIAS DE } \\
\text { TRANSFORMAÇÄO } \\
\end{array}$ & $\begin{array}{l}\text { FABRICACĀO DE PRODUTOS } \\
\text { TEXTEIS }\end{array}$ & $\begin{array}{l}\text { TECELAGEM - INCLUSIVE FIAÇÃO E } \\
\text { TECELAGEM }\end{array}$ \\
\hline VIGOR & $\begin{array}{l}\text { INDÚSTRIAS DE } \\
\text { TRANSFORMAÇĀO } \\
\end{array}$ & $\begin{array}{l}\text { FABRICACÃO DE PRODUTOS } \\
\text { ALIMENTICIOS E BEBIDAS } \\
\end{array}$ & $\begin{array}{l}\text { LATICINIOS } \\
\end{array}$ \\
\hline WEG & $\begin{array}{l}\text { INDÚSTRIAS DE } \\
\text { TRANSFORMAÇĀAO }\end{array}$ & $\begin{array}{l}\text { FABRICACAAO DE MÁQUINAS E } \\
\text { EQUIPAMENTOS }\end{array}$ & $\begin{array}{l}\text { FABRICAÇÃO DE MOTORES, BOMBAS, } \\
\text { COMPRESSORES E EQUIPAMENTOS DE } \\
\text { TRANSMISSAOO } \\
\end{array}$ \\
\hline WEMBLEY & $\begin{array}{l}\text { INDÚSTRIAS DE } \\
\text { TRANSFORMACAAO }\end{array}$ & $\begin{array}{l}\text { FABRICAÇÃO DE PRODUTOS } \\
\text { TÉXTEIS }\end{array}$ & $\begin{array}{l}\text { TECELAGEM - INCLUSIVE FIAÇĀo E } \\
\text { TECELAGEM }\end{array}$ \\
\hline
\end{tabular}

Fonte: CNAE. Elaboração própria. 
Anexo C- Classificação da Amostra por Porte, segundo BNDES

\begin{tabular}{|c|c|}
\hline Empresa (Nome Pregão) & Tamanho \\
\hline ACESITA & Grande \\
\hline ACOS VILL & Grande \\
\hline ADUBOS TREVO & Grande \\
\hline AES TIETE & Grande \\
\hline ALBARUS & Grande \\
\hline ALL AMER LAT & Grande \\
\hline ALPARGATAS & Grande \\
\hline AMBEV & Grande \\
\hline ARACRUZ & Grande \\
\hline ARTHUR LANGE & Grande \\
\hline AVIPAL & Grande \\
\hline BAN ARMAZENS & Média \\
\hline BARDELLA & Grande \\
\hline BAUMER & Média \\
\hline BELGO MINEIR & Grande \\
\hline BIC MONARK & Grande \\
\hline BLUE TREE & Média \\
\hline BRASIL T PAR & Grande \\
\hline BRASIL TELEC & Grande \\
\hline BRASKEM & Grande \\
\hline BRASMOTOR & Grande \\
\hline BRAZIL REALT & Grande \\
\hline BUETTNER & Grande \\
\hline CACIQUE & Grande \\
\hline CAEMI & Grande \\
\hline CAIUA & Grande \\
\hline CBC CARTUCHO & Grande \\
\hline CEB & Grande \\
\hline CEDRO & Grande \\
\hline CELESC & Grande \\
\hline CELPA & Grande \\
\hline CELPE & Grande \\
\hline CELUL IRANI & Grande \\
\hline CEMAT & Grande \\
\hline CEMIG & Grande \\
\hline CERJ & Grande \\
\hline CESP & Grande \\
\hline CHIARELLI & Média \\
\hline CIA HERING & Grande \\
\hline COELBA & Grande \\
\hline COELCE & Grande \\
\hline COMGAS & Grande \\
\hline CONFAB & Grande \\
\hline CONST A LIND & Grande \\
\hline COPESUL & Grande \\
\hline COSERN & Grande \\
\hline COTEMINAS & Grande \\
\hline CRT CELULAR & Grande \\
\hline
\end{tabular}




\begin{tabular}{|c|c|}
\hline Empresa (Nome Pregão) & Tamanho \\
\hline D F VASCONC & Média \\
\hline DIMED & Grande \\
\hline DIXIE TOGA & Grande \\
\hline DOC IMBITUBA & Grande \\
\hline DOCAS & Grande \\
\hline DOHLER & Grande \\
\hline DROGASIL & Grande \\
\hline DURATEX & Grande \\
\hline EBE & Grande \\
\hline ELDORADO & Média \\
\hline ELECTROLUX & Grande \\
\hline ELEKEIROZ & Grande \\
\hline ELEKTRO & Grande \\
\hline ELETROBRAS & Grande \\
\hline ELETROPAULO & Grande \\
\hline ELUMA & Grande \\
\hline EMAE & Grande \\
\hline EMBRACO & Grande \\
\hline EMBRAER & Grande \\
\hline EMBRATEL PAR & Grande \\
\hline ENCORPAR & Grande \\
\hline ENERSUL & Grande \\
\hline ESCELSA & Grande \\
\hline ESTRELA & Grande \\
\hline ETERNIT & Grande \\
\hline EUCATEX & Grande \\
\hline F CATAGUAZES & Grande \\
\hline FAB C RENAUX & Grande \\
\hline FERBASA & Grande \\
\hline FERTIBRAS & Grande \\
\hline FIBAM & Média \\
\hline FORJA TAURUS & Grande \\
\hline FOSFERTIL & Grande \\
\hline FRAS-LE & Grande \\
\hline GAZOLA & Média \\
\hline GER PARANAP & Grande \\
\hline GERDAU & Grande \\
\hline GERDAU MET & Grande \\
\hline GLOBEX & Grande \\
\hline GPC PART & Grande \\
\hline GRADIENTE & Grande \\
\hline GRANOLEO & Grande \\
\hline GRAZZIOTIN & Grande \\
\hline GUARARAPES & Grande \\
\hline HOTEIS OTHON & Grande \\
\hline IGUACU CAFE & Grande \\
\hline INDS ROMI & Grande \\
\hline INEPAR & Grande \\
\hline IOCHP-MAXION & Grande \\
\hline IPIRANGA DIS & Grande \\
\hline IPIRANGA PET & Grande \\
\hline
\end{tabular}




\begin{tabular}{|c|c|}
\hline Empresa (Nome Pregão) & Tamanho \\
\hline IPIRANGA REF & Grande \\
\hline ITAUTEC & Grande \\
\hline IVEN & Grande \\
\hline J B DUARTE & Média \\
\hline JOAO FORTES & Grande \\
\hline KARSTEN & Grande \\
\hline KEPLER WEBER & Grande \\
\hline KLABIN S/A & Grande \\
\hline LA FONTE PAR & Grande \\
\hline LA FONTE TEL & Grande \\
\hline LECO & Grande \\
\hline LF TEL & Grande \\
\hline LIGHT & Grande \\
\hline LIX DA CUNHA & Grande \\
\hline LOJAS AMERIC & Grande \\
\hline LOJAS HERING & Média \\
\hline LOJAS RENNER & Grande \\
\hline MAGNESITA & Grande \\
\hline MANASA & Grande \\
\hline MANGELS INDL & Grande \\
\hline MARCOPOLO & Grande \\
\hline MARISOL & Grande \\
\hline MELPAPER & Grande \\
\hline MENDES JR & Grande \\
\hline MET DUQUE & Grande \\
\hline METAL LEVE & Grande \\
\hline METISA & Média \\
\hline MICHELETTO & Média \\
\hline MILLENNIUM & Grande \\
\hline MULTIBRAS & Grande \\
\hline NADIR FIGUEI & Grande \\
\hline P.ACUCAR-CBD & Grande \\
\hline PARANAPANEMA & Grande \\
\hline PARMALAT & Grande \\
\hline PAUL F LUZ & Grande \\
\hline PERDIGAO S/A & Grande \\
\hline PET MANGUINH & Grande \\
\hline PETROBRAS & Grande \\
\hline PETROFLEX & Grande \\
\hline PETROPAR & Grande \\
\hline PETROQ UNIAO & Grande \\
\hline PETTENATI & Grande \\
\hline PLASCAR PART & Grande \\
\hline POLIALDEN & Grande \\
\hline POLIPROPILEN & Grande \\
\hline POLITENO & Grande \\
\hline PORTOBELLO & Grande \\
\hline PRONOR & Grande \\
\hline RANDON PART & Grande \\
\hline RASIP AGRO & Média \\
\hline RECRUSUL & Média \\
\hline
\end{tabular}




\begin{tabular}{|c|c|}
\hline Empresa (Nome Pregão) & Tamanho \\
\hline RHODIA-STER & Grande \\
\hline RIO GDE ENER & Grande \\
\hline RIOSULENSE & Média \\
\hline RIPASA & Grande \\
\hline ROSSI RESID & Grande \\
\hline SABESP & Grande \\
\hline SADIA S/A & Grande \\
\hline SANSUY & Grande \\
\hline SANTANENSE & Grande \\
\hline SARAIVA LIVR & Grande \\
\hline SCHLOSSER & Grande \\
\hline SCHULZ & Grande \\
\hline SEARA ALM & Grande \\
\hline SEMP & Grande \\
\hline SERGEN & Grande \\
\hline SID NACIONAL & Grande \\
\hline SID TUBARAO & Grande \\
\hline SONDOTECNICA & Média \\
\hline SOUZA CRUZ & Grande \\
\hline SPRINGER & Grande \\
\hline SULTEPA & Grande \\
\hline SUPERGASBRAS & Grande \\
\hline SUZANO & Grande \\
\hline SUZANO PAPEL & Grande \\
\hline TAM S/A & Grande \\
\hline TEC BLUMENAU & Média \\
\hline TECHNOS REL & Grande \\
\hline TECNOSOLO & Média \\
\hline TEKA & Grande \\
\hline TEKNO & Grande \\
\hline TELE CL SUL & Grande \\
\hline TELE CTR OES & Grande \\
\hline TELE LEST CL & Grande \\
\hline TELE NORD CL & Grande \\
\hline TELE NORT CL & Grande \\
\hline TELE SUDESTE & Grande \\
\hline TELEFONICA & Grande \\
\hline TELEMAR & Grande \\
\hline TELEMAR N L & Grande \\
\hline TELEMIG CL & Grande \\
\hline TELEMIG PART & Grande \\
\hline TELESP & Grande \\
\hline TELESP CL PA & Grande \\
\hline TEX RENAUX & Grande \\
\hline TRAFO & Média \\
\hline TRAN PAULIST & Grande \\
\hline TREVISA & Média \\
\hline TUPY & Grande \\
\hline ULTRAPAR & Grande \\
\hline UNIPAR & Grande \\
\hline USIMINAS & Grande \\
\hline
\end{tabular}




\begin{tabular}{|l|c|}
\hline \multicolumn{1}{|c|}{ Empresa (Nome Pregão) } & Tamanho \\
\hline V C P & Grande \\
\hline VALE R DOCE & Grande \\
\hline VICUNHA TEXT & Grande \\
\hline VIGOR & Grande \\
\hline WEG & Grande \\
\hline WEMBLEY & Grande \\
\hline
\end{tabular}

Fonte: BNDES. Elaboração Própria. 
Anexo D - Valor de Mercado por Empresa da Amostra 1999 a 2003 - (Valores em RS mil)

\begin{tabular}{|c|c|c|c|c|c|}
\hline Empresa (Nome Pregão) & 1999 & 2000 & 2001 & 2002 & 2003 \\
\hline ACESITA & 772.674 & 710.766 & 494.463 & 668.414 & 1.225 .099 \\
\hline ACOS VILL & 18.919 & 105.188 & 82.405 & 79.109 & 379.064 \\
\hline ADUBOS TREVO & 4.679 & 29.034 & 92.050 & 240.294 & 533.472 \\
\hline AES TIETE & 917.681 & 1.552 .932 & 1.440 .922 & 1.344 .509 & 1.460 .786 \\
\hline ALBARUS & 239.580 & 271.040 & 196.020 & 215.380 & 287.980 \\
\hline ALL AMER LAT & 88.888 & 103.025 & 307.614 & 297.469 & 327.750 \\
\hline ALPARGATAS & 218.132 & 254.847 & 235.494 & 232.020 & 389.129 \\
\hline AMBEV & 1.692 .638 & 17.397 .020 & 18.145.399 & 19.875 .848 & 26.842 .558 \\
\hline ARACRUZ & 3.682 .998 & 2.594 .450 & 3.853 .119 & 5.897 .958 & 9.367 .536 \\
\hline ARTHUR LANGE & 8.029 & 12.936 & 17.397 & 26.765 & 39.256 \\
\hline AVIPAL & 161.677 & 151.976 & 151.976 & 142.276 & 206.946 \\
\hline BAN ARMAZENS & 930 & 923 & 5.100 & 2.829 & 45 \\
\hline BARDELLA & 103.534 & 227.152 & 89.436 & 81.931 & 109.518 \\
\hline BAUMER & 2.686 & 2.686 & 2.640 & 2.886 & 8.800 \\
\hline BELGO MINEIR & 780.234 & 869.074 & 926.766 & 2.523 .949 & 4.754 .581 \\
\hline BIC MONARK & 104.195 & 91.005 & 88.722 & 209.640 & 174.169 \\
\hline BLUE TREE & 52.500 & 52.500 & 2.043 & 2.547 & 36.800 \\
\hline BRASIL T PAR & 6.868 .693 & 7.088 .964 & 6.295 .439 & 5.828 .022 & 7.257 .981 \\
\hline BRASIL TELEC & 55.455 & 8.619 .522 & 6.391 .538 & 6.222 .256 & 8.473 .723 \\
\hline BRASKEM & 917.952 & 1.047 .851 & 811.019 & 720.360 & 4.101.322 \\
\hline BRASMOTOR & 673.462 & 463.729 & 487.685 & 448.372 & 434.888 \\
\hline BRAZIL REALT & 96.600 & 117.238 & 165.006 & 199.450 & 239.342 \\
\hline BUETTNER & 9.374 & 11.101 & 32.377 & 37.008 & 37.002 \\
\hline CACIQUE & 36.590 & 42.245 & 59.792 & 59.875 & 78.254 \\
\hline CAEMI & 337.844 & 598.229 & 1.066.367 & 2.057 .867 & 4.978 .078 \\
\hline CAIUA & 214.175 & 269.550 & 152.220 & 146.688 & 116.358 \\
\hline CBC CARTUCHO & 2.213 & 2.587 & 8.923 & 15.676 & 32.079 \\
\hline CEB & 156.241 & 124.488 & 131.524 & 74.620 & 75.757 \\
\hline CEDRO & 64.544 & 75.010 & 78.572 & 89.327 & 85.680 \\
\hline CELESC & 613.745 & 500.223 & 413.862 & 456.944 & 614.899 \\
\hline CELPA & 191.498 & 191.553 & 122.350 & 128.000 & 188.189 \\
\hline CELPE & 575.405 & 593.626 & 613.396 & 921.753 & 509.574 \\
\hline CELUL IRANI & 18.250 & 16.355 & 21.773 & 12.819 & 42.060 \\
\hline CEMAT & 140.838 & 105.535 & 58.959 & 40.393 & 64.571 \\
\hline CEMIG & 5.328 .247 & 4.153 .856 & 5.142 .740 & 4.079 .890 & 7.444 .433 \\
\hline CERJ & 851.294 & 681.610 & 766.811 & 694.935 & 1.274 .048 \\
\hline CESP & 917.681 & 1.552 .932 & 1.318 .099 & 635.512 & 1.186 .358 \\
\hline CHIARELLI & 789 & 1.803 & 3.828 & 2.638 & 6.893 \\
\hline CIA HERING & 182.838 & 106.342 & 107.313 & 89.734 & 129.233 \\
\hline COELBA & 1.096 .655 & 465.566 & 634.102 & 836.961 & 812.516 \\
\hline COELCE & 712.204 & 748.911 & 994.729 & 470.697 & 611.035 \\
\hline COMGAS & 2.585 .180 & 1.048 .004 & 1.082 .198 & 785.577 & 1.891 .363 \\
\hline CONFAB & 458.805 & 124.678 & 228.500 & 358.126 & 584.362 \\
\hline CONST A LIND & 920 & 690 & 1.725 & 3.105 & 19.688 \\
\hline COPESUL & 1.156 .672 & 1.502 .172 & 781.129 & 660.956 & 2.057 .975 \\
\hline COSERN & 607.915 & 639.567 & 436.549 & 476.813 & 518.204 \\
\hline COTEMINAS & 553.073 & 660.513 & 744.431 & 1.485 .092 & 1.220 .048 \\
\hline CRT CELULAR & 838.124 & 1.508.357 & 1.408 .423 & 885.543 & 1.714 .330 \\
\hline
\end{tabular}




\begin{tabular}{|c|c|c|c|c|c|}
\hline Empresa (Nome Pregão) & 1999 & 2000 & 2001 & 2002 & 2003 \\
\hline D F VASCONC & 2.375 & 8.889 & 11.262 & 11.766 & 20.742 \\
\hline DIMED & 40.151 & 39.687 & 42.112 & 46.314 & 92.107 \\
\hline DIXIE TOGA & 94.720 & 76.022 & 158.524 & 92.940 & 300.341 \\
\hline DOC IMBITUBA & 3.998 & 5.998 & 10.799 & 6.899 & 6.599 \\
\hline DOCAS & 35.057 & 20.844 & 17.100 & 11.996 & 22.141 \\
\hline DOHLER & 32.969 & 34.511 & 146.111 & 109.494 & 183.689 \\
\hline DROGASIL & 16.549 & 23.530 & 86.547 & 30.249 & 37.664 \\
\hline DURATEX & 464.522 & 586.421 & 522.589 & 554.725 & 827.147 \\
\hline EBE & 244.659 & 869.791 & 866.273 & 594.585 & 854.669 \\
\hline ELDORADO & 780 & 2.781 & 3.194 & 2.795 & 1.916 \\
\hline ELECTROLUX & 165.025 & 132.020 & 149.068 & 506.111 & 551.508 \\
\hline ELEKEIROZ & 22.748 & 13.873 & 81.391 & 70.980 & 496.111 \\
\hline ELEKTRO & 605.930 & 609.276 & 356.268 & 273.095 & 1.219 .425 \\
\hline ELETROBRAS & 21.193 .379 & 19.373 .566 & 17.720 .566 & 12.671 .297 & 25.787 .067 \\
\hline ELETROPAULO & 4.145.671 & 4.148.467 & 3.834 .091 & 1.087 .735 & 3.332 .059 \\
\hline ELUMA & 48.694 & 43.440 & 40.589 & 84.793 & 175.959 \\
\hline EMAE & 101.200 & 125.666 & 362.081 & 221.313 & 242.003 \\
\hline EMBRACO & 497.801 & 575.518 & 527.806 & 1.310 .195 & 897.383 \\
\hline EMBRAER & 4.634 .953 & 7.477 .260 & 8.046.778 & 9.687 .648 & 16.850 .087 \\
\hline EMBRATEL PAR & 13.522 .340 & 8.972 .627 & 3.434 .919 & 1.305 .375 & 3.805 .596 \\
\hline ENCORPAR & 4.437 & 7.162 & 7.011 & 5.149 & 7.857 \\
\hline ENERSUL & 440.400 & 478.233 & 813.246 & 613.982 & 557.615 \\
\hline ESCELSA & 455.100 & 546.029 & 364.067 & 182.033 & 318.558 \\
\hline ESTRELA & 11.479 & 7.868 & 11.532 & 11.910 & 30.394 \\
\hline ETERNIT & 257.548 & 225.394 & 159.509 & 180.588 & 185.900 \\
\hline EUCATEX & 340.087 & 152.753 & 149.022 & 99.434 & 45.003 \\
\hline F CATAGUAZES & 183.289 & 205.297 & 199.902 & 142.795 & 179.739 \\
\hline FAB C RENAUX & 23.830 & 23.484 & 5.889 & 5.004 & 5.957 \\
\hline FERBASA & 44.528 & 44.153 & 78.384 & 156.326 & 260.047 \\
\hline FERTIBRAS & 37.384 & 71.842 & 44.134 & 47.213 & 222.722 \\
\hline FIBAM & 1.569 & 1.796 & 1.464 & 1.632 & 4.172 \\
\hline FORJA TAURUS & 58.586 & 47.619 & 66.089 & 168.254 & 120.346 \\
\hline FOSFERTIL & 1.075 .185 & 1.135 .078 & 874.832 & 1.035 .419 & 2.343 .706 \\
\hline FRAS-LE & 79.491 & 68.187 & 66.977 & 119.445 & 171.814 \\
\hline GAZOLA & 2.721 & 1.457 & 1.399 & 2.769 & 5.827 \\
\hline GER PARANAP & 926.881 & 720.800 & 860.274 & 735.024 & 800.951 \\
\hline GERDAU & 2.428.436 & 1.832 .601 & 2.314 .515 & 3.624 .319 & 8.565.793 \\
\hline GERDAU MET & 817.826 & 658.420 & 758.222 & 1.218 .423 & 2.680 .807 \\
\hline GLOBEX & 749.561 & 1.465 .635 & 941.473 & 614.434 & 936.707 \\
\hline GPC PART & 104.425 & 104.425 & 162.219 & 104.425 & 104.425 \\
\hline GRADIENTE & 114.390 & 382.216 & 124.059 & 76.710 & 61.833 \\
\hline GRANOLEO & 5.677 & 5.537 & 13.199 & 19.375 & 18.450 \\
\hline GRAZZIOTIN & 15.099 & 20.782 & 34.455 & 22.497 & 48.686 \\
\hline GUARARAPES & 359.007 & 284.084 & 273.203 & 430.248 & 645.840 \\
\hline HOTEIS OTHON & 1.916 & 1.894 & 5.512 & 3.674 & 1.470 \\
\hline IGUACU CAFE & 70.696 & 69.630 & 76.456 & 85.545 & 176.878 \\
\hline INDS ROMI & 39.151 & 51.149 & 66.238 & 95.420 & 231.645 \\
\hline INEPAR & 1.427 .439 & 1.493 .452 & 95.165 & 30.957 & 25.225 \\
\hline IOCHP-MAXION & 166.665 & 90.379 & 76.233 & 60.892 & 200.643 \\
\hline IPIRANGA DIS & 554.945 & 559.233 & 391.837 & 325.802 & 491.034 \\
\hline IPIRANGA PET & 938.294 & 781.275 & 671.247 & 392.673 & 718.634 \\
\hline IPIRANGA REF & 313.893 & 292.971 & 208.640 & 82.811 & 285.850 \\
\hline
\end{tabular}




\begin{tabular}{|c|c|c|c|c|c|}
\hline Empresa (Nome Pregão) & 1999 & 2000 & 2001 & 2002 & 2003 \\
\hline ITAUTEC & 1.404 .062 & 1.036 .398 & 540.318 & 479.314 & 601.321 \\
\hline IVEN & 96.000 & 249.438 & 285.000 & 282.000 & 203.862 \\
\hline J B DUARTE & 705 & 705 & 691 & 602 & 1.497 \\
\hline JOAO FORTES & 22.074 & 20.324 & 22.092 & 25.193 & 33.579 \\
\hline KARSTEN & 39.372 & 38.761 & 43.218 & 33.658 & 62.417 \\
\hline KEPLER WEBER & 25.074 & 98.088 & 97.778 & 107.809 & 277.497 \\
\hline KLABIN S/A & 668.311 & 761.554 & 861.308 & 1.031 .968 & 3.372 .256 \\
\hline LA FONTE PAR & 204.865 & 182.976 & 412.790 & 343.991 & 378.357 \\
\hline LA FONTE TEL & 56.137 & 92.281 & 299.091 & 434.025 & 225.194 \\
\hline LECO & 4.995 & 11.250 & 56.480 & 16.965 & 26.101 \\
\hline LF TEL & 98.969 & 64.827 & 853.415 & 859.690 & 859.690 \\
\hline LIGHT & 2.791 .415 & 3.116 .537 & 1.718 .474 & 1.780 .239 & 3.036 .744 \\
\hline LIX DA CUNHA & 3.232 & 5.081 & 12.625 & 25.556 & 23.631 \\
\hline LOJAS AMERIC & 463.428 & 247.309 & 292.062 & 629.609 & 1.923 .050 \\
\hline LOJAS HERING & 1.079 & 7.054 & 2.429 & 1.966 & 4.179 \\
\hline LOJAS RENNER & 55.755 & 105.291 & 98.508 & 58.894 & 69.348 \\
\hline MAGNESITA & 154.805 & 147.577 & 143.241 & 198.977 & 444.820 \\
\hline MANASA & 1.800 & 3.400 & 6.400 & 6.100 & 8.700 \\
\hline MANGELS INDL & 20.808 & 16.896 & 16.630 & 16.168 & 42.869 \\
\hline MARCOPOLO & 159.138 & 204.167 & 283.625 & 466.229 & 515.239 \\
\hline MARISOL & 88.082 & 140.689 & 136.846 & 101.028 & 86.443 \\
\hline MELPAPER & 3.404 & 2.430 & 28.151 & 28.151 & 16.421 \\
\hline MENDES JR & 25.414 & 25.414 & 118.367 & 264.656 & 134.544 \\
\hline MET DUQUE & 15.412 & 15.498 & 18.466 & 29.220 & 26.341 \\
\hline METAL LEVE & 222.592 & 240.093 & 299.634 & 534.460 & 922.743 \\
\hline METISA & 9.509 & 15.331 & 22.002 & 31.349 & 46.922 \\
\hline MICHELETTO & 3.844 & 4.234 & 3.203 & 2.746 & 3.403 \\
\hline MILLENNIUM & 72.138 & 60.345 & $\mathbf{9 1 . 4 6 8}$ & 90.263 & 190.994 \\
\hline MULTIBRAS & 1.147 .583 & 623.829 & 792.898 & 937.077 & 1.064 .145 \\
\hline NADIR FIGUEI & 18.711 & 32.260 & 44.050 & 46.060 & 128.298 \\
\hline P.ACUCAR-CBD & 3.648 .879 & 5.310 .994 & 5.627 .766 & 6.528 .524 & 7.303 .695 \\
\hline PARANAPANEMA & 489.900 & 475.605 & 330.635 & 169.031 & 528.934 \\
\hline PARMALAT & 497.983 & 497.983 & 864.425 & 864.425 & 544.696 \\
\hline PAUL F LUZ & 1.852 .762 & 1.686.105 & 2.923 .215 & 2.585 .504 & 2.384 .040 \\
\hline PERDIGAO S/A & 669.794 & 656.707 & 662.375 & 588.081 & 1.033 .153 \\
\hline PET MANGUINH & 119.377 & 260.813 & 254.760 & 254.788 & 214.606 \\
\hline PETROBRAS & 46.136 .751 & 51.446 .778 & 56.404 .010 & 54.453 .908 & 88.658 .594 \\
\hline PETROFLEX & 67.864 & 59.823 & 70.380 & 84.928 & 215.661 \\
\hline PETROPAR & 3.390 & 12.574 & 13.286 & 26.244 & 114.818 \\
\hline PETROQ UNIAO & 465.975 & 633.803 & 617.255 & 658.825 & 898.758 \\
\hline PETTENATI & 20.420 & 31.934 & 30.029 & 18.017 & 24.023 \\
\hline PLASCAR PART & 37.584 & 17.875 & 17.396 & 6.326 & 32.156 \\
\hline POLIALEEN & 87.759 & 56.471 & 180.677 & 170.986 & 409.729 \\
\hline POLIPROPILEN & 82.421 & 33.243 & 95.711 & 105.287 & 439.729 \\
\hline POLITENO & 32.532 & 19.113 & 120.569 & 1.374 .807 & 368.437 \\
\hline PORTOBELLO & 24.916 & 24.382 & 28.386 & 28.386 & 84.050 \\
\hline PRONOR & 35.508 & 43.702 & 68.068 & 30.859 & 82.658 \\
\hline RANDON PART & 41.950 & 46.828 & 90.339 & 184.953 & 418.782 \\
\hline RASIP AGRO & 4.879 & 10.580 & 10.956 & 21.912 & 23.641 \\
\hline RECRUSUL & 18.396 & 8.996 & 12.857 & 7.984 & 6.027 \\
\hline RHODIA-STER & 342.571 & 181.434 & 201.554 & 141.112 & 423.772 \\
\hline RIO GDE ENER & 435.175 & 1.387 .514 & 1.040 .636 & 662.223 & 592.847 \\
\hline
\end{tabular}




\begin{tabular}{|c|c|c|c|c|c|}
\hline Empresa (Nome Pregão) & 1999 & 2000 & 2001 & 2002 & 2003 \\
\hline RIOSULENSE & 238 & 360 & 297 & 1.294 & 4.664 \\
\hline RIPASA & 129.706 & 187.237 & 448.480 & 522.609 & 1.171.237 \\
\hline ROSSI RESID & 81.113 & 73.388 & 50.213 & 36.050 & 170.198 \\
\hline SABESP & 5.886 .491 & 4.969 .686 & 3.759 .304 & 2.620 .121 & 4.647.867 \\
\hline SADIA S/A & 286.857 & 905.007 & 956.550 & 995.700 & 2.723 .480 \\
\hline SANSUY & 4.995 & 8.428 & 7.859 & 6.964 & 8.295 \\
\hline SANTANENSE & 15.767 & 26.702 & 39.749 & 30.793 & 13.844 \\
\hline SARAIVA LIVR & 240.187 & 248.240 & 258.725 & 211.750 & 212.765 \\
\hline SCHLOSSER & 960 & 1.056 & 1.248 & 1.056 & 1.248 \\
\hline SCHULZ & 7.520 & 8.219 & 14.360 & 11.796 & 22.566 \\
\hline SEARA ALM & 77.673 & 79.543 & 225.354 & 249.096 & 423.000 \\
\hline SEMP & 9.180 & 12.756 & 33.749 & 29.280 & 20.389 \\
\hline SERGEN & 6.266 & 20.120 & 25.813 & 30.749 & 25.489 \\
\hline SID NACIONAL & 5.021 .048 & 4.454.387 & 2.618 .118 & 3.668 .952 & 11.239 .975 \\
\hline SID TUBARAO & 1.273 .668 & 1.081 .160 & 1.165 .139 & 1.999 .725 & 4.873.292 \\
\hline SONDOTECNICA & 12.840 & 12.874 & 12.326 & 12.883 & 14.936 \\
\hline SOUZA CRUZ & 4.084 .018 & 2.751 .210 & 4.340 .799 & 5.447 .398 & 9.253.239 \\
\hline SPRINGER & 33.739 & 37.928 & 44.316 & 53.014 & 86.532 \\
\hline SULTEPA & 23.159 & 18.747 & 13.996 & 9.364 & 9.442 \\
\hline SUPERGASBRAS & 19.011 & 35.803 & 60.617 & 48.833 & 54.231 \\
\hline SUZANO & 1.225 .620 & 1.350 .656 & 1.260 .915 & 1.344 .303 & 3.470 .966 \\
\hline SUZANO PAPEL (Bahia Sul) & 536.575 & 439.031 & 780.232 & 905.343 & 2.056.332 \\
\hline TAM S/A & 334.034 & 301.037 & 254.745 & 238.215 & 227.049 \\
\hline TEC BLUMENAU & 474 & 240 & 2.883 & 961 & 2.398 \\
\hline TECHNOS REL & 154.440 & 154.618 & 158.902 & 181.450 & 230.287 \\
\hline TECNOSOLO & 1.920 & 1.792 & 1.408 & 3.699 & 6.716 \\
\hline TEKA & 12.787 & 32.989 & 38.999 & 29.921 & 22.760 \\
\hline TEKNO & 6.091 & 9.370 & 29.502 & 46.692 & 71.050 \\
\hline TELE CL SUL & 1.728 .077 & 1.566 .190 & 1.143 .590 & 838.839 & 1.324 .358 \\
\hline TELE CTR OES & 1.226 .308 & 2.765 .467 & 2.307 .629 & 2.379 .000 & 3.501 .243 \\
\hline TELE LEST CL & 451.521 & 737.824 & 541.425 & 250.798 & 391.671 \\
\hline TELE NORD CL & 1.435 .088 & 1.420 .729 & 1.073 .564 & 909.496 & 1.328 .203 \\
\hline TELE NORT CL & 514.035 & 453.718 & 443.202 & 148.823 & 276.766 \\
\hline TELE SUDESTE & 3.611 .887 & 2.435 .561 & 2.259 .762 & 2.519 .031 & 2.559 .279 \\
\hline TELEFONICA & 10.359 .476 & 13.746 .871 & 18.829 .799 & 17.705 .631 & 23.663.717 \\
\hline TELEMAR & 14.228 .448 & 14.311 .387 & 13.049 .629 & 9.544 .963 & 16.408 .604 \\
\hline TELEMAR N L & 2.258 .006 & 3.144.317 & 13.208 .644 & 10.556 .285 & 13.007 .987 \\
\hline TELEMIG CL & 740.180 & 803.633 & 824.541 & 847.086 & 1.048 .557 \\
\hline TELEMIG PART & 1.264 .910 & 2.263 .450 & 1.711 .842 & 1.119 .574 & 2.039 .693 \\
\hline TELESP & 18.319 .951 & 12.159 .248 & 14.542 .159 & 15.031 .688 & 20.904 .912 \\
\hline TELESP CL PA & 8.847 .670 & 8.271 .261 & 3.719 .973 & 4.799 .955 & 8.186 .736 \\
\hline TEX RENAUX & 17.117 & 12.824 & 18.892 & 5.690 & 5.690 \\
\hline TRAFO & 14.802 & 11.614 & 14.119 & 9.678 & 27.695 \\
\hline TRAN PAULIST & 457.090 & 505.149 & 885.899 & 827.480 & 1.914 .329 \\
\hline TREVISA & 1.723 & 2.956 & 2.977 & 3.021 & 16.009 \\
\hline TUPY & 115.560 & 253.597 & 391.953 & 227.524 & 140.139 \\
\hline ULTRAPAR & 313.834 & 277.796 & 991.100 & 1.484 .116 & 2.358 .356 \\
\hline UNIPAR & 275.332 & 396.565 & 378.367 & 440.157 & 948.922 \\
\hline USIMINAS & 1.781 .136 & 1.544 .444 & 1.319 .062 & 1.453 .827 & 6.585 .672 \\
\hline VCP & 1.597 .945 & 1.989 .099 & 3.096 .091 & 4.598.724 & 7.001 .557 \\
\hline VALE R DOCE & 17.428 .086 & 18.029.743 & 20.440 .650 & 39.249 .660 & 62.770 .517 \\
\hline VICUNHA TEXT & 110.494 & 61.628 & 103.162 & 94.179 & 149.738 \\
\hline
\end{tabular}


xxiii

\begin{tabular}{|l|r|r|r|r|r|}
\hline & & & & \multicolumn{1}{c|}{} \\
\hline \multicolumn{1}{|c|}{ Empresa (Nome Pregão) } & \multicolumn{1}{c|}{$\mathbf{1 9 9 9}$} & \multicolumn{1}{c|}{$\mathbf{2 0 0 0}$} & \multicolumn{1}{c|}{$\mathbf{2 0 0 1}$} & \multicolumn{1}{c|}{$\mathbf{2 0 0 2}$} & \multicolumn{1}{c|}{2003} \\
\hline VIGOR & 23.628 & 34.749 & 57.905 & 24.817 & 49.634 \\
WEG & 618.389 & 716.942 & 1.182 .806 & 1.709 .140 & 3.023 .785 \\
WEMBLEY & 77.895 & 113.700 & 136.942 & 217.803 & 343.680 \\
\hline Sornatório & 263.337 .170 & 288.186 .718 & 299.574 .242 & 313.710 .386 & 509.677 .590 \\
\hline
\end{tabular}


Anexo E - Valor Contábil por Empresa da Amostra 1999 a 2003 (Valores em RS mil)

\begin{tabular}{|c|c|c|c|c|c|}
\hline Empresa (Nome Pregão) & 1999 & 2000 & 2001 & 2002 & 2003 \\
\hline ACESITA & 1.445 .173 & 1.249 .464 & 1.147 .423 & 836.292 & 1.021 .341 \\
\hline ACOS VILL & -78.681 & 86.314 & 101.446 & 72.482 & 224.202 \\
\hline ADUBOS TREVO & -143.776 & 31.101 & 116.157 & 147.849 & 206.532 \\
\hline AES TIETE & 389.549 & 698.014 & 668.025 & 433.973 & 443.742 \\
\hline ALBARUS & 204.346 & 194.653 & 214.325 & 249.626 & 304.212 \\
\hline ALL AMER LAT & 190.978 & 204.965 & 233.531 & 264.287 & 331.242 \\
\hline ALPARGATAS & 350.184 & 401.384 & 417.885 & 438.391 & 493.275 \\
\hline AMBEV & 1.406 .790 & 3.076 .945 & 3.363.437 & 4.129 .647 & 4.308.217 \\
\hline ARACRUZ & 2.148.321 & 2.407 .238 & 2.437 .803 & 2.194 .648 & 2.738 .136 \\
\hline ARTHUR LANGE & 14.786 & 14.988 & 17.270 & 19.891 & 23.181 \\
\hline AVIPAL & 414.240 & 439.986 & 436.080 & 401.556 & 453.111 \\
\hline BAN ARMAZENS & 7.370 & 4.920 & 4.818 & 1.862 & 1.961 \\
\hline BARDELLA & 242.686 & 248.385 & 244.457 & 247.247 & 239.922 \\
\hline BAUMER & 10.587 & 11.031 & 11.868 & 16.095 & 16.768 \\
\hline BELGO MINEIR & 1.562.247 & 1.891 .853 & 2.005.776 & 2.290 .593 & 2.694 .823 \\
\hline BIC MONARK & 159.029 & 173.901 & 182.438 & 183.823 & 175.345 \\
\hline BLUE TREE & 1.096 & 1.807 & 2.067 & 2.641 & 2.377 \\
\hline BRASIL T PAR & 6.242 .727 & 6.112 .448 & 6.000 .974 & 6.225 .547 & 6.137.327 \\
\hline BRASIL TELEC & 1.701 .482 & 7.147 .680 & 6.864 .313 & 6.963 .535 & 6.662 .844 \\
\hline BRASKEM & 2.085 .276 & 2.267 .793 & 2.125 .338 & 1.821 .768 & 2.112 .574 \\
\hline BRASMOTOR & 666.223 & 759.217 & 716.702 & 747.029 & 783.813 \\
\hline BRAZIL REALT & 183.767 & 228.591 & 235.667 & 271.838 & 297.099 \\
\hline BUETTNER & 861 & 1.332 & 1.995 & 1.904 & 501 \\
\hline CACIQUE & 100.481 & 110.453 & 122.646 & 135.404 & 150.523 \\
\hline CAEMI & 712.693 & 797.226 & 854.317 & 543.316 & 984.591 \\
\hline CAIUA & 444.505 & 450.620 & 877.301 & 558.694 & 369.410 \\
\hline CBC CARTUCHO & 36.170 & 38.349 & 40.501 & 48.691 & 59.416 \\
\hline CEB & 442.707 & 461.924 & 493.813 & 314.954 & 293.752 \\
\hline CEDRO & 128.481 & 139.392 & 148.021 & 154.694 & 160.768 \\
\hline CELESC & 1.145 .804 & 1.146 .186 & 1.059 .400 & 637.587 & 777.777 \\
\hline CELPA & 598.007 & 585.863 & 888.020 & 847.007 & 890.004 \\
\hline CELPE & 684.756 & 579.330 & 1.081 .177 & 1.100 .572 & 1.096 .287 \\
\hline CELUL IRANI & 68.108 & 75.049 & 74.016 & 70.006 & 79.492 \\
\hline CEMAT & 428.869 & 316.232 & 567.543 & 499.293 & 452.008 \\
\hline CEMIG & 7.588 .983 & 7.817 .533 & 6.902 .056 & 5.680 .883 & 6.558 .569 \\
\hline CERJ & 245.554 & 381.815 & 186.932 & 433.434 & 352.470 \\
\hline CESP & 10.915 .920 & 10.692 .641 & 9.896 .373 & 6.478 .849 & 7.106 .529 \\
\hline CHIARELLI & 23.974 & 24.016 & 23.143 & 24.141 & 14.695 \\
\hline CIA HERING & 128.725 & 129.450 & 88.905 & 7.203 & 18.805 \\
\hline COELBA & 1.082 .703 & 2.228 .443 & 1.608 .425 & 1.671 .688 & 1.684 .575 \\
\hline COELCE & 1.236 .557 & 1.224 .277 & 1.203 .692 & 1.170 .665 & 1.137 .425 \\
\hline COMGAS & 280.161 & 841.162 & 828.888 & 886.945 & 911.785 \\
\hline CONFAB & 307.791 & 294.634 & 340.815 & 461.978 & 430.478 \\
\hline CONST A LIND & 5.358 & 4.025 & 5.645 & 5.680 & 5.404 \\
\hline COPESUL & 907.646 & 903.855 & 918.697 & 1.000 .771 & 1.077 .646 \\
\hline COSERN & 182.940 & 405.652 & 470.053 & 496.013 & 501.009 \\
\hline COTEMINAS & 851.482 & 931.177 & 1.051 .426 & 1.202 .619 & 1.382 .779 \\
\hline CRT CELULAR & 420.784 & 644.265 & 709.788 & 817.713 & 954.897 \\
\hline D F VASCONC & 1.343 & 1.521 & 1.550 & -76 & -1.716 \\
\hline
\end{tabular}




\begin{tabular}{|c|c|c|c|c|c|}
\hline Empresa (Nome Pregão) & 1999 & 2000 & 2001 & 2002 & 2003 \\
\hline DIMED & 80.652 & 81.945 & 85.611 & 88.435 & 93.622 \\
\hline DIXIE TOGA & 239.820 & 241.361 & 184.348 & 191.676 & 209.298 \\
\hline DOC IMBITUBA & 6.713 & 6.148 .770 & 8.395 & 5.397 & -15.378 \\
\hline DOCAS & 136.708 & 192.390 & 192.920 & 172.306 & 159.372 \\
\hline DOHLER & 170.026 & 184.481 & 198.400 & 214.268 & 228.422 \\
\hline DROGASIL & 85.133 & 85.194 & 87.080 & 92.426 & 96.867 \\
\hline DURATEX & 614.445 & 849.755 & 864.074 & 905.061 & 936.591 \\
\hline EBE & 579.378 & 656.912 & 454.520 & 617.428 & 692.652 \\
\hline ELDORADO & 16.066 & 13.943 & 12.624 & 7.032 & 8.256 \\
\hline ELECTROLUX & 288.218 & 230.347 & 184.627 & 427.874 & 381.677 \\
\hline ELEKEIROZ & 138.039 & 146.057 & 154.953 & 181.700 & 235.020 \\
\hline ELEKTRO & 1.356 .609 & 1.304 .627 & 648.172 & -291.606 & 99.167 \\
\hline ELETROBRAS & 59.437 .068 & 62.136 .331 & 64.285 .524 & 66.550 .862 & 67.837 .732 \\
\hline ELETROPAULO & 2.778 .457 & 2.557 .800 & 2.969 .123 & 2.106 .324 & 2.192 .599 \\
\hline ELUMA & 112.710 & 95.600 & 123.736 & 123.004 & 161.526 \\
\hline EMAE & 910.424 & 922.054 & 861.598 & 900.093 & 876.398 \\
\hline EMBRACO & 482.590 & 534.572 & 530.776 & 703.931 & 767.007 \\
\hline EMBRAER & 697.106 & 1.538 .726 & 2.456 .867 & 3.327 .201 & 3.731 .768 \\
\hline EMBRATEL PAR & 5.731 .053 & 6.082 .170 & 5.346 .672 & 4.719 .793 & 4.874 .802 \\
\hline ENCORPAR & 58.246 & 57.361 & 61.336 & 65.311 & 68.336 \\
\hline ENERSUL & 472.420 & 481.898 & 519.927 & 427.449 & 442.992 \\
\hline ESCELSA & 785.110 & 775.617 & 731.403 & 223.021 & 357.929 \\
\hline ESTRELA & 10.016 & 11.398 & 13.024 & 18.296 & 14.421 \\
\hline ETERNIT & 279.703 & 262.931 & 235.900 & 237.229 & 240.097 \\
\hline EUCATEX & 388.361 & 382.923 & 304.591 & 269.541 & 213.164 \\
\hline F CATAGUAZES & 373.541 & 362.031 & 361.294 & 288.317 & 308.540 \\
\hline FAB C RENAUX & 34.192 & 31.550 & 21.844 & 5.768 & 2.337 \\
\hline FERBASA & 147.904 & 167.183 & 215.996 & 261.539 & 347.863 \\
\hline FERTIBRAS & 78.761 & 85.769 & 89.619 & 78.789 & 129.521 \\
\hline FIBAM & 8.124 & 8.072 & 8.019 & 7.973 & 7.958 \\
\hline FORJA TAURUS & 123.723 & 140.689 & 162.126 & 177.520 & 206.230 \\
\hline FOSFERTIL & 456.149 & 489.644 & 542.567 & 549.258 & 788.991 \\
\hline FRAS-LE & 55.169 & 66.264 & 71.079 & 74.282 & 89.066 \\
\hline GAZOLA & 12.337 & 5.788 & 4.330 & 3.042 & 4.976 \\
\hline GER PARANAP & 2.418.339 & 2.329 .328 & 2.331 .769 & 2.251 .712 & 2.255 .818 \\
\hline GERDAU & 2.063 .098 & 2.365.207 & 2.685 .759 & 3.293 .226 & 4.128.396 \\
\hline GERDAU MET & 996.895 & 1.158 .263 & 1.328 .706 & 1.576 .066 & 1.972 .096 \\
\hline GLOBEX & 479.676 & 520.122 & 547.217 & 561.245 & 562.155 \\
\hline GPC PART & 169.018 & 163.260 & 157.408 & 153.852 & 170.142 \\
\hline GRADIENTE & 242.522 & 420.673 & 310.156 & 272.475 & 91.657 \\
\hline GRANOLEO & 73.682 & 72.859 & 75.641 & 80.839 & 81.503 \\
\hline GRAZZIOTIN & 59.018 & 65.636 & 70.673 & 73.197 & 77.746 \\
\hline GUARARAPES & 453.467 & 516.672 & 566.047 & 642.770 & 690.430 \\
\hline HOTEIS OTHON & 24.484 & 32.882 & 17.492 & 120.702 & 78.479 \\
\hline IGUACU CAFE & 97.497 & 102.599 & 114.668 & 137.921 & 168.255 \\
\hline INDS ROMI & 201.271 & 211.129 & 221.239 & 235.056 & 266.694 \\
\hline INEPAR & 531.614 & 364.503 & 272.231 & 50.684 & -40.263 \\
\hline IOCHP-MAXION & 177.646 & 167.389 & 181.801 & 156.636 & 151.525 \\
\hline IPIRANGA DIS & 402.755 & 435.966 & 432.930 & 470.520 & 527.006 \\
\hline IPIRANGA PET & 970.733 & 994.606 & 923.686 & 855.056 & 949.434 \\
\hline IPIRANGA REF & 340.867 & 359.746 & 301.434 & 3.389 & 110.327 \\
\hline ITAUTEC & 235.169 & 278.045 & 269.775 & 308.828 & 313.178 \\
\hline IVEN & 415.165 & 405.869 & 383.224 & 116.567 & 208.079 \\
\hline
\end{tabular}




\begin{tabular}{|c|c|c|c|c|c|}
\hline Empresa (Nome Pregão) & 1999 & 2000 & 2001 & 2002 & 2003 \\
\hline J B DUARTE & 4.170 & 2.132 & 624 & 764 & 2.113 \\
\hline JOAO FORTES & 73.020 & 72.042 & 72.242 & 73.281 & 75.142 \\
\hline KARSTEN & 82.197 & 75.352 & 79.248 & 90.632 & 98.498 \\
\hline KEPLER WEBER & 2.069 & 58.186 & 65.997 & 77.679 & 94.090 \\
\hline KLABIN S/A & 336.953 & 403.397 & 1.287 .973 & 1.083 .566 & 1.817 .701 \\
\hline LA FONTE PAR & 454.580 & 425.139 & 520.506 & 485.271 & 419.803 \\
\hline LA FONTE TEL & 290.530 & 225.906 & 255.073 & 254.346 & 228.270 \\
\hline LECO & 113.791 & 115.941 & 93.015 & 93.676 & 101.934 \\
\hline LF TEL & 84.418 & 231.033 & 540.968 & 549.727 & 535.359 \\
\hline LIGHT & 2.481 .140 & 2.185 .833 & -86.480 & 1.007 .944 & 519.541 \\
\hline LIX DA CUNHA & 36.563 & 43.534 & 50.252 & 58.687 & 61.051 \\
\hline LOJAS AMERIC & 218.348 & 178.451 & 220.653 & 218.590 & 210.918 \\
\hline LOJAS HERING & 9.007 & 72 & -1.092 & -2.786 & -3.341 \\
\hline LOJAS RENNER & 176.389 & 164.657 & 136.426 & 39.349 & 95.880 \\
\hline MAGNESITA & 312.032 & 348.192 & 378.682 & 452.439 & 520.517 \\
\hline MANASA & 17.694 & 19.962 & 24.133 & 21.487 & 10.553 \\
\hline MANGELS INDL & 143.220 & 145.676 & 146.876 & 142.406 & 156.604 \\
\hline MARCOPOLO & 202.918 & 212.611 & 212.271 & 340.183 & 381.113 \\
\hline MARISOL & 117.602 & 136.203 & 142.436 & 137.156 & 152.452 \\
\hline MELPAPER & 69.719 & 67.044 & 57.942 & 59.610 & 64.541 \\
\hline MENDES JR & 599.823 & 693.173 & 698.317 & 666.881 & 666.519 \\
\hline MET DUQUE & 44.042 & 46.183 & 48.109 & 49.404 & 51.829 \\
\hline METAL LEVE & 207.786 & 255.340 & 307.473 & 436.108 & 561.851 \\
\hline METISA & 22.649 & 25.339 & 28.178 & 34.568 & 41.024 \\
\hline MICHELETTO & 15.958 & 11.871 & 9.848 & 9.091 & 9.115 \\
\hline MILLENNIUM & 202.523 & 226.021 & 258.238 & 317.376 & 369.264 \\
\hline MULTIBRAS & 1.140 .955 & 1.317 .612 & 1.245 .882 & 1.311 .776 & 1.362 .697 \\
\hline NADIR FIGUEI & 117.617 & 120.335 & 122.934 & 127.196 & 131.065 \\
\hline P.ACUCAR-CBD & 2.315 .436 & 2.962 .603 & 3.403 .890 & 3.592 .040 & 3.768 .422 \\
\hline PARANAPANEMA & 297.904 & 232.112 & 73.533 & 97.547 & -64.589 \\
\hline PARMALAT & 805.256 & 765.558 & 880.509 & 688.522 & 452.835 \\
\hline PAUL F LUZ & 4.582 .983 & 4.264 .526 & 3.837 .621 & 3.125 .054 & 3.084 .219 \\
\hline PERDIGAO S/A & 523.663 & 554.931 & 672.808 & 675.640 & 763.187 \\
\hline PET MANGUINH & 111.008 & 135.879 & 179.355 & 184.285 & 184.575 \\
\hline PETROBRAS & 17.564.122 & 24.945.639 & 28.966 .503 & 34.324 .906 & 49.367 .329 \\
\hline PETROFLEX & 130.897 & 114.397 & 101.215 & 144.328 & 205.147 \\
\hline PETROPAR & 121.887 & 124.077 & 140.127 & 147.531 & 177.532 \\
\hline PETROQ UNIAO & 562.984 & 578.841 & 613.695 & 525.253 & 515.051 \\
\hline PETTENATI & 80.492 & 96.290 & 91.922 & 80.919 & 73.933 \\
\hline PLASCAR PART & 95.805 & 46.148 & 37.684 & -7.511 & 69.147 \\
\hline POLIALDEN & 211.695 & 229.490 & 356.031 & 377.987 & 448.179 \\
\hline POLIPROPILEN & 248.094 & 279.877 & 314.249 & 385.611 & 444.860 \\
\hline POLITENO & 315.736 & 372.572 & 387.001 & 433.835 & 434.118 \\
\hline PORTOBELLO & 89.225 & 64.114 & 72.479 & 52.960 & 53.948 \\
\hline PRONOR & 123.732 & 124.534 & 243.182 & 191.193 & 184.342 \\
\hline RANDON PART & 117.856 & 113.133 & 112.273 & 116.612 & 167.368 \\
\hline RASIP AGRO & 34.914 & 29.093 & 30.874 & 31.561 & 31.596 \\
\hline RECRUSUL & 54.163 & 50.011 & 34.154 & 10.240 & -11.712 \\
\hline RHODIA-STER & -60.230 & 140.175 & 148.927 & 85.042 & 261.302 \\
\hline RIO GDE ENER & 1.108 .555 & 953.363 & 861.862 & 700.627 & 962.829 \\
\hline RIOSULENSE & 3.882 & 4.062 & 4.785 & 5.059 & 5.744 \\
\hline RIPASA & 612.342 & 782.964 & 855.718 & 918.198 & 1.003 .546 \\
\hline ROSSI RESID & 186.829 & 197.146 & 188.490 & 271.115 & 265.678 \\
\hline
\end{tabular}




\begin{tabular}{|c|c|c|c|c|c|}
\hline Empresa (Nome Pregão) & $\begin{array}{l}1999 \\
\end{array}$ & 2000 & 2001 & 2002 & 2003 \\
\hline SABESP & 8.271 .543 & 8.268 .473 & 7.996 .690 & 7.246 .476 & 7.576 .943 \\
\hline SADIA S/A & 858.977 & 948.113 & 1.121 .599 & 1.261 .654 & 1.487 .422 \\
\hline SANSUY & 24.886 & 30.346 & 31.111 & 32.561 & 37.163 \\
\hline SANTANENSE & 80.957 & 86.733 & 93.777 & 79.909 & 45.670 \\
\hline SARAIVA LIVR & 78.602 & 82.755 & 87.707 & 90.921 & 95.032 \\
\hline SCHLOSSER & 4.930 & 1.418 & 18.561 & 5.655 & -4.521 \\
\hline SCHULZ & 73.825 & 70.889 & 71.886 & 73.019 & 75.931 \\
\hline SEARA ALM & 217.268 & 227.223 & 290.171 & 347.800 & 409.837 \\
\hline SEMP & 272 & 1.679 & 2.918 & 6.897 & 9.304 \\
\hline SERGEN & 59.381 & 60.957 & 63.286 & 63.673 & 97.626 \\
\hline SID NACIONAL & 5.852 .356 & 5.703 .701 & 5.118 .133 & 4.895 .192 & 7.419 .382 \\
\hline SID TUBARAO & 3.733 .063 & 3.750 .363 & 3.682 .981 & 3.665 .038 & 5.646 .682 \\
\hline SONDOTECNICA & 34.926 & 35.381 & 40.535 & 42.699 & 43.064 \\
\hline SOUZA CRUZ & 1.404 .596 & 1.199 .213 & 1.254 .822 & 1.502 .448 & 1.536 .925 \\
\hline SPRINGER & 67.200 & 78.969 & 81.251 & 93.803 & 91.430 \\
\hline SULTEPA & 172.787 & 214.961 & 217.571 & 182.769 & 188.322 \\
\hline SUPERGASBRAS & 99.172 & 100.038 & 86.177 & 85.791 & 127.519 \\
\hline SUZANO & 1.441 .004 & 1.849 .389 & 1.283 .342 & 1.754 .959 & 2.318 .893 \\
\hline SUZANO PAPEL & 1.226 .707 & 1.406 .716 & 1.497 .967 & 1.625 .964 & 1.959 .224 \\
\hline TAM S/A & 375.240 & 498.645 & 461.319 & 204.475 & 41.926 \\
\hline TEC BLUMENAU & 10.863 & 10.789 & 12.636 & 13.745 & 11.671 \\
\hline TECHNOS REL & 138.769 & 150.491 & 133.893 & 149.124 & 161.110 \\
\hline TECNOSOLO & 14.469 & 12.309 & 14.345 & 14.491 & 15.939 \\
\hline TEKA & 20.625 & 69.683 & 75.979 & 25.371 & 25.055 \\
\hline TEKNO & 44.354 & 52.819 & 61.881 & 75.711 & 91.355 \\
\hline TELE CL SUL & 560.966 & 770.081 & 808.329 & 845.330 & 926.986 \\
\hline TELE CTR OES & 1.014 .492 & 1.067 .433 & 1.010 .175 & 1.218 .523 & 1.556 .086 \\
\hline TELE LEST CL & 167.138 & 451.963 & 445.556 & 443.048 & 401.287 \\
\hline TELE NORD CL & 354.091 & 575.884 & 621.976 & 710.145 & 877.042 \\
\hline TELE NORT CL & 352.763 & 258.324 & 250.790 & 227.595 & 227.227 \\
\hline TELE SUDESTE & 917.168 & 1.622 .473 & 1.735 .749 & 1.779 .685 & 1.903 .363 \\
\hline TELEFONICA & 27.155 .000 & 48.211 .000 & 53.023 .000 & 59.715 .000 & 53.278 .000 \\
\hline TELEMAR & 11.470 .183 & 10.331 .445 & 10.023 .273 & 9.120 .138 & 8.544 .633 \\
\hline TELEMAR N L & 3.780 .218 & 3.759 .767 & 10.732 .655 & 10.628 .614 & 10.498 .411 \\
\hline TELEMIG CL & 398.230 & 423.042 & 495.712 & 530.713 & 649.208 \\
\hline TELEMIG PART & 1.043 .490 & 649.277 & 714.315 & 763.253 & 873.512 \\
\hline TELESP & 13.777 .263 & 14.464 .420 & 14.699 .323 & 14.482 .637 & 12.269 .060 \\
\hline TELESP CL PA & 2.266 .976 & 3.857 .125 & 2.742 .647 & 4.009 .957 & 3.393 .161 \\
\hline TEX RENAUX & 27.782 & 27.839 & 28.459 & 3.974 & $\mathbf{3 . 0 3 1}$ \\
\hline TRAFO & 41.081 & 32.665 & 37.250 & 31.036 & 28.947 \\
\hline TRAN PAULIST & 1.687 .613 & 1.695 .904 & 3.327.317 & 3.349 .534 & 3.421 .446 \\
\hline TREVISA & -75.307 & 32.540 & 33.140 & 26.254 & 27.510 \\
\hline TUPY & 152.808 & 165.412 & 179.985 & 127.530 & 135.615 \\
\hline ULTRAPAR & 819.558 & 897.704 & -799.893 & 1.191 .084 & 1.356 .693 \\
\hline UNIPAR & 511.758 & 592.358 & 669.028 & 737.627 & 806.348 \\
\hline USIMINAS & 3.342 .496 & 3.473 .022 & 3.358 .170 & 3.033 .420 & 3.999 .421 \\
\hline VCP & 1.985 .415 & 2.318 .446 & 2.604 .345 & 2.823 .492 & 3.468 .130 \\
\hline VALE R DOCE & 10.502 .002 & 10.565 .590 & 11.766 .563 & 12.750 .519 & 14.939.574 \\
\hline VICUNHA TEXT & 544.973 & 518.029 & 551.549 & 467.546 & 556.107 \\
\hline VIGOR & 254.488 & 252.224 & 178.398 & 146.773 & 148.848 \\
\hline WEG & 408.627 & 466.119 & 573.648 & 693.651 & 861.426 \\
\hline WEMBLEY & 278.824 & 300.250 & 346.610 & 310.607 & 375.923 \\
\hline Somatório & 281.537 .461 & 335.837 .168 & 347.261 .873 & $357,305.320$ & 383.294 .987 \\
\hline
\end{tabular}

Fonte: SABE. Balanço Patrimonial. Elaboração Própria. 